INFECTION BIOLOGY AND DYNAMICS OF INOCULUM PRODUCTION BY CRONARTIUM QUERCUUM f. sp. FUSIFORME

ON QUERCUS RUBRA

BY

PATRICIA GARDNER PATTERSON

A DISSERTATION PRESENTED TO THE GRADUATE COUNCIL OF THE UNIVERSITY OF FLORIDA

IN PARTIAL FULFILLMENT OF THE REQUIREMENTS

FOR THE DEGREE OF DOCTOR OF PHILOSOPHY

UNIVERSITY OF FLORIDA 


\section{ACKNOWLEDGEMENTS}

The author wishes to express sincere gratitude to Dr. Robert A. Schmidt, Chairman of the Supervisory Committee, for his friendship, advice, guidance, and most especially for his patience during the course of this study. His criticism mixed with unfaltering enthusiasm and encouragement in appropriate quantities during the three years of this work was greatly appreciated.

Thanks arealso extended to the members of the Supervisory Committee: Dr. R. D. Berger, Dr. G. M. Blakeslee, and Dr. D. J. Mitche11, for their advice and friendship, and for their time spent in critical review of this manuscript.

Great appreciation is extended to Dr. K. M. Portier for his many hours of instruction and assistance with the statistical analysis of thesedata. Without his guidance these analyses would not have been possible.

Special thanks are given to Harvey Patterson for his help with preliminary greenhouse work and spore collections. Thanks are also given to Ed Sharp for his guidance with the graphics and to Stan Patterson for his statistical advice.

Dr. E. W. Erdos, Dr. H. C. Aldrich, and Dr. J. W. Kimbrough were invaluable in their assistance with the electron microscopic examination work. For their instruction and assistance much gratitude is given.

Many thanks are also expressed to Dr. R. S. Webb for his support and guidance in both statistical analysis and manuscript preparation. 
Finally, deepest gratitude is given to my parents and children for their unending faith and encouragement without which this opportunity would not have been possible. 
TABLE OF CONTENTS

Page

ACKNOWLEDGEMENTS . . . . . . . . . . . . . . . . . .

LIST OF FIGURES. . . . . . . . . . . . .

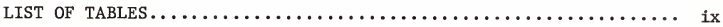

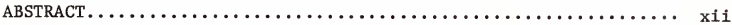

INTRODUCTION $\ldots \ldots \ldots \ldots \ldots \ldots \ldots \ldots \ldots \ldots \ldots \ldots \ldots \ldots \ldots \ldots \ldots \ldots \ldots \ldots \ldots \ldots \ldots$

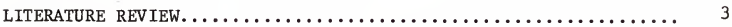

MATERIALS AND METHODS........................... 16

Microscopic Examination of Infection Biology........... 16

Influence of Environmental Factors.................. 19

Temperature Experiments -- Aeciospore Inoculations..... 19

Temperature Experiments -- Urediospore Inoculations.... 22

Leaf Surface Moisture Experiments -- Aeciospore

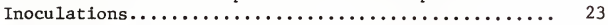

Leaf Surface Moisture Experiments --Urediospore

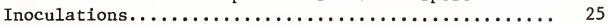

Leaf Age Experiments -- Aeciospore Inoculations....... 26

Leaf Age Experiments -- Urediospore Inoculations....... 26

Quantification of Inoculum................... 27

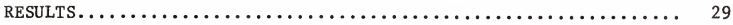

Microscopic Examination of Infection Biology........... 29

Influence of Environmental Factors................ 30

Temperature Experiments -- Aeciospore Inoculations..... 30

Temperature Experiments --Urediospore Inoculations.... 48

Leaf Surface Moisture Experiments -- Aeciospore

Inoculations............................ 56

Leaf Surface Moisture Experiments --Urediospore

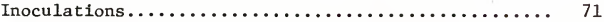

Leaf Age Experiments --Aeciospore Inoculations....... 82

Leaf Age Experiments -- Urediospore Inoculations....... 82 
Quantification of Inoculum.................... 82

Discussion. . . . . . . . . . . . . . . . 107

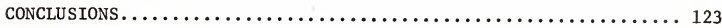

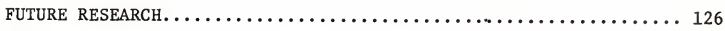

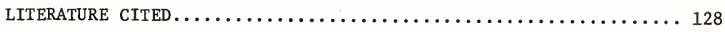

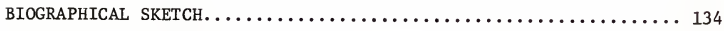


LIST OF FIGURES

Figure

Page

1 Electron photomicrographs of aeciospores of

Cronartium quercuum f. sp. fusiforme........... 32

2 Electron photomicrographs of germination following inoculation with aeciospores of Cronartium quercuum $\mathrm{f}$. sp. fusiforme on Quercus rubra leaf tissue......... 34

3 Electron photomicrographs of uredial pustules and urediospores of Cronartium quercuum f. sp. fusiforme

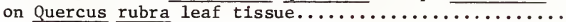

4 Electron photomicrographs of telia of Cronartium quercuum $\mathrm{f}$. sp. fusiforme on Quercus rubra leaf

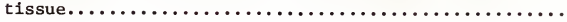

5 The effect of temperature on germination following inoculation with aeciospores of Cronartium quercuum $f$.

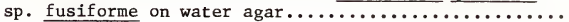

6 The effect of temperature on germination following inoculation with aeciospores of Cronartium quercuum $f$.

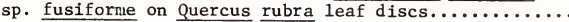

7 The effect of temperature on appressorial formation following inoculation with aeciospores of Cronartium quercuum f. sp. fusiforme on Quercus rubra leaf discs..

The effect of temperature on germination following inoculation with urediospores of Cronartium quercuum

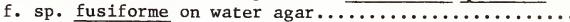

9 The effect of temperature on germination following inoculation with urediospores of Cronartium quercuum f. sp. fusiforme on Quercus rubra leaf discs.........

10 The effect of temperature on appressorial formation following inoculation with urediospores of Cronartium quercuum f. sp. fusiforme on Quercus rubra leaf discs.. 
11 The effect of continuous leaf surface moisture on germination following inoculation with aeciospores of Cronartium quercuum f. sp. fusiforme on Quercus

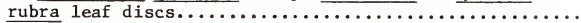

12 The effect of continuous leaf surface moisture on appressorial formation following inoculation with aeciospores of Cronartium quercuum f. sp. fusiforme

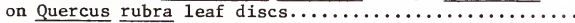

13 The effect of an interruption in the period of leaf surface moisture on germination and appressorial formation following inoculation with aeciospores Cronartium quercuum f. sp. fusiforme on Quercus

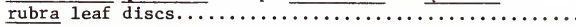

14 The effect of continuous leaf surface moisture on germination following inoculation with urediospores - of Cronartium quercuum $f$. sp. fusiforme on Quercus

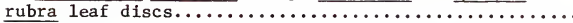

15 The effect of continuous leaf surface moisture on appressorial formation following inoculation with urediospores of Cronartium quercuum f. sp. fusiforme

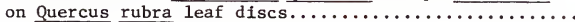

16 The effect of an interruption in the period of leaf surface moisture on germination and appressorial formation following inoculation with urediospores of Cronartium quercuum f. sp. fusiforme on Quercus rubra leaf discs.

17 The effect of leaf age on germination and appressorial formation following inoculation with aeciospores of Cronartium quercuum f. sp. fusiforme on Quercus rubra

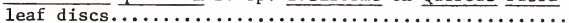

18 The effect of leaf age on germination and appressorial formation following inoculation with urediospores of Cronartium quercuum f. sp. fusiforme on Quercus rubra

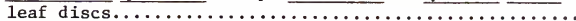

19 The effect of leaf age on the number of sori per $\mathrm{cm}^{2}$ produced following inoculation with aeciospores of Cronartium quercuum $\mathrm{f}$. sp. fusiforme on 2- to 11-day-

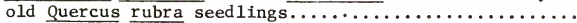


20 Time of occurrence for infection and disease development following inoculation with aeciospores of Cronartium quercuum $f$. sp. fusiforme on Quercus rubra seedlings maintained at optimal temperature

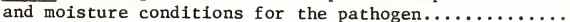

21 The effect of leaf age on the number of sori per $\mathrm{cm}^{2}$ produced following inoculation with urediospores of Cronartium quercuum f. sp. fusiforme on 2- to 11-day-

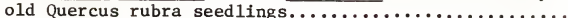

22 Time of occurrence for infection and disease development following inoculation with urediospores of Cronartium quercuum f. sp. fusiforme on Quercus rubra seedlings maintained at optimal temperature and

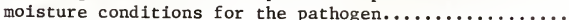




\section{LIST OF TABLES}

Table

1

The calculated effect of temperature on percentages and rates of germination following inoculation with aeciospores of Cronartium quercuum $\mathrm{f}$. sp. fusiforme

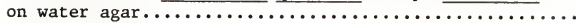

The calculated effect of temperature on percentages and rates of germination following inoculation with aeciospores of Cronartium quercuum $\mathrm{f}$. $\mathrm{sp}$. fusiforme

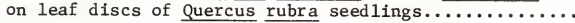

The calculated effect of temperature on percentages and rates of appressorial formation following inoculation with aeciospores of Cronartium quercuum f. sp. fusiforme on leaf discs of Quercus rubra seedlings.....

The calc lated effect of temperature on percentages and rates of germination following inoculation with urediospores of Cronartium quercuum $f$. sp. fusiforme

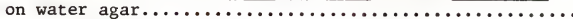

The calculated effects of temperature on percentages and rates of germination following inoculation with urediospores of Cronartium quercuum f. sp. fusiforme

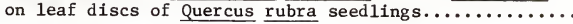

The calculated effect of temperature on percentages and rates of appressorial formation following inoculation with urediospores of Cronartium quercuum f. sp. fusiforme on leaf discs of Quercus rubra

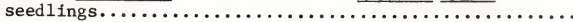

The effect of duration of continuous leaf surface moisture on percentages and rates of germination following inoculation with aeciospores of Cronartium quercuum $\mathrm{f} . \mathrm{sp}$. fusiforme on leaf discs of Quercus

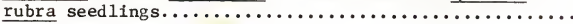

The effect of duration of continuous leaf surface moisture on percentages and rates of appressorial formation following inoculation with urediospores of Cronartium quercuum $\mathrm{f}$. sp. fusiforme on leaf discs

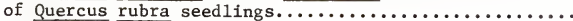


9 Influence of an interruption of leaf surface moisture on percentage germination following inoculation with aeciospores of Cronartium quercuum $\mathrm{f}$. sp. fusiforme on leaf discs of Quercus rubra seedlings............

Influence of an interruption of leaf surface moisture on percentage appressorial formation following inoculation with aeciospores of Cronartium quercuum $f$. sp. fusiforme on leaf discs of Quercus rubra seedlings....

The effect of duration of continuous leaf surface moisture on percentages and rates of germination following inoculation with aeciospores of Cronartium quercuum $f$. sp. fusiforme on leaf discs of Quercus

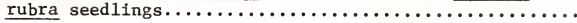

12 The effect of duration of continuous leaf surface moisture on percentages and rates of appressorial formation following inoculation with aeciospores of Cronartium quercuum f. sp. fusiforme on leaf discs

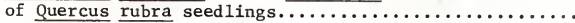

13 Influence of an interruption of leaf surface moisture on percentage germination following inoculation with urediospores of Cronartium quercuum $f$. sp. fusiforme on leaf discs of Quercus rubra seedlings............

14 Influence of an interruption of leaf surface moisture on percentage appressorial formation following inoculation with urediospores of Cronartium quercuum $f$. sp. fusiforme on leaf discs of Quercus rubra seedlings.....

15 The calculated effect of leaf age on percentages and rates of germination following inoculation with aeciospores of Cronartium quercuum f. sp. fusiforme on leaf discs of Quercus rubra seedlings.............

16 The calculated effect of leaf age on percentages and rates of appressorial formation following inoculation with aeciospores of Cronartium quercuum $f$. sp. fusiforme on leaf discs of Quercus rubra seedlings....

The calculated effect of leaf age on percentage of germination following inoculation with urediospores of Cronartium quercuum f. sp. fusiforme on leaf discs

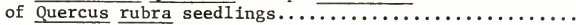


18 The calculated effect of leaf age on percentages and rates of appressorial formation following inoculation with urediospores of Cronartium quercuum $f$. sp. fusiforme on leaf discs of Quercus rubra seedlings.....

The effect of leaf age on the cumulative number of sori per $\mathrm{cm}^{2}$ produced following inoculation with aeciospores of Cronartium quercuum f. sp. fusiforme on 2- to 16-dayold leaves of Quercus rubra seedlings...............

The effect of leaf age on number of uredia and telia produced following inoculation with aeciospores of Cronartium quercuum f. sp. fusiforme on 2- to 11-day-

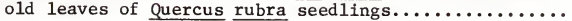

21 Inoculum efficiency following inoculation with aeciospores of Cronartium quercuum $f$. sp. fusiforme on 2 - to 11-day-old leaves of Quercus rubra seedlings maintained in a growth chamber at $21^{\circ} \mathrm{C} . \ldots \ldots \ldots \ldots \ldots$

The effect of leaf age on the number of sori per $\mathrm{cm}^{2}$ produced following inoculation with urediospores of Cronartium quercuum $\mathrm{f}$. sp. fusiforme on 2- to 14-day-

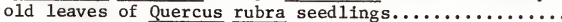

23 The effect of leaf age on number of uredia and telia produced following inoculation with urediospores of Cronartium quercuum f. sp. fusiforme on 2- to 11-day-

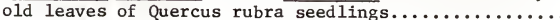

24 Inoculum efficiency following inoculation with urediospores of Cronartium quercuum $\mathrm{f}$. sp. fusiforme on 2- to 11-day-old leaves of Quercus rubra seedlings maintained

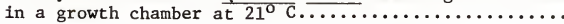




\begin{abstract}
Dissertation Presented to the Graduate Council of the University of Florida in Partial Fulfillment of the

Requirements for the Degree of Doctor of Philosophy
\end{abstract}

\title{
INFECTION BIOLOGY AND DYNAMICS OF INOCULUM PRODUCTION \\ BY CRONARTIUM QUERCUUM f. SP. FUSIFORME \\ ON QUERCUS RUBRA
}

By

Patricia Gardner Patterson

June, 1981

Chairman: Robert A. Schmidt

Major Department: Plant Pathology

The infection biology, role of environmental factors, and dynamics of inoculum production by Cronartium quercuum (Berk.) Miyabe ex Shirai f. sp. fusiforme (Cumm.) Burds. et Snow on northern red oak (Quercus rubra L.) were investigated under laboratory conditions.

The scanning electron microscope was used to observe aeciospore and urediospore wall morphology and the formation of germ tubes and appressoria. Germination began within 15 minutes after aeciospores or urediospores were placed on water agar or oak leaf discs. Aeciospores and urediospores frequently produced branched germ tubes and appressoria approximately 1 hour and 3 hours, respectively, after inoculation. Directional growth toward stomata was not apparent. Appressorial formation and the production of infection hyphae occurred only over stomata. The optimum temperature for aeciospore and urediospore germination on water agar and leaf discs was $21 \mathrm{C}$ and $18 \mathrm{C}$, respectively. 
Appressorial formation from aeciospores and urediospores on leaf discs was maximum at $15 \mathrm{C}$ and $18 \mathrm{C}$, respectively.

A minimum of 6 hours of oak leaf surface moisture was necessary for maximum aeciospore germination and appressorial formation. Appressoria were not formed when continuous leaf surface moisture was less than 3 hours duration. The percentage of aeciospores that formed appressoria increased with increasing duration of leaf surface moisture. Urediospore germination and appressorial formation increased steadily with increasing duration of surface moisture; maximum germination occurred after 24 hours of surface moisture. Leaf age did not influence aeciospore or urediospore germination or appressorial formation although interruption of the continuous moisture period delayed both events.

In vitro sporulation did not occur on leaf discs. The incubation period for the production of immature uredia on intact leaves was 6 days and 5 days following aeciospore and urediospore inoculations, respective1y. Following aeciospore and urediospore inoculations the latent period for mature uredia was 7 days and 6 days, respectively.

The maximum infectious period for the population of uredial sori was 9 days following aeciospore inoculation of 2-day-old leaves. The maximum infectious period for the population of uredial sori was at least 24 days (which was the termination of the experiment) following urediospore inoculation of 2-, 5-, 7-, and 9-day-old leaves.

The incubation period for the production of immature telia was 8 days and 6 days following aeciospore and urediospore inoculations, respectively. Following aeciospore and urediospore inoculations the latent period for telia production was 9 days and 7 to 8 days, respectively. 
Uredia preceded telia although uredial formation was not required for telial formation. Telia, but no uredia, were produced on leaves older than 6 days and 9 days when inoculated with aeciospores and urediospores, respectively. The average population ratios of telia to uredia for 2-, 5-, and 6-day-old leaves following aeciospore inoculation were $1.53,2.00$, and 31.00 , respectively. The average population ratios of telia to uredia for 2-, 5-, 7-, and 9-day-old leaves following urediospore inoculation were $1.20,3.82,73.83$, and 107.5 , respectively. The maximum number of uredia and telia formed on leaves 5- and 6-day-old, respectively, when inoculated with aeciospores, and on leaves 2- and 7days-old, respectively, when inoculated with urediospores. Secondary infection by urediospores was not evident after either aeciospore or urediospore inoculations.

Inoculum efficiency was calculated from inoculations with $1000 \pm$ 100 aeciospores or urediospores per $\mathrm{cm}^{2}$ on oak leaves. After 24 hours $34 \%$ of aeciospores germinated, $62 \%$ of these formed appressoria; .22 uredial sorus and 1.07 telial sori per $\mathrm{cm}^{2}$ had formed after 20 days. After 24 hours $74 \%$ of the urediospores germinated, $28 \%$ of these formed appressoria; .66 uredial sorus and 2.63 telial sori per $\mathrm{cm}^{2}$ had formed after 30 days. 


\section{INTRODUCTION}

Fusiform rust, a destructive disease of slash and loblolly pines, limits effective management of these species and is of great economic importance in the South. Increases in distribution, incidence, and impact since 1930 have been significant and coincide with the increase in plantation management.

The causal fungus, Cronartium quercuum (Berk.) Miyabe ex Shirai f. sp. fusiforme (Cumm.) Burds. et Snow, which attacks both the pine and the oak, has the potential to produce large quantities of inocula on both hosts. A significant positive correlation exists between fusiform rust incidence on pine and the abundance of susceptible oak and number of telia on oak. Therefore, research into the development of the epidemic on oak is important. Specifically, it is necessary to understand the infection biology and role of environmental factors in the dynamics of inoculum production by the pathogen on oak. The objectives of this study were: (i) to characterize the infection biology of C. quercuum f. sp. fusiforme on oak tissue in the laboratory; (ii) to determine the roles of temperature, leaf surface moisture, and leaf age on the production of inoculum by $\underline{\mathrm{C}}$. quercuum $\mathrm{f}$. $\mathrm{sp}$. fusiforme on oak leaves in the laboratory; and (iii) to quantify inoculum production from the germination of aeciospores through the occurrence of telia of C. quercuum f. sp. fusiforme on oak leaves in the laboratory in environmental conditions most favorable to this pathogen. 
These data will contribute to the subsequent development of a simulation model of inoculum production on oak. 


\section{LITERATURE REVIEW}

Fusiform rust, caused by the macrocyclic, heteroecious basiodiomycete Cronartium quercuum f. sp. fusiforme, is increasing in forests of the southern United States (Czabator, 1971). It is the most destructive disease of southern forests, and it significantly limits productivity of slash pine (Pinus elliottii Engelm. var. elliottii) and loblolly pine ( $\underline{P}$. taeda L.) throughout much of their ranges (Dinus and Schmidt, 1977).

Millions of dollars are lost annually because of damage to pines by fusiform rust (Powers et al., 1974); an annual loss of 562 million board feet of sawtimber and 194 million cubic feet of growing stock was reported in this recent estimate. This is a yearly stumpage loss of approximately 28 million dollars and a loss of 150 million dollars in finished wood products. In $1974,18.6$ million cubic feet of wood and 3.9 million dollars were lost in Florida as a result of fusiform rust (Phelps and Chellman, 1975). Rust incidence has increased as the intensive management of southern pine forests increased (Schmidt et al., 1974; Griggs and Schmidt, 1977).

Phelps (1977) evaluated fusiform rust incidence in slash pine plantations in 10 southern states and reported increased incidence of the disease and distribution of the pathogen relative to an evaluation made 35 years previously. Rust incidence is highest in a ridge extending northeast to southeast through the central portions of South Carolina, 
Georgia, Alabama, and Mississippi. In Florida, fusiform rust incidence increases from $0-15 \%$ in the south and along the east coast to $46-60 \%$ in the northwest region of the state (Schmidt et al., 1974).

Twenty species and varieties of oaks are common natural primary

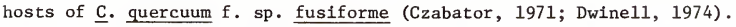
In addition, 30 other species of Castanea, Castanopsis, Lithocarpus, and Quercus have been inoculated successfully with aeciospores and urediospores (Czabator, 1971). The black oak group, which includes water oak (Q. nigra L.), willow oak (Q. phellos L.), southern red oak (Q. falcata Michx. var. falcata), northern red oak (Q. rubra L.), and turkey oak (Q. laevis Walt.), are much more susceptible to infection than white oaks (Dwine11, 1974). Of the alternate hosts, loblolly and slash pines are the two most susceptible species (Powers, 1975). Pond pine ( $\underline{P}$. serotina Michx.) and longleaf pine ( $\underline{P}$. palustris Mill.) are moderately resistant, while spruce pine ( $\underline{P} . \underline{\text { glabra }}$ Walt.), sand pine ( $\underline{P}$. clausa (Chapm.) Vasey), Virginia pine (‥ virginiana Mill.), and short-

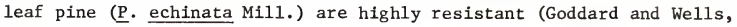
1977).

The pathogen, $\underline{\mathrm{c}}$. quercuum f. sp. fusiforme, is a basidiomycete in the order Uredinales. The genus Cronartium is distinguished by (i) sessile, one-celled teliospores united in columns; (ii) a prominent aecial periderm; and (iii) pedicillate urediospores (Czabator, 1971). Burdsall and Snow (1977) and Hedgcock and Siggers (1949) found that although $\underline{\mathrm{C}}$. quercuum and $\underline{\mathrm{C}}$. fusiforme Cumm. attack different species of pine, both have comparable life cycles, attack most of the same alternate host species, and are morphologically identical. 
Serological differences between $\underline{c}$. fusiforme and $\underline{\mathrm{C}}$. querccum (Gooding and Powers, 1965), different pathogenic interactions on Quercus spp. (Dwinell, 1969), and significant differences in aeciospore sizes (Dwine11, 1969) have been demonstrated. However, these differences do not warrant separation into species (Burdsall and Snow, 1977).

The pathogenic differences of $\underline{c}$. fusiforme and $\underline{c}$. quercuum were investigated by Powers (1972) using aeciospore collections from different pine hosts. Isolates of $\underline{\mathrm{C}}$. quercuum from jack pine ( $\underline{\mathrm{P}}$. banksiana Lamb.) produced $70 \%$ infection (trees with galls) on jack pine, but none on Virginia pine; the Virginia pine isolates produced galls on $43 \%$ of the Virginia pine seedlings and none on the jack pine. This demonstration of distinct physiological specialization was substantiated by Kais and Snow (1972). When pines of five species were inoculated uniformly with isolates of $\underline{\mathrm{C}}$. $\underline{\text { fusiforme }}$ and $\underline{\mathrm{C}}$. quercuum, differences in susceptibility of the pines were observed during the first year. Cronartium quercuum isolates were distinguished from $\underline{C}$. fusiforme by gall shape and by host range. These results established that races of $\underline{c}$. quercuum existed (Kais and Snow, 1972).

Burdsall and Snow (1977) suggested that the term formae speciales instead of races be used to designate the subspecies taxonomic groups of c. quercuum. Four formae speciales of $\underline{c}$. quercuum were erected on the basis of their interactions on different pine species: $\underline{c}$. quercuum $f$. sp. banksiana on jack pine, f. sp. virginiana on Virginia pine, f. sp. echinata, on shortleaf pine, and f. sp. fusiforme on loblolly and slash pine. 
The life cycle of $\underline{\mathrm{C}}$. quercuum $\mathrm{f}$. sp. fusiforme is initiated in the spring (March-June) when basidiospores (sporidia) from oak hosts are wind-disseminated and may infect pine. Germination and subsequent penetration by the spores occur on succulent hypocotyls, cotyledons, stem tissue, or primary needles (Miller, 1970). Penetration is either direct or through stomata (Miller et al., 1976; Patton and Johnson, 1966). Hyphae grow into stem and branch tissues as irregularly oblong primary hyphae, usually single-celled but occasionally several-septate (Miller et al., 1980). Unicellular, uninucleate, unbranched or occasionally branched haustoria ramify throughout perennial shoot tissues (Jewell et al., 1962). Host reaction to haustorial development is manifested by hypertrophy and hyperplasia and finally in the formation of typical spindle-shaped galls.

One or two years after infection, pycnia are produced in extensive, shallow cavities under the bark on the pine gall (Czabator, 1971). In the fall pycniospores are released in viscid, yellow to red drops (Hedgcock and Siggers, 1949). Their role is unknown, but in other rust fungi pycniospores function in diploidization (Wa1ker, 1957).

Cronartium quercuum $\mathrm{f}$. sp. fusiforme overwinters as mycelium in the vascular cambium and galls on the pine. Subsequently aecial sori are formed and produce nonrepeating, vegetative aeciospores, usually as a result of dikaryotization (Hiratsuka, 1973). The aecia are typically associated with pycnia (Hiratsuka, 1973). The aecial stage of many rusts forms within a few days following the appearance of pycnia (Littlefield and Heath, 1979). Typically the aecia form on the abaxial surface of the leaf, although the sori may also appear on adaxial surfaces 
(Littlefield and Heath, 1979). In coniferous hosts, aecia of ten occur in association with localized galls or swellings. These aecia typically do not appear until the season following the production of pycniospores, the latter not occurring until approximately 2 years after basidiospore infection (Boyce, 1961).

The aggregated hyphae of $\underline{C}$. quercuum $f$. sp. fusiforme, which form the aecium, grow tangentially among host cells at a depth of 6 to 10 cells below the peridial layer (Colley, 1918). The hyphae force the cortical cells apart and masses of disassociated hyphae form between these cells which may extend to a depth of 15 to 20 cells in the cortex of the host (Jewell et al., 1962).

Rijkenberg and Truter (Littlefield and Heath, 1979) concluded that, in general, aeciospore initials are annellophoric in their mode of development, not meristematically arthrosporic as described by Hughes, 1970 . An annulus remains on the wall of the aeciosporophore (Littlefield and Heath, 1979). After separation from the sporophore, while still in a chain, each aeciospore initial divides into an immature binucleate aeciospore $(\mathrm{N}+\mathrm{N})$ and a wedge-shaped intercalary cell (Littlefield and Heath, 1979; Hughes, 1970). The release of the mature aeciospore is aided by the disintegration of the intercalary or disjunctor cells (Littlefield and Heath, 1979). Hughes (1970) clearly showed that the ultimate cleaving of the aeciospores and intercalary cells is an arthrosporic process, while the formation of the aeciospore initials is an annellophoric process.

Each aecial sorus of $\underline{\mathrm{C}}$. quercuum $\mathrm{f}$. sp. fusiforme produces large quantities of thick-walled orange spores that average $15.5 \times 25.1 \mu \mathrm{m}$ 
(Czabator, 1971). The spores are obovate to ellipsoid, and coarsely verrucose but generally with a smooth area near the broad end of the spore (Czabator, 1971). Walkinshaw et al. (1967) found that the aeciospores of $\underline{\mathrm{C}}$. quercuum f. sp. fusiforme had an extremely thick wall with annulated projections.

Aeciospores are formed and wind-disseminated in early spring (Hedgecock and Siggers, 1949). Aeciospore infection occurs only on young oak leaves (Czabator, 1971).

Walkinshaw et al. (1967) found aeciospore germination to be rapid, and, once initiated, the process continued in vitro until lysis of the elongated germ tube occurred. The average length of germ tubes produced on agar was approximately $320 \mu \mathrm{m}$, but lengths of 600 to $700 \mu \mathrm{m}$ were common.

Typically thr germ tubes from aeciospores form appressoria and penetrate their hosts by growing through stomata (Littlefield and Heath, 1979). Germination of the aeciospores results in a binucleate mycelium in the oak leaf tissue, from which uredia and telia are produced. The mycelium in the oak leaf is massed in the mesophy 11 , but ramifies into the palisade layer and under the upper epidermis, where the uredia and telia are formed (Czabator, 1971). Eleuterius (1968) suggested that typically only one uredium, followed by one or more telia, is produced by the mycelium derived from one aeciospore infection.

Uredia, in generaly, are sori which produce repeating, dikaryotic urediospores on a dikaryotic mycelium (Hiratsuka, 1973). Uredia form on leaves, stems, fruits, or fronds of herbaceous plants; however, none are reported to have formed on woody stems or branches as commonly happens with pycnia and aecia in perennial infections, as exemplified 
by C. quercuum f. sp. fusiforme (Littlefield and Heath, 1979). Typically uredia are formed subepidermally, becoming erumpent; however, some Hemileia spp. produce pedicellate urediospores that extend beyond the leaf surface through stomata (Littlefield and Heath, 1979).

The fundamental cell in urediosporogenesis is the sporogenous cell; each uredium contains many of these cells (Littlefield and Heath, 1979). Elongated spore buds are produced sympodially through budding by the sporogenous cells. Following conjugate nuclear division a septum forms near the base of the elongated spore bud, separating the latter, which has become the urediospore initial, from the sporogenous cell (Littlefield and Heath, 1979). Harder (1976) found a second conjugate septum which separates the urediospore initial into a proximal pedicel and distal, immature urediospore.

Urediospores of $\underline{\mathrm{c}}$. quercuum $\mathrm{f}$. sp. fusiforme are ovate to obovate, averaging approximately $14 \times 21 \mu \mathrm{m}$ in size (Czabator, 1971). Conical spines that lack annulation cover the spore surface (Littlefield and Heath, 1979).

Urediospores are wind-disseminated and are capable of reinfecting the oak host (Czabator, 1971). Hedgecock and Siggers (1949) reported that inoculating oak leaves with urediospores resulted in uredia in only $33 \%$ of the cases and that oak inoculation was not successful beyond the second generation of urediospores in the greenhouse. However, Czabator (1971) indicated that successive urediospore inoculation was successful for several years at approximately 10-day intervals; this may not be an important factor in the field (Czabator, 1971).

Germ tubes of urediospores usually form appressoria over a stoma before infection occurs (Littlefield and Heath, 1979). Allen (1928) 
found that two events were involved in germ tube growth and appressorial formation: directional growth towards the stoma and induction of the appressorium once the stoma has been encountered. Johnson (1934) first postulated that directional growth of the germ tube may be a thigmotrophic response to the plant surface. He noted that the urediospore germ tubes of Puccinia graminis f. sp. tritici Eriks. \& P. Henn. grew predominantly along the transverse axis of the plant leaf. Maheshwari and Hildebrandt (1967) also observed that $\underline{P}$. antirrhini Diet. \& Holw. germ tubes grew at right angles to the parallel ridges of the host cuticle, and would do so even on isolated cuticles or leaf replicas.

Lewis and Day (1972) suggested that epicuticular wax is the primary stimulus for the directional growth of $\underline{\mathrm{P}}$. graminis $f$. sp. tritici germ tubes. However, some leaf surfaces lack this crystal lattice and directional growth still occurred (Maheshwari and Hildebrandt, 1967; Wynn, 1976). Thus the exact nature of the thigmotrophic stimulus of the leaf surface is unknown and may differ among rusts. The observation of directional growth among germ tubes of various rust fungi suggests that a thigmotrophic stimulus enhances the likelihood of stomatal penetration (Littlefield and Heath, 1979).

Inoculation of oak leaves with $\underline{\mathrm{C}}$. quercuum $\mathrm{f}$. sp. fusiforme aeciospores did not necessarily form uredia and of ten resulted directly in the production of telia (Snow and Roncadori, 1965). These hair-like telia form from the same mycelia that produce uredia (Eleuterius, 1968). The telia are composed of hundreds of teliospores held together in a matrix. Germination of the teliospores during moist periods produces a promycelium bearing four uninucleate basidiospores (Hedgcock and 
Siggers, 1949). Basidiospores are wind-disseminated and may infect pines.

Studies on variation in pathogenicity among $\underline{C}$. quercuum $f$. sp. fusiforme isolates showed that the seedlings from one slash pine parent tree were more resistant to basidiospore inocula from Texas and Mississippi than to inocula from Alabama or Florida (Snow and Kais, 1970). Variability in pathogenicity among inocula was observed from different states, from various locations within a state and from different galls at one location (Snow et al., 1975). The largest difference in pathogenic variation occurred with inocula collected from the same individual gall. Snow et al. (1975) inoculated seedlings from open-pollinated slash pine families with known degrees of fusiform rust resistance with basidiospores of $\underline{\text { C. quercuum }} \mathrm{f}$. sp. fusiforme from diverse geographical sources. In one experiment, 10 pine families were exposed to inocula that had been collected along a transect across Texas, Louisiana, Mississippi, Georgia, and Florida. Two families were resistant to all inocula, three were uniformly susceptible, and the remaining families were resistant to some inocula. Virulence of isolates did not conform to any geographic pattern. Differential responses were detected in two families from approximately the same origin, which indicated extreme variability in the virulence of the isolates. An example of differential response was shown by pine Family six, which was resistant to inoculum from Louisiana, but susceptible to inoculum from Florida. Pine Family seven, by contrast, was more susceptible to inoculum from Louisiana than that from Texas. Pathogenic variability was observed among pine families from approximately the same geographical origin. 
Favorable macroclimatic and microclimatic conditions are necessary for plant disease development. Each stage of the pathogen has particular requirements for development. The influence of temperature on the germination of aeciospores, urediospores, and teliospores of $\underline{\text {. }}$ quercuum f. sp. fusiforme on water agar was studied by Siggers (1947). The following thermal limits of temperature on the germinating spores were determined: aeciospores, 11 to $29 \mathrm{C}$ with an optimum at $21 \mathrm{C}$; urediospores, 8 to $29 \mathrm{C}$ with an optimum at $17 \mathrm{C}$; and teliospores, 15 to $26 \mathrm{C}$ with an optimum at $21 \mathrm{C}$. Reduced hyphal growth and apical curling of the germ tubes were observed commonly in tests in which the average temperatures ranged from 26 to $29 \mathrm{C}$.

The effect of environmental variation on the germination and subsequent appressorial formation in some rusts also has been studied. Vargas et al. (1967) found that urediospores of Puccinia cynodontis Lacroix germinated in a range of temperatures from 1.5 to $34 \mathrm{C}$ with an optimum range of 18 to $34 \mathrm{C}$. However, light intensities greater than $200 \mathrm{ft}-\mathrm{c}$ during this period decreased germination. With $\underline{\mathrm{P}}$. coronata Cda. var. avenae Fraser \& Led., Politowski and Browning (1975) found $21 \mathrm{C}$ with 2 hours of dew period to be optimum for generation. Politowski and Browning (1974) also found that light significantly increased appressorial formation from the germinated aeciospore.

For some rusts the temperature at which the urediospores are produced influenced both the germination capacity of the spores and the response of the spores to storage (Czabator, 1971). With certain cereal rusts, urediospores formed at $16 \mathrm{C}$ had better viability and germination than those which developed at 22 or 29 C (Hobbs, 1962). 
In addition to temperature, moisture conditions are important variables in conditioning the incidence and distribution of rust diseases. Van Arsdel et al. (1956) found that the spread of white pine blister rust, caused by Cronartium ribicola Fischer, was limited principally by the lack of sufficient moisture for sporidial formation and germination. When periods of high relative humidity occurred, a prior period of 2 weeks without three consecutive days over $28 \mathrm{C}$ became important to provide production of fertile teliospores.

Lack of precipitation may be a limiting factor for spread of fusiform rust in east Texas (Anon., 1977). Snow et a1. (1968) found that infection of pine seedlings with basidiospores of $\underline{C}$. quercuum $f$. sp. fusiforme was significantly related to the number of hours with relative humidity greater than $97 \%$, and highest infection occurred on nights following afternoon or early evening rains.

High temperature in central Florida and low temperatures at the northern edge of the fusiform rust belt may be a limiting factor in disease development (Anon., 1977). Siggers (1949) reported that low temperatures in late winter retarded the development of oak leaves and decreased $\underline{\text { C. quercuum }}$ f. sp. fusiforme urediospore production.

Snow and Roncadori (1965) reported that uredial formation was significantly less on leaves 6 days old or older when inoculated with aeciospores. No uredia were formed on leaves 16 days old at the time of inoculation.

Measuring plant diseases and their determining factors is the domain of quantitative epidemiology which is concerned with the dynamics of the two interacting populations of host and pathogen (Kato, 1974; Kranz, 1974). Epidemics are complex and epidemiologists typically begin 
their study at the single spore stage, i.e., the dispersal and infection unit. One infection unit may originate from one dispersal unit, but not all dispersal units are effective in establishing infection (Zadoks and Schein, 1979); effective dispersal units form only a fraction of those units produced.

Quantification of the number of dispersal units is imperative for a detailed understanding of the processes and subprocesses of an epidemic (Vanderplank, 1975). Vanderplank (1975) discussed the following relationships between the numbers of infections and amount of inoculum: (i) disease may be proportional to inoculum; (ii) disease may decrease in proportion to inoculum; (iii) an antagonistic interaction between spores may reduce the levels of effective inoculum and disease; or (iv) facultative synergism between spores may result in increased levels of effective inocr um and disease. As an example, Schein (Zadoks and Schein, 1979) found that approximately $50 \%$ of the urediospores of Puccinia recondita f. sp. tritici Rob. ex Desm. transferred to a leaf produced pustules. The author also found that the number of spores necessary to produce pustules in Uromyces appendiculatus (Pers.) Unger was approximately 11 to 1 , or about $9 \%$ efficiency.

Infection efficiency is defined as the ratio between the number of spores applied per unit area and the resultant pustules formed per unit area (Zadoks and Schein, 1979). Infection efficiency may ultimately be viewed in the form of life tables which contain such vital statistics as the numerical composition of a population, its age distribution, the survival ratios for various age classes, and each group's life expectancy (Zadoks and Schein, 1979). Cohort life tables, in which a group of individuals of the same age from birth to death is studied, do not 
depend on age classification and may be used to study pathogen populations (Zadoks and Schein, 1979). For example, cohort life tables for P. recondita isolate 1037 on primary leaves of wheat have been developed and the survivorship relations between parasite and host may be used effectively to compare interactions among races and cultivars (Zadoks and Schein, 1979).

Spore survivorship relations may also be studied to determine the effect of environment on components of the life tables. Environmental effects on infection processes, and ultimately on infection efficiency, may be designated as the stimulus-response relation which may evoke a definite and unique response relationship in either a qualitative (allor-none response) or in a quantitative manner (percentage of spores which germinated, etc.) (Zadoks and Schein, 1979).

Simulation of a plant disease attempts to replicate the essence of this interactive system, i.e., host, parasite, and climate over time (Teng and Zadoks, 1980). Quantification of infection processes is an integral component of many disease simulation models. Many such models have been developed: Waggoner and Horsfall (1969) with tomato early blight - EPIDEM, Zadoks (1965) with wheat rust, Berger (1976) and Berger (unpublished data) with Cercospora leaf spot, and many others. Simulation models for fusiform rust have not been developed because the necessary information is not available and this is particularly true for the development of the epidemic on oak. 
MATERIALS AND METHODS

\section{Microscopic Examination of Infection Biology}

Northern red oak acorns were obtained from the Bent Creek Fusiform Rust Testing Center of the U. S. Forest Service Southeastern Forest Experiment Station located near Asheville, NC. Acorns were germinated in the greenhouse in flats containing a sand-vermiculite mixture and were transplanted to 6-inch pots containing sand-vermiculite mixture. The seedlings were maintained in a shade house and watered twice a week without fertilization prior to inoculation with aeciospores or urediospores.

Aeciospores of $\underline{C}$. quercuum f. sp. fusiforme were obtained in March, 1977-80 from galls occurring on slash pines near Valdosta and Macon, Georgia, and Gainesville, Florida. The spores were collected using handsuction bottles; collections from individual areas were mixed. The spores were vacuum-dried in a desiccator at room temperature.

The aeciospores were stored in sterile vials at $4 \mathrm{C}$ for 1 year. Prior to inoculation the spores were hydrated for 24 hours at $25 \mathrm{C}$ in $100 \%$ relative humidity in a $10 \mathrm{~mm}$ deep petri plate. Prior to their use in experiments, a suspension of aeciospores in distilled water was sprayed onto water agar plates; after 6 hours viability was assessed via percentage germination. A spore was considered to be germinated when the germ tube equalled the shortest diameter of the spore. Only 
spores from those vials in which $25 \%$ to $75 \%$ of the spores germinated were used in subsequent experiments. No attempt was made to separate spores from individual galls on locations or to identify sources of spores for individual experiments.

The adaxial surfaces of 2- to 8-day-old oak leaves were sprayed with an aqueous suspension of aeciospores (approximately 250,000 \pm 25,000 spores $/ \mathrm{m} 1$ ). The concentration was determined using a hemacytometer and was used in all subsequent aeciospore inoculation experiments. Inoculated trees were covered with opaque plastic bags for 24 hours to maintain high relative humidity. The bags were removed and the seedlings exposed to low light intensities in a 12-hour alternating light-dark schedule until uredial pustules formed. Throughout this incubation period, the seedlings were maintained in a growth chamber at $21 \mathrm{C}$. Uredia developed on the abaxial surface of leaves of northern red oak seedlings previously inoculated with the aeciospores. Urediospores were collected with a small camel's-hair brush and transferred to petri plates lined on the bottom with filter paper. The plates were covered and stored at $4 \mathrm{C}$ for approximately $24 \mathrm{hr}$ prior to inoculations. Prior to their use in experiments, the urediospores were applied with a camel's-hair brush onto a water agar plate and evaluated after 6 hours for germination. Only spores in which $25 \%$ to $79 \%$ germination occurred were used in the experiments.

Two- to eight-day-old oak leaves were mechanically inoculated with an aqueous suspension of urediospores (approximately 250,000 $\pm 25,000$ spores/m1) using a camel's-hair brush. This concentration of spores was determined using a hemacytometer and was used in all subsequent 
urediospore inoculation experiments. Inoculated trees were covered with plastic bags for 24 hours to maintain high relative humidity. The bags were removed and the seedlings exposed to a 12-hour alternating lightdark schedule in the growth chamber until uredial pustules formed.

Suspensions of aeciospores or urediospores were sprayed onto northern red oak leaf discs that were randomly excised from the leaves. Three leafdiscs, each approximately $0.4 \mathrm{~cm}$ in diameter, per plate were sprayed with each suspension resulting in a density of $1000 \pm 100$ spores per $\mathrm{cm}^{2}$ of leaf disc surface. This density was determined by ten sample counts of spores $/ \mathrm{cm}^{2}$ : aeciospores - 947, 1010, 1101, 1074, 1090, 982, 1019, 927, 992, and 1073; urediospores - 951, 1009, 1076, 1053, 1006, 962, 1065, 926, 919, and 1042. These plates were incubated in an incubator at $21 \mathrm{C}$ (aeciospores) and $18 \mathrm{C}$ (urediospores) for up to 24 hours. Water agar plates without leaf discs were similarly sprayed with spore suspensions and incubated for determination of spore viability. Aeciospore and urediospore germination and appressorial formation were examined using the electron microscope. Leaf disc samples inoculated with either aeciospores and urediospores were fixed at room temperature for 1 hour in a mixture of $2 \%$ gluteraldehyde and $2 \%$ paraformaldehyde in $0.025 \mathrm{M}$ cacodylate buffer adjusted to $\mathrm{pH} 7.2$ (Benny and Aldrich, 1975). Specimens were dehydrated progressively in a graded ethanol-distilled water series of $5,10,50,75,95$, and $100 \%$ ethanol concentrations. Each leaf disc specimen was dehydrated for 5 minutes in each of the first five dilutions and for 30 minutes in the final concentration. The discs were critically point-dried using liquid carbon dioxide in a Model H Critical Point Dryer. Each leaf discs was coated, using an $\mathrm{IB}^{2}$ Ion Coater 
with a thin layer of gold under vacuum for 6 minutes. Specimens were observed using a S-450 Scanning Electron Microscope (SEM).

Additional aeciospores and urediospores were observed for spore shape and surface ornamentation without fixation, dehydration or critical point-drying. Aeciospores and urediospores were brushed onto cellophane tape placed on SEM stubs and coated with a thin layer of gold under vacuum for 6 minutes prior to viewing.

\section{Influence of Environmental Factors}

Temperature Experiments --Aeciospore Inoculations

The effect of temperature on spore germination and appressorial formation of $\underline{\mathrm{C}}$. quercuum $\mathrm{f}$. sp. fusiforme was investigated. Ninety-one water agar plates were inoculated with aeciospores and incubated in the dark for 24 hours at each of seven temperatures $(10,15,20,21,25$, 27 , and $30 \mathrm{C}$ ). In these and subsequent experiments, temperature was observed to vary approximately $\pm .5 \mathrm{C}$. One plate was examined hourly for 1 to 12 hours and then 24 hours after inoculation using a reflected light microscope at 200x. Percentage germination of 100 spores in each of three replications was recorded. The optimum temperature for germination was determined to be $21 \mathrm{C}$. This temperature was used in subsequent experiments to assess aeciospore viability.

In a similar manner ninety-one water agar plates each with three oak leaf discs were sprayed with aeciospores and incubated. One plate was examined hourly for 1 to 12 hours and then 24 hours after inoculation at each temperature, and each leaf disc was observed using the reflected light microscope at 200x. One hundred spores of each of three 
discs per plate were observed and percent germination was recorded. The percentage of spores which formed appressoria (number of spores which produced appressoria divided by the number of spores which germinated) was also recorded.

In an attempt to describe the nature of the associations between percent germination and time, and percent appressorial formation and time, various linear and non-1inear models were examined. A three parameter logistic equation was used to describe these data for the different temperature (and leaf age) experiments. It is recognized that there may exist alternative models which describe these data as we11, if not better than, the logistic model. The logistic curve was chosen because it has been shown to provide acceptable empirical description of data of this type in biology. Recent work (Zadoks, 1978) has suggested that other models which do not have the symmetric sigmoidal shape requirement of the logistic curve may be more appropriate, but are much more complex to apply and interpret. The logistic equation used in this study is:

$$
Y=\frac{D}{1+e^{a-b t}}
$$

where, $\mathrm{Y}=$ germination or appressorial formation (\%)

$D=$ theoretical maximum limit of germination or appressorial formation (\%)

$\mathrm{b}=$ initial relative rate $(\%$ per hour $)$

$a=$ location parameter (such that $\frac{a}{b}$ has unit time)

$t=$ time (hours)

$\mathrm{e}=$ exponential constant $(2.7183 \ldots)$.

Non-linear regression was used to obtain the parameter estimates which resulted in best fit. 
To give some indication of goodness of fit of the logistic curve to these data, a measure of percentage variation $\left(R^{2}\right)$ explained by the model was computed for each fit. This measure is given as

$$
\mathrm{R}^{2}=\left[1-\frac{\mathrm{MSE}}{\mathrm{MSTC}}\right]
$$

where,

$$
\begin{aligned}
R^{2} & =\text { proportion of variation explained, } \\
\text { MSE } & =\text { mean squared error from the fitted model, } \\
\text { MSTC } & =\text { mean squared total corrected for the mean. }
\end{aligned}
$$

The times to $10 \%$ and $90 \%$ maximum germination and appressorial formation were calculated in an attempt to provide useful epidemiological parameters of percent germination or percent appressorial formation. The following equations were used:

Time to $10 \%$ maximum ( ${ }_{.10}$ ),

$$
\begin{aligned}
& 0.10 \mathrm{D}=\frac{\mathrm{D}}{1+\mathrm{e}^{\mathrm{a-bt}}} \\
& \mathrm{t} .10=\frac{2.21-\mathrm{a}}{-\mathrm{b}}
\end{aligned}
$$

Time to $90 \%$ maximum ( $\left.{ }_{.90}\right)$,

$$
\begin{aligned}
& 0.90 D=\frac{D}{1+e^{a-b t}} \\
& t_{.90}=\frac{1.97+a}{b} .
\end{aligned}
$$

The maximum rate (percent per hour) of germination or appressorial formation is the maximum of the derivation of $y$ with respect to $t$, given as

$$
\frac{d Y(t)}{d t}=\frac{D b e^{a-b t}}{\left(1+e^{a-b t}\right)^{2}}
$$


By setting to zero the second derivative of $Y$ with respect to $t$, which is

$$
\frac{d^{2} Y(t)}{d t^{2}}=\frac{D b^{2} e^{a-b t}}{\left(1+e^{a-b t}\right)^{3}}\left(1-e^{a-b t}\right),
$$

and solving for $t$, the time (hours) at which the maximum rate occurs is given as

$$
t_{\max }=\frac{a}{b}
$$

This is, in fact, the time to $50 \%$ maximum theoretical germation or appressorial formation. Given the estimates of $t_{\max }$ and $b$ an estimate of a can be obtained by use of equation (9) above. The maximum rate is then given by evaluating $\frac{d Y(t)}{d t}$ at the value $t_{\max }$. This is given as

$$
\mathrm{r}_{\max }=\frac{\mathrm{dY}(\mathrm{t})}{\mathrm{dt}} \mid \mathrm{t}=\mathrm{t}_{\max }=\frac{\mathrm{Db}}{4} \text {. }
$$

The quantities $\mathrm{t}_{\max }$ and $\mathrm{r}_{\max }$ were computed to provide additional description of the data.

Similar analyses were conducted for germination and appressorial formation data obtained from all temperature and leaf age experiments using both aeciospore and urediospore inoculations.

\section{Temperature Experiments -- Urediospore Inoculation}

Seventy-eight water agar plates were inoculated with $\underline{\mathrm{C}}$. quercuum f. sp. fusiforme urediospores and incubated in the dark for 24 hours at each of $\mathrm{six}$ temperatures $(10,15,18,21,25$, and $30 \mathrm{C})$. One plate was examined hourly 1 to 12 and then 24 hours after inoculation using a reflected light microscope to determine the percent germination and appressorial formation for three replications of 100 spores. The optimum temperature for germination was $18 \mathrm{C}$. This temperature was used in subsequent experiments to assess urediospore viability. 
In a similar manner seventy-eight water agar plates each with three leaf discs were sprayed with urediospores and incubated. One plate was examined hourly 1 to 12 and then 24 hours after inoculation at each temperature and each leaf disc was observed with a reflected light microscope at 200x. One hundred spores on each of three discs per plate were observed and percent germination and appressorial formation were recorded.

Leaf Surface Moisture Experiments--Aeciospore Inoculations

For studies on the effect of leaf surface moisture on spore germination and appressorial formation by $\underline{C}$. quercuum f. sp. fusiforme, two incubation humidity levels, wet and dry, were established to control leaf surface moisture. The wet level was developed by covering plates of water agar with leaf discs which had been inoculated with an aeciospore suspension. The dry level was developed by uncovering plates of water agar with leaf discs similarly inoculated. A container of silica gel was placed in the dry-level incubator to reduce relative humidity which removed the free surface moisture necessary for spore germination. Ninety-four plates of water agar with leaf discs were sprayed with an aeciospore suspension and exposed for each of 10 moisture periods ( 0 to 9 hours) of consecutive wetness at $21 \mathrm{C}$. For example, 13 plates with inoculated leaf disc were incubated without lids ( 0 hour wet); 13 plates with inoculated leaf discs were incubated in the wet incubator for one hour and transferred to the dry incubator for the remainder of the experiment ( 23 hours); 12 plates with inoculated leaf discs were incubated in the wet chamber for 2 hours and transferred to the dry incubator for the remainder of the experiment (22 hours), etc. At the 
end of the experiment leaf discs were viewed microscopically to determine percentages of aeciospore germination and appressorial formation. The relationships between percent germination or percent appressorial formation and leaf surface moisture with both aeciospore and urediospore inoculations were examined using polynomial regression analysis. The intent was to determine whether linear or non-1inear (quadratic) trends were evident in the data.

The effect of interruption of the free moisture period on percentage aeciospore germination and appressorial formation was studied. In one experiment, eight plates of water agar with leaf discs were inoculated with an aeciospore suspension and place in the wet incubator for 2 hours. No significant differences in germination or appressorial formation after at least 6 hours of continuous moisture had been formed in previous experiments. Thus, interruption of moisture periods of less than 6 hours was investigated. At the end of both 1 and 2 hours in the wet incubator, one plate was observed microscopically for percent spore germination and appressorial formation. The remaining six plates were transferred to the dry incubator for 6 consecutive hours. At the end of this period one plate was observed for percent spore germination and appressorial formation. The remaining five plates were returned to the wet incubator. Four of these five plates were examined hourly and the fifth plate was observed after 24 hours; percentage germination and appressorial formation were recorded.

In another experiment on the interruptions in the leaf surface moisture, eight plates of water agar with leaf discs were inoculated and placed in the wet incubator for 6 hours and then transferred to the dry 
incubator for two hours. At the end of the period, the plates were returned to the wet incubator for 16 hours. Individual plates with the three leaf discs were observed hourly from 6 to 12 hours and again at 24 hours; percentage spore germination and appressorial formation were recorded.

\section{Leaf Surface Moisture Experiments --Urediospore Inoculations}

The effect of continuous moisture of $\underline{\mathrm{C}}$. quercuum f. sp. fusiforme urediospore germination and appressorial formation was investigated. Thirteen plates of water agar with leaf discs were inoculated with a urediospore suspension using a camel's-hair brush and exposed to 0 to 6 and 24 hours of consecutive wetness of $18 \mathrm{C}$. The plates were transferred between the wet and dry incubators over this period in a similar manner as indicated in the aeciospore moisture experiment. Fvaluations of the number of urediospores that germinated or formed appressoria were conducted using polynomial regression analysis as discussed in the aeciospore moisture experiment.

The effect of an interruption of the free moisture period was studied to determine the influence upon urediospore germination and appressorial formation. In one experiment, nine plates of water agar with leaf discs were inoculated with a urediospore suspension and placed in the wet incubator for one hour before transfer to the dry incubator for one hour. One plate was evaluated hourly for percent spore germination and appressorial formation. The remaining plates were returned to the wet incubator and observed hourly from 3 to 8 hours and again at 24 hours; percentage germination and appressorial formation were recorded. 
In the second experiment, the plates of water agar with leaf discs were placed in the wet incubator for one hour, transferred to the dry incubator for three hours, and returned to the wet incubator for the remaining 20 hours of the experiment. The plates were evaluated hourly for percent germination and appressorial formation from 2 to 9 hours and again at 24 hours after inoculation.

\section{Leaf Age Experiments-- Aeciospore Inoculations}

The effect of oak leaf age on $\underline{C}$. quercuum $f$. sp. fusiforme spore germination and appressorial formation was the final environmental variable studied. Three discs were each removed from northern red oak leaves which were $2,4,5,6,11$, and 16 days old. The discs from each leaf-age category were placed onto one petri plate containing $2 \%$ water agar and sprayed with an aeciospore suspension. The 11 plates were covered to maintain high leaf surface moisture and placed in the dark at $21 \mathrm{C}$ for 24 hours. Aeciospore germination and appressorial formation were recorded.

\section{Leaf Age Experiments -- Urediospore Inoculations}

Three discs were removed from northern red oak leaves which were 2, $4,9,13$, and 20 days old to study the effect of leaf age on urediospore germination and appressorial formation. The three leaf discs from each leaf-age category were placed onto one $2 \%$ water agar plate and inoculated using a camel's-hair brush with an urediospore suspension. The 11 plates were covered to maintain free moisture on the leaf surface and placed in the dark for 24 hours at $18 \mathrm{C}$. Urediospore germination and appressorial formation were recorded. 
Quantification of Inoculum

To quantify uredial and telial inoculum production in the laboratory by $\underline{\mathrm{C}}$. quercuum $\mathrm{f}$. sp. fusiforme, oak seedlings were inoculated with aeciospores or urediospores. The seedlings were maintained in a growth chamber at $21 \mathrm{C}$ with low levels of 1ight with a 12-hour alternating light-dark schedule.

One northern red oak seedling from each of five foliar age classes $(2,5,6,8$, and 11 days since initial flush) was inoculated with an aeciospore suspension providing $1000 \pm 100$ spores $/ \mathrm{cm}^{2}$ on the leaf surfaces. These trees and an uninoculated control were covered with large opaque plastic bags to maintain high relative humidity and placed in a growth chamber at $21 \mathrm{C}$. After 24 hours, the bags were removed and the fungus allowed to incubate for an additional 21 days in a 12-hour, a1ternating light-dark schedule. Immature uredia and telia were distinguished by the presence of non-spore producing sori which resembled conical frustrums. An incubation period was defined as the number of days between inoculation and the appearance of the immature sori. The latent period was defined as the number of days between inoculation and the appearance of mature (or spore-producing) sori. The cumulative daily number of immature and mature uredia and telia per leaf age class was recorded.

One northern red oak seedling from each of five foliar age classes $(2,5,7,9$, and 11 days since initial flush) was inoculated using a camel's-hair brush with a urediospore suspension providing approximately $1000 \pm 100$ spores $/ \mathrm{cm}^{2}$ on the leaf surfaces. These trees and an uninoculated control were covered with large opaque plastics bags to maintain 
high relative humidity and placed in a growth chamber at $21 \mathrm{C}$. After 24 hours, the bags were removed and the fungus allowed to incubate for an additional 29 days at a 12-hour alternating light-dark schedule. The cumulative dafly number of immature and mature uredia and telia per leaf age class was recorded. The average number of uredial or telial sori formed per age class was averaged for all leaf age classes that exhibited these sori.

Insufficient data were available to model the relationship between leaf age and average number of uredia and telia produced from either aeciospore or urediospore inoculations; therefore, simple means and standard error were calculated. To provide an indication of significance between these means, t-tests were performed at the $\alpha=.051$ eve1. Due to the small number of observations, the conclusions of these tests are tentative.

Inoculum efficiency tables were calculated for the average number of uredial and telial sori formed within all leaf age classes after inoculation with either aeciospores or urediospores. The time periods of infection and disease development with aeciospore and urediospore inoculations at optimal temperature and moisture conditions on $Q$. rubra seedlings were determined. 


\section{RESULTS}

\section{Microscopic Examination of Infection Biology}

The orange, oval aeciospores from field collections of $\underline{c}$. quercuum f. sp. fusiforme exhibited smooth and verrucose areas separated by transitional zones (Fig. 1-A). The spores had free standing, welldefined, and elongated verrucae (surface projections) with distinct annulations (Fig. 1-B).

The appearance of a germ tube began within 15 minutes after the aeciospores were sprayed onto all age classes of leaf discs or onto water agar. Germinated aeciospores produced branched and unbranched germ tubes (Fig. 2-C, D). Growth of germ tubes towards specific stomata appeared random. Bright orange, bulbous appressoria formed only over stomata in approximately four hours after inoculation onto all age classes of leaf discs (Fig. 2-D, E). Appressorla formed from aeciospores that exhibited branched and unbranched germ tubes. Infection hyphae were observed in the stomatal chamber (Fig. 2-D). Penetration occurred only through stomata.

The latent period for production of immature and mature uredia from aeciospore inoculation was 5-6 days on northern red oak leaf discs. Erumpent uredial pustules appeared on the abaxial leaf surface and the echinulate urediospores exhibited no surficial annulations (Fig. 3-F, G, H). 
Within approximately 15 minutes after inoculation with urediospores, branched and unbranched germ tubes were produced on leaves of a11 age classes and on water agar. Bright orange, bulbous appressoria formed only over stomata (Fig. 3-1). Penetration occurred only through stomata.

The incubation period for the production of immature telia was 8-9 days (Fig. 4-J). The latent period for the production of mature telia was $8-11$ days (Fig. 4-K).

\section{Influence of Environmental Factors}

\section{Temperature Experiments-- Aeciospore Inoculations}

The optimum temperature for germination of aeciospores on water agar was $21 \mathrm{C}$ (Fig. 5). Approximately $76 \%$ of the spores germinated after 24 hours at this temperature. At temperatures above and below this level, percentage germination decreased. For example, approximately $10 \%$ and $1 \%$ of the spores germinated at 10 and $30 \mathrm{C}$, respectively. Percentage germination was higher at temperatures approaching the optima; approximately $60 \%$ and $70 \%$ of the spores germinated at 15 and $20 \mathrm{C}$, respectively.

The effect of temperature on parameters of aeciospore germination on water agar was analyzed using non-linear regression. The theoretical maximum (D) for percent spore germination was $76 \%$ and the maximum germination rate occurred after 3.5 hours at this temperature. An additional 1.4 hours ( 4.9 hours total) were required to attain $90 \%$ of the theoretical maximum germination. At 15 and $20 \mathrm{C}$, respectively, progressively greater theoretical maxima for spore germination were 
Figure 1 - (A,B). Electron photomicrographs of aeciospores of Cronartium quercuum f. sp. fusiforme: A) Aeciospore exhibiting smooth and verrocose areas (6240 X; bar = $6.7 \mu \mathrm{m})$; B) Aeciospore exhibiting annulated spore wall projections (a) $(11325 \mathrm{X}$; bar $=6.7 \mu \mathrm{m})$. 

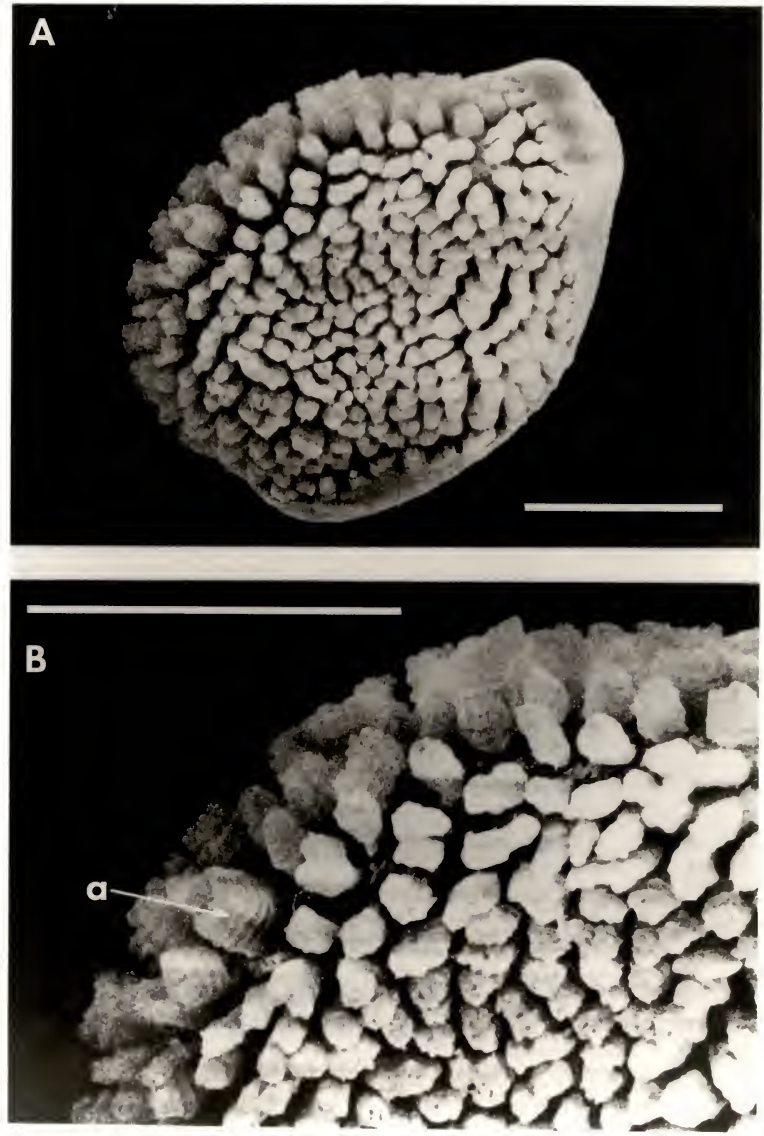
Figure 2 - (C,D,E). Electron photomicrographs of germination following inoculation with aeciospores of Cronartium quercuum f. sp. fusiforme on Quercus rubra leaf tissue: $\frac{\text { C) Branched }}{\text { ) }}$ germ tube ( $\mathrm{g}$ ) of aeciospore (s) on abaxial surface of leaf disc $(2813 \mathrm{X}$; bar $=5 \mu \mathrm{m})$; D) Germinated aeciospore (s) with ge 1 tube $(\mathrm{g})$ and appressorium (a) formed over stoma $(1350 \mathrm{X}$; bar $=4.5 \mu \mathrm{m})$; E) Enlarged portion of appressorium (a) with infection hyphae (p) (2511 X; bar $=5 \mu \mathrm{m})$. 

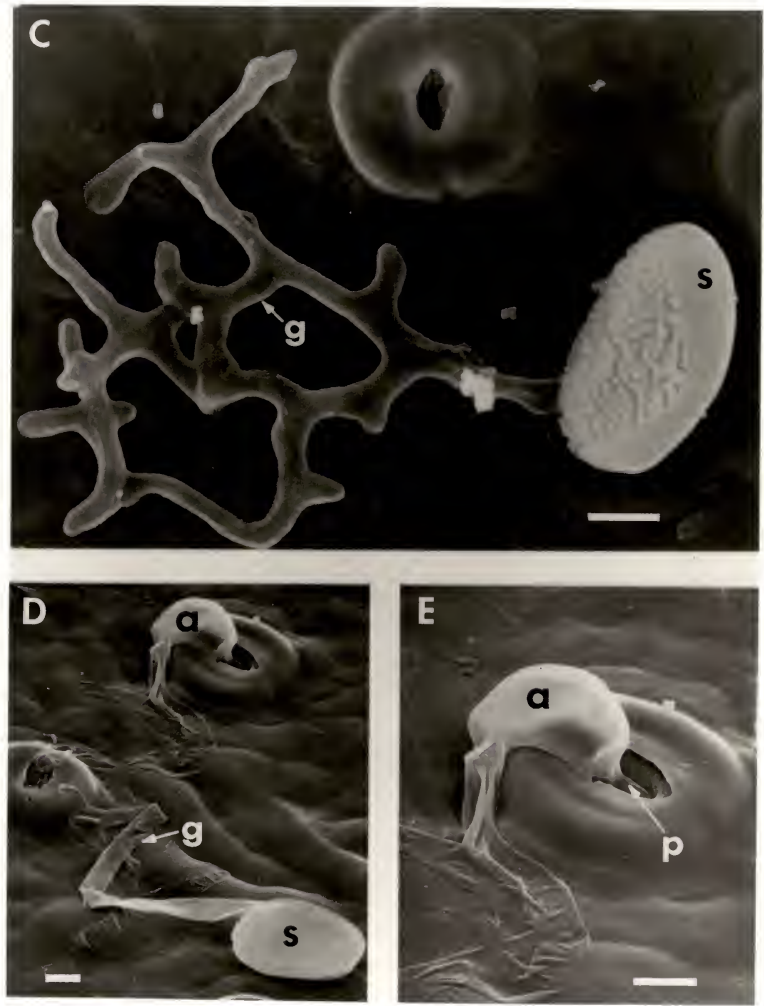
Figure 3 - $(\mathrm{F}, \mathrm{G}, \mathrm{H}, \mathrm{I})$. Electron photomicrographs of uredia1 pustules and urediospores of Cronartium quercuum $f$. sp. fusiforme on Quercus rubra leaf tissue: F) Erumpent uredial pustule with urediospores $(220 \mathrm{X}$; bar $=50 \mu \mathrm{m}) ; \mathrm{G})$ Uredial pustule with echinulated urediospores $(1170 \mathrm{X}$; bar $=6.7 \mu \mathrm{m})$;

H) Ovate urediospore $(6417 \mathrm{X}$; bar $=6.7 \mu \mathrm{m})$; I) Urediospore (s) with branched germination tube $(\mathrm{g})$ and appressorium (a) formed over stoma (1300 X; bar $=5 \mu \mathrm{m})$. 

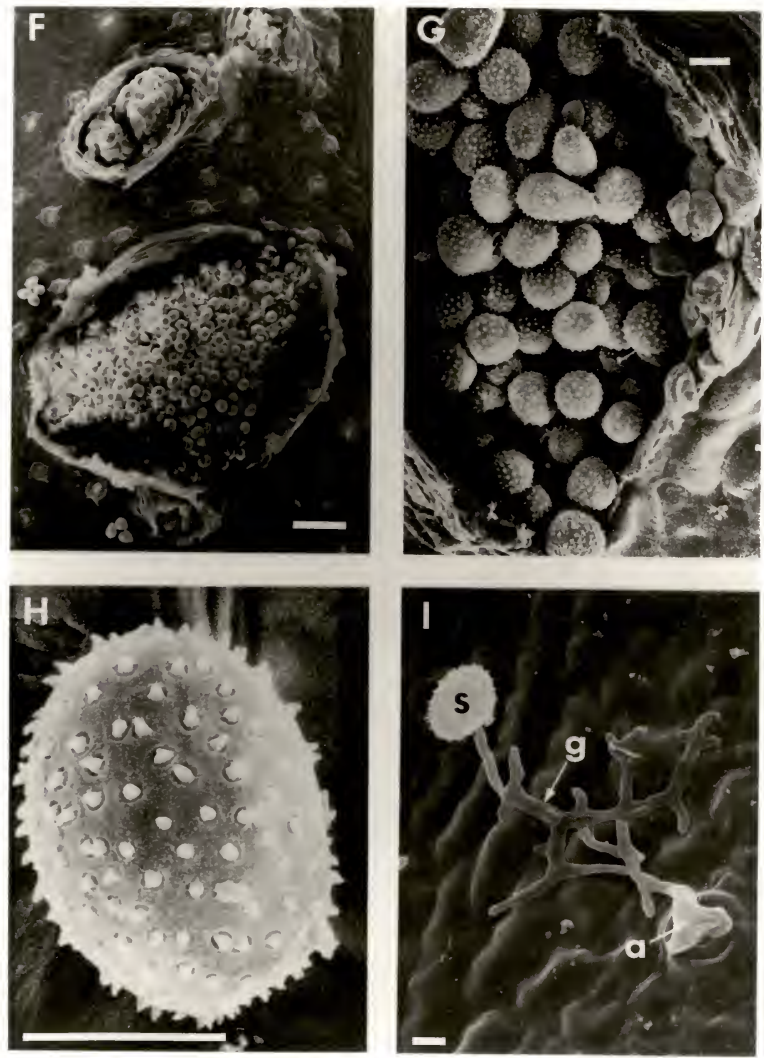
Figure $4-(\mathrm{J}, \mathrm{K})$. Electron photomicrographs of telia of Cronartium quercuum f. sp. fusiforme on Quercus rubra leaf tissue: $\mathrm{J})$ Developing telial column ( $\mathrm{t}$ ) with uredial pustule (u) adjacent $(320 \mathrm{X}$; bar $=50 \mu \mathrm{m})$. K) Mature telial column with probasidia (p) present. Urediospores (u) are present on the _eaf surface $(700 \mathrm{X}$; bar $=50 \mu \mathrm{m})$. 

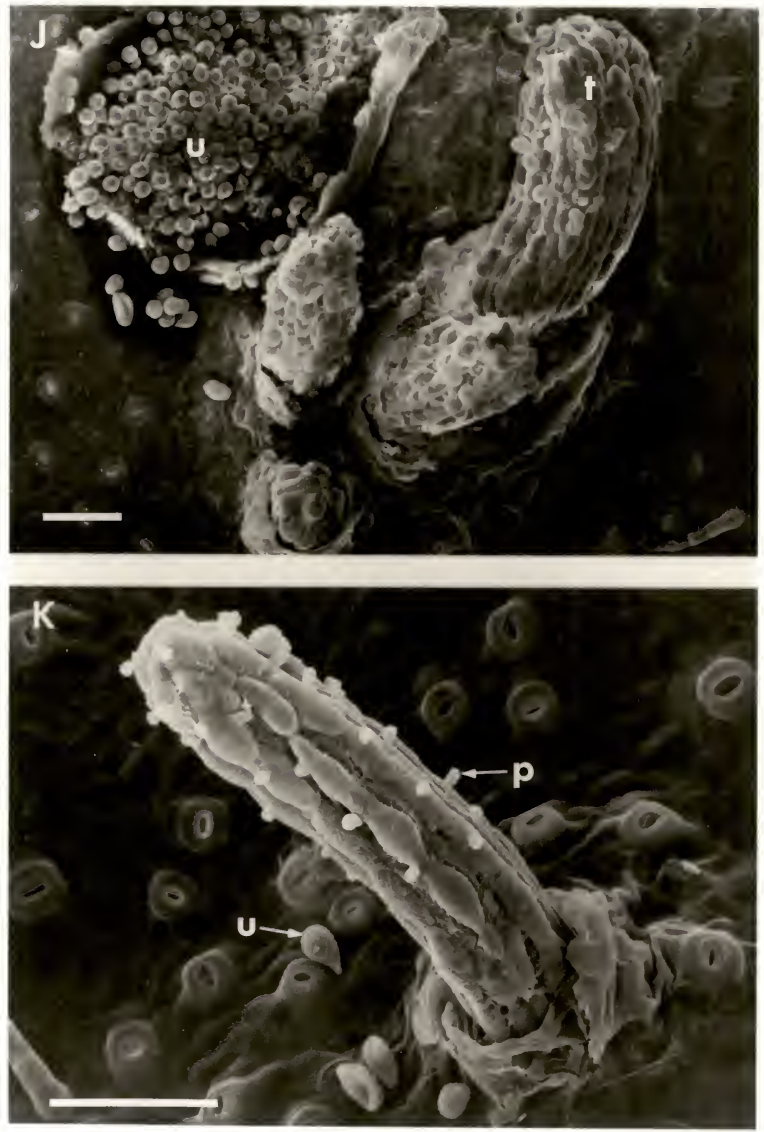
Figure 5 - The effect of temperature on germination following inoculation with aeciospores of Cronartium quercuum $f$. sp. fusiforme on water agar. 


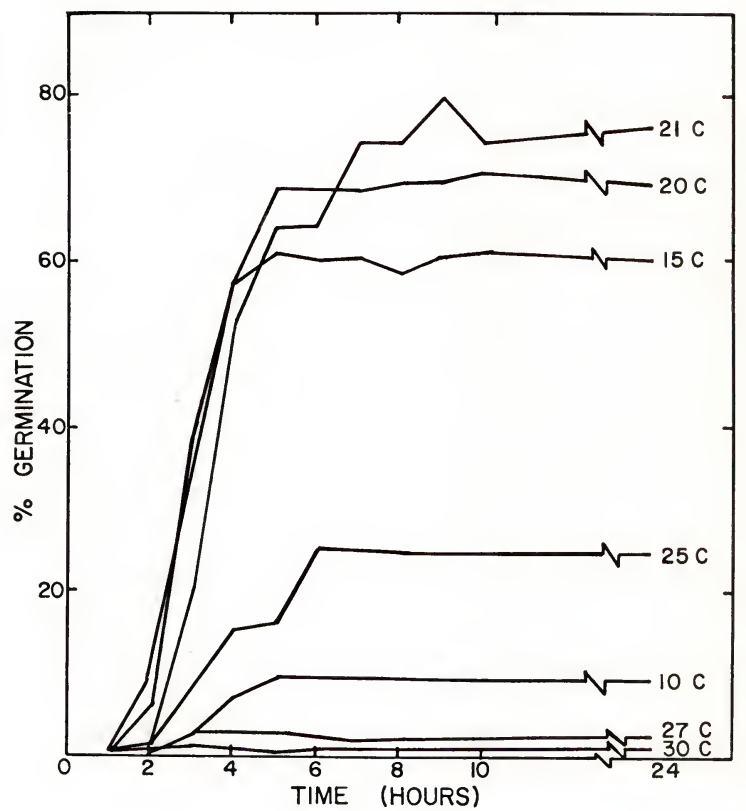


observed while these maxima progressively decreased at temperatures exceeding the optimum.

On both northern red oak leaf discs and the water agar control, $75 \%$ ?

maximum aeciospore germination $(35 \%)$ after 24 hours occurred at $21 \mathrm{C}$ (Fig. 6). Minimal germination of 2 and $3 \%$ occurred at 10 an $30 \mathrm{C}$, respectively. In genera1, low percentage germination occurred at 10 and $30 \mathrm{C}$, intermediate germination occurred at 15, 25, and $27 \mathrm{C}$, and high germination occurred at 20 and $21 \mathrm{C}$ (optimum).

At the optimum temperature $(21 \mathrm{C})$, the theoretical maximum number of aeciospores expected to germinate on water agar was approximately $76 \%$ (Table 1). The maximum germination rate at this temperature occurred after 3.5 hours. An additional 1.4 hours ( 4.9 hours total) were required for the theoretical maximum number of germinated aeciospores to reach $90 \%$. At 15 and $20 \mathrm{C}$, respectively, the theoretical maximum number of germinating aeciospores progressively increased as compared to temperatures above the optimum when the theoretical maxima decreased. The optimum temperature for the theoretical maximum number of aeciospores expected to germinate $(36 \%)$ on oak leaf discs was also $21 \mathrm{C}$ (Table 2). The maximum germination rate at this temperature occurred after 5.8 hours while an additional 3.2 hours were required for the theoretical maximum number of germinated aeciospores to reach $90 \%$. As with aeciospores germinated on water agar, the theoretical maximum numbers of aeciospores expected to germinate on oak leaf discs were normally distributed about the optimum.

After 24 hours the percentage of aeciospores which formed appressoria was maximum at $15 \mathrm{C}$ (Fig. 7). After 24 hours at 10, 25, and $30 \mathrm{C}$, 
Figure 6 - The effect of temperature on germination following inoculation with aeciospores of Cronartium quercuum $f$. sp. fusiforme on Quercus rubra leaf discs. 


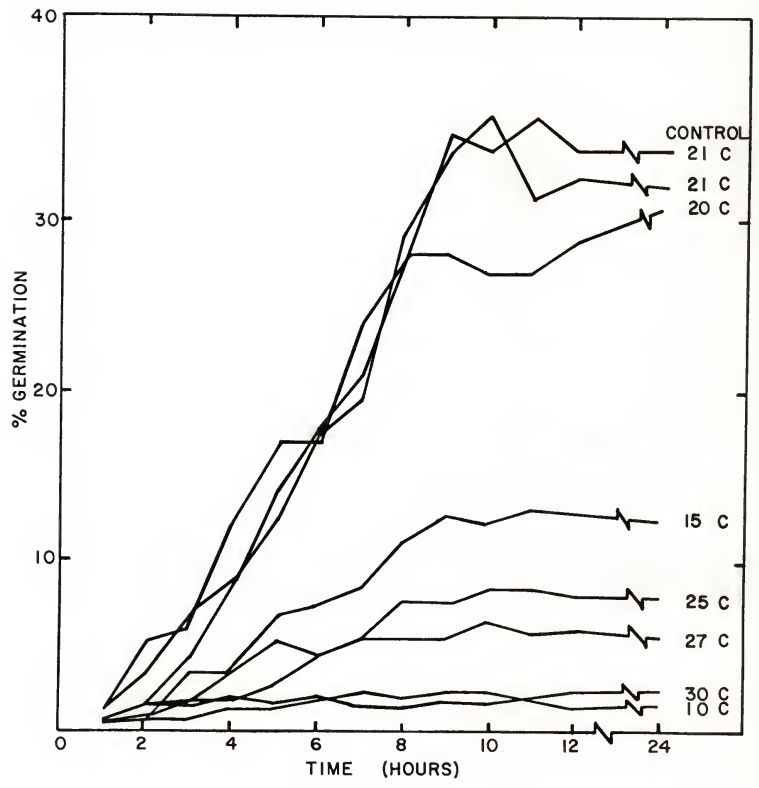




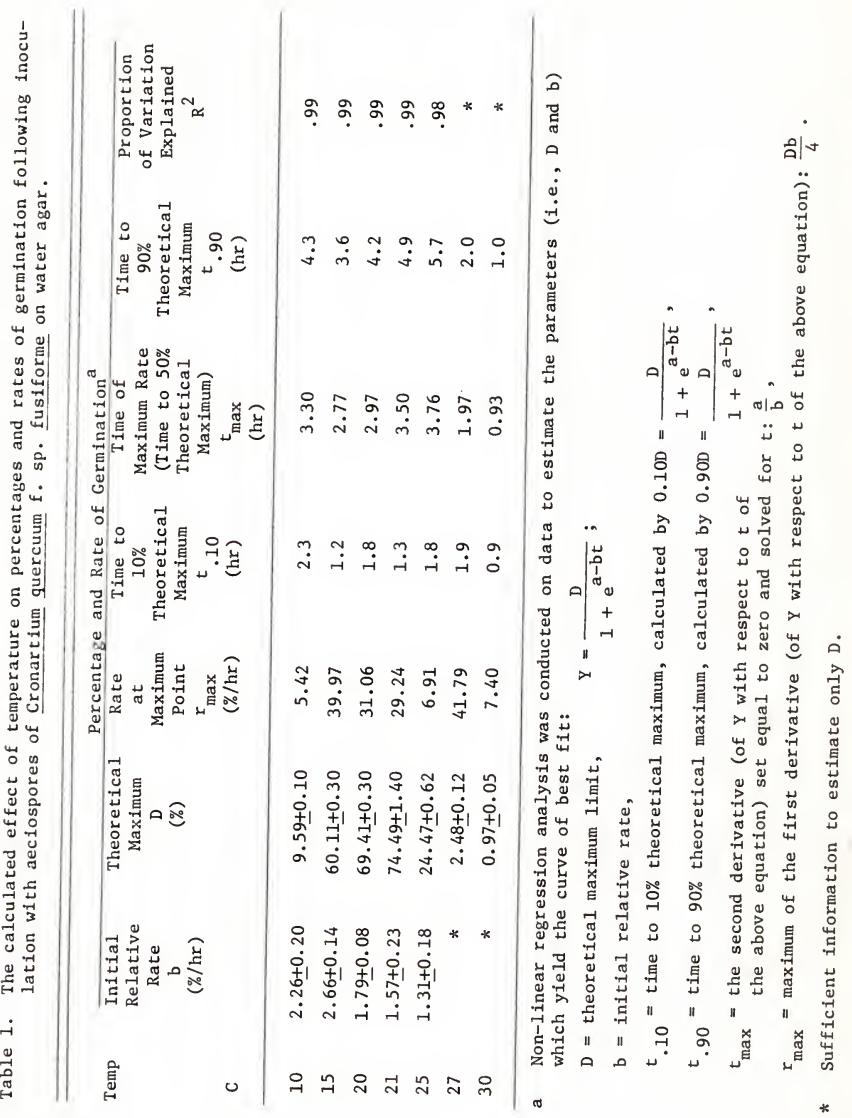




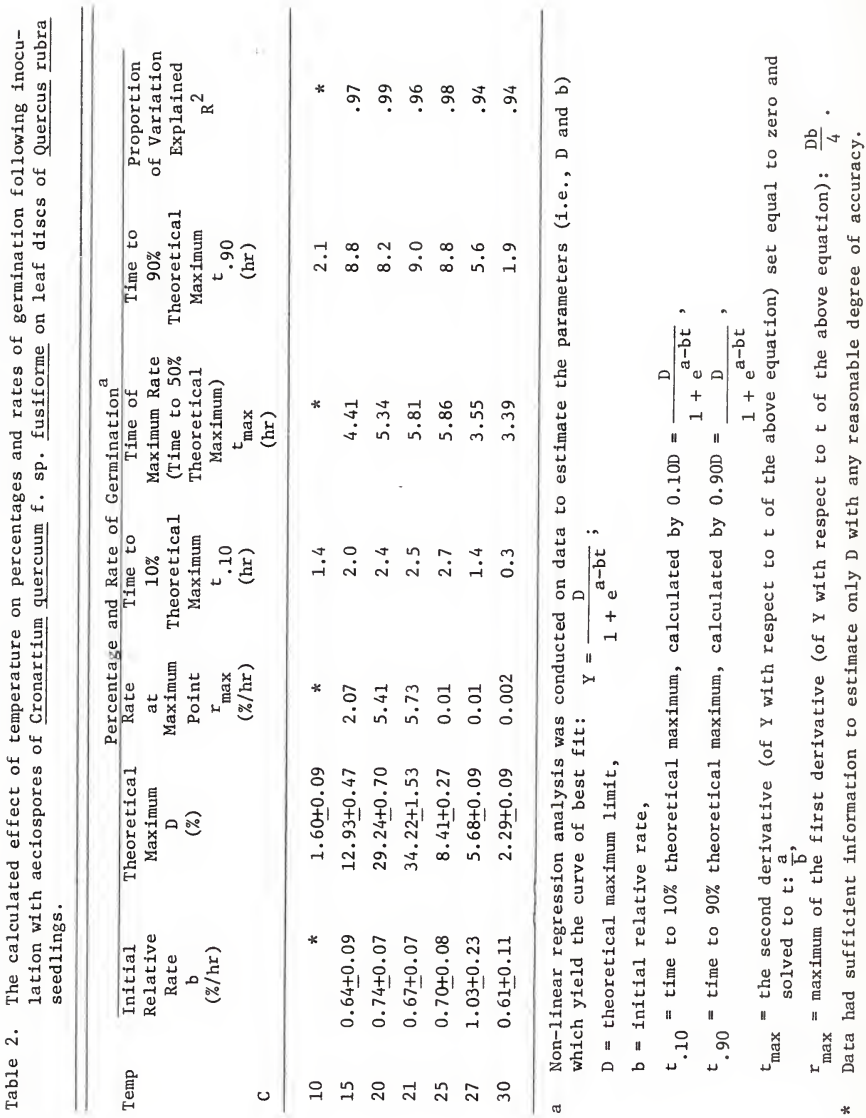


Figure 7 - The effect of temperature on appressorial formation following inoculation with aeciospores of Cronartium quercuum f. sp. fusiforme on Quercus rubra leaf discs. 


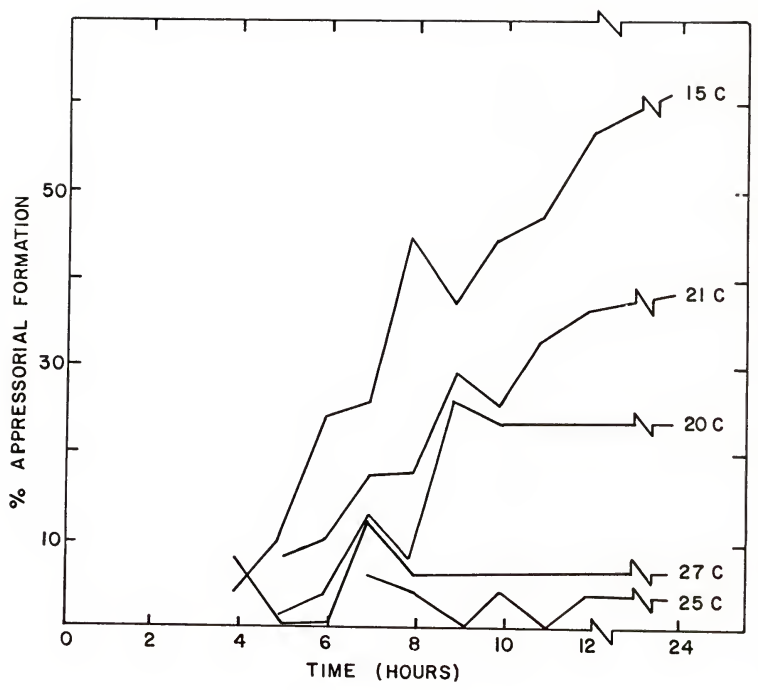


virtually no appressoria had formed. At $15 \mathrm{C}$ the theoretical maximum number of spores to form appressoria was approximately $62 \%$ (Table 3). The maximum rate of appressorial formation occurred after 7.4 hours, and an additional 2.1 hours were required to reach $90 \%$ of the maximum. At temperatures above the optimum, increasingly fewer numbers of spores were expected to form appressoria and the time to $90 \%$ of this theoretical maximum steadily decreased.

\section{Temperature Experiments -- Urediospore Inoculations}

The optimum temperature after 24 hours for urediospore germination (71\%) on water agar was $18 \mathrm{C}$ (Fig. 8). Similarly high percentages of germination were observed at 15 and 21 C. Approximately 40 to $50 \%$ of the urediospores germinated after 24 hours at 10 and $25 \mathrm{C}$. Minimal germination $(5 \%)$ occurred at $30 \mathrm{C}$. The optimum temperature for the theoretical maximum number of urediospores expected to germinate was $18 \mathrm{C}$ (Table 4). The maximum rate of germination occurred after 1.3 hours while an additional 2.1 hours were required for the theoretical maximum number of urediospores expected to germinate to reach $90 \%$. Theoretical maximum numbers of urediospores expected to germinate were distributed about the optimum temperature. The minimum number of spores expected to germinate occurred at $30 \mathrm{C}$.

The optimum temperature for urediospore germination on oak leaf discs was $18 \mathrm{C}$ (Fig. 9). Similarly high percentages of germination occurred at 15 and $21 \mathrm{C}(52$ to $60 \%)$ but at 10,25 , and $30 \mathrm{C}$ the percent germination was less than $20 \%$. The theoretical maximum numbers of urediospores expected to germinate were normally distributed about the optimum temperature $(18 \mathrm{C})$ while the minimum number of spores expected to germinate occurred at $30 \mathrm{C}$ (Table 5). 


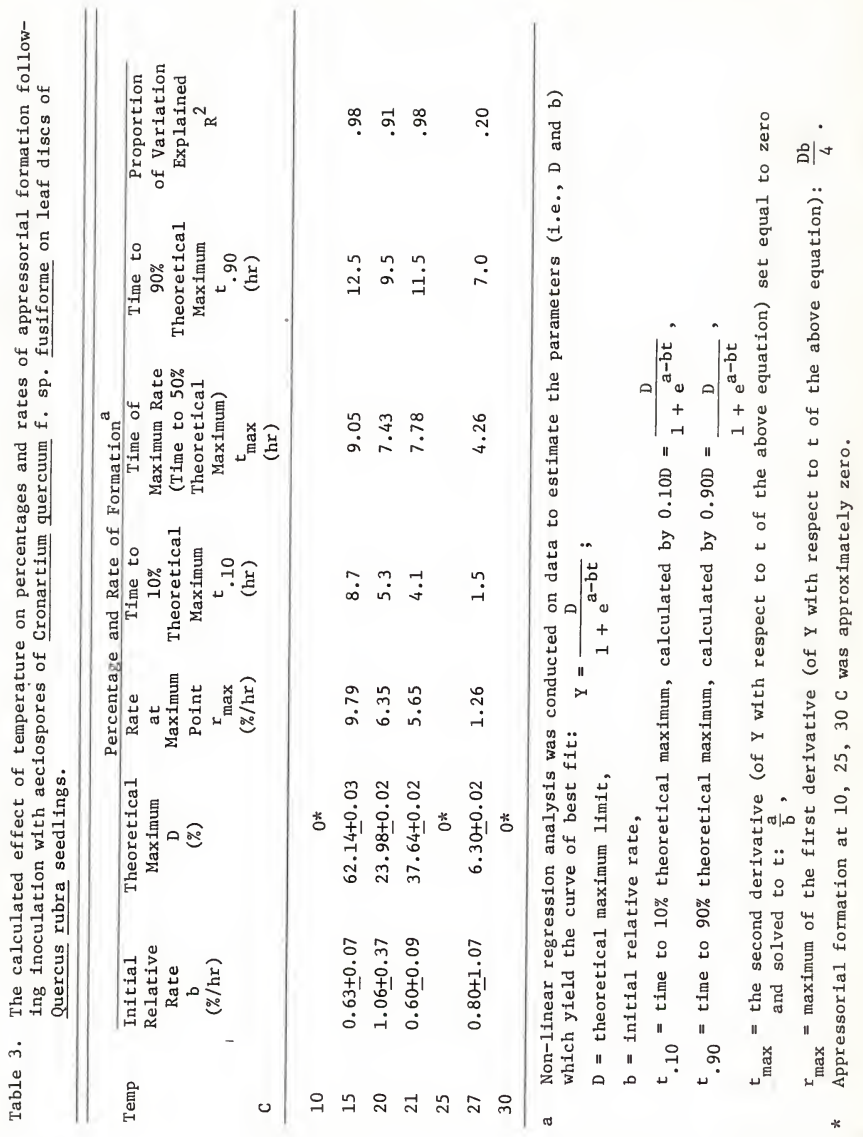


Figure 8. The effect of temperature on germination following inoculation with urediospores of Cronartium quercuum f. sp. fusiforme on water agar. 


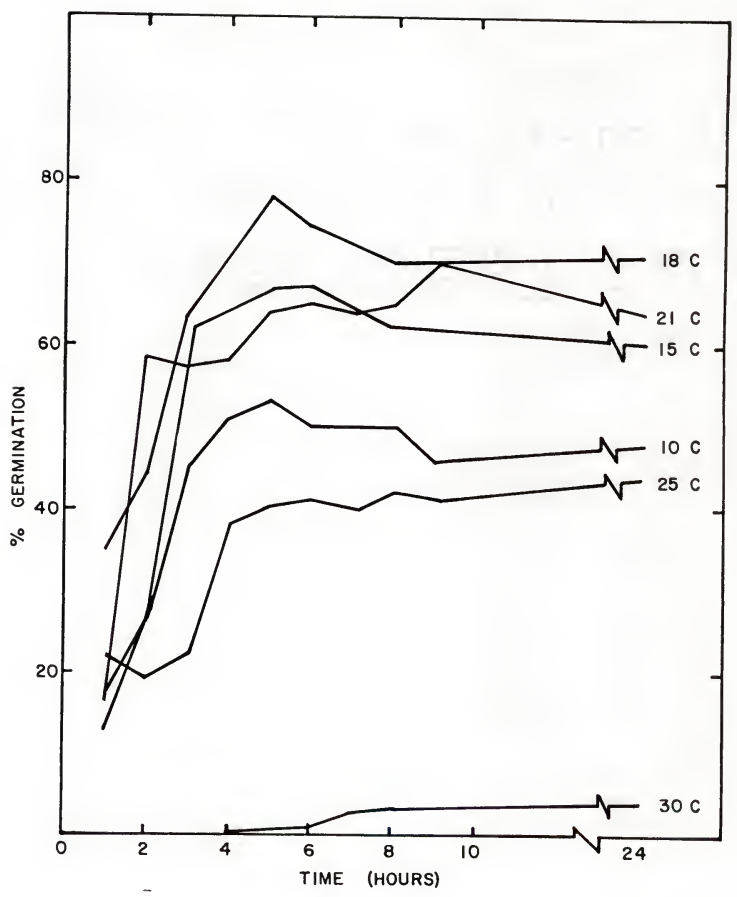




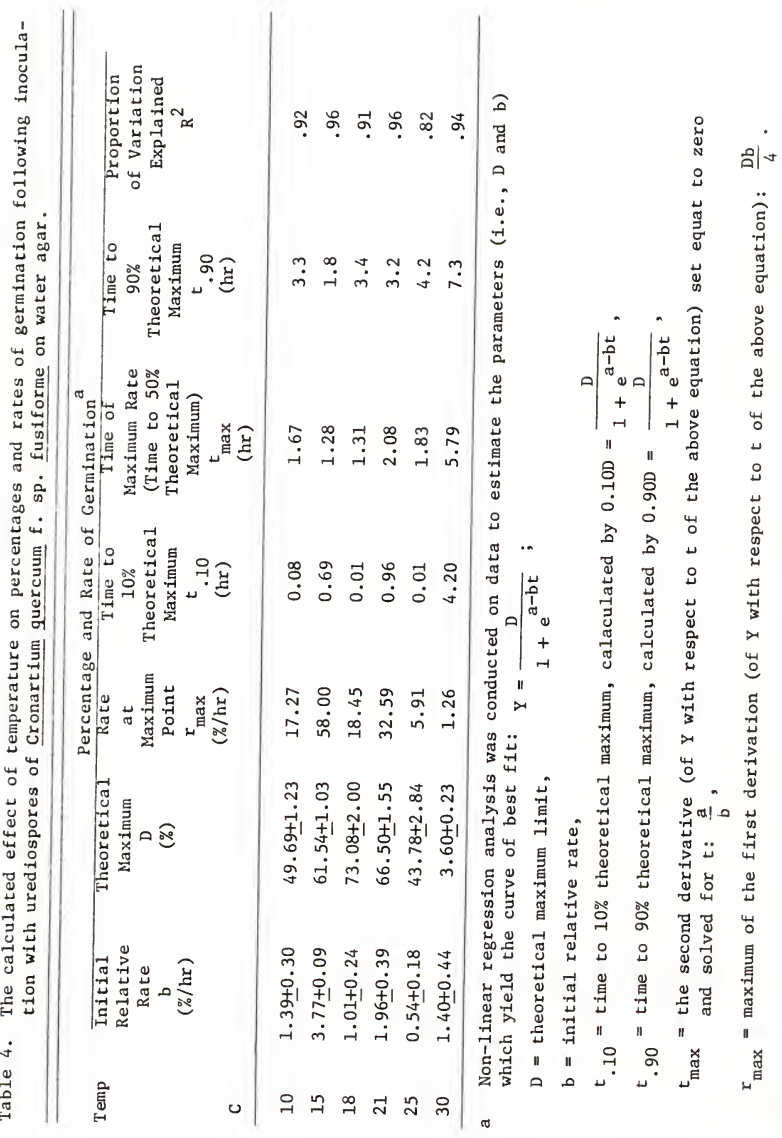


Figure 9. The effect of temperature on germination following inoculation with urediospores of Cronartium quercuum f. sp. fusiforme on Quercus rubra leaf discs. 


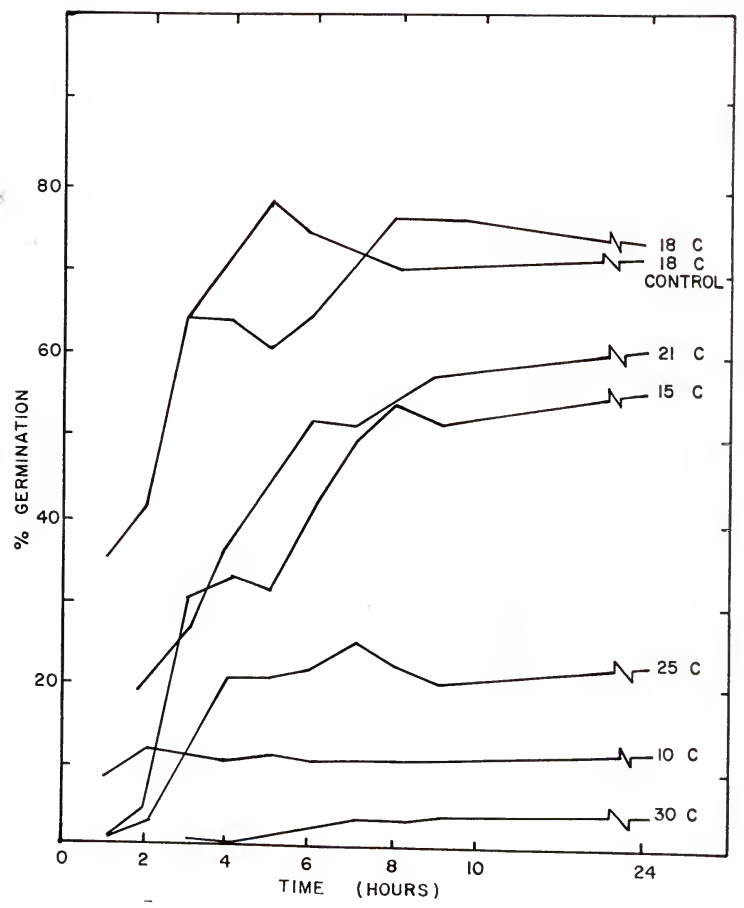




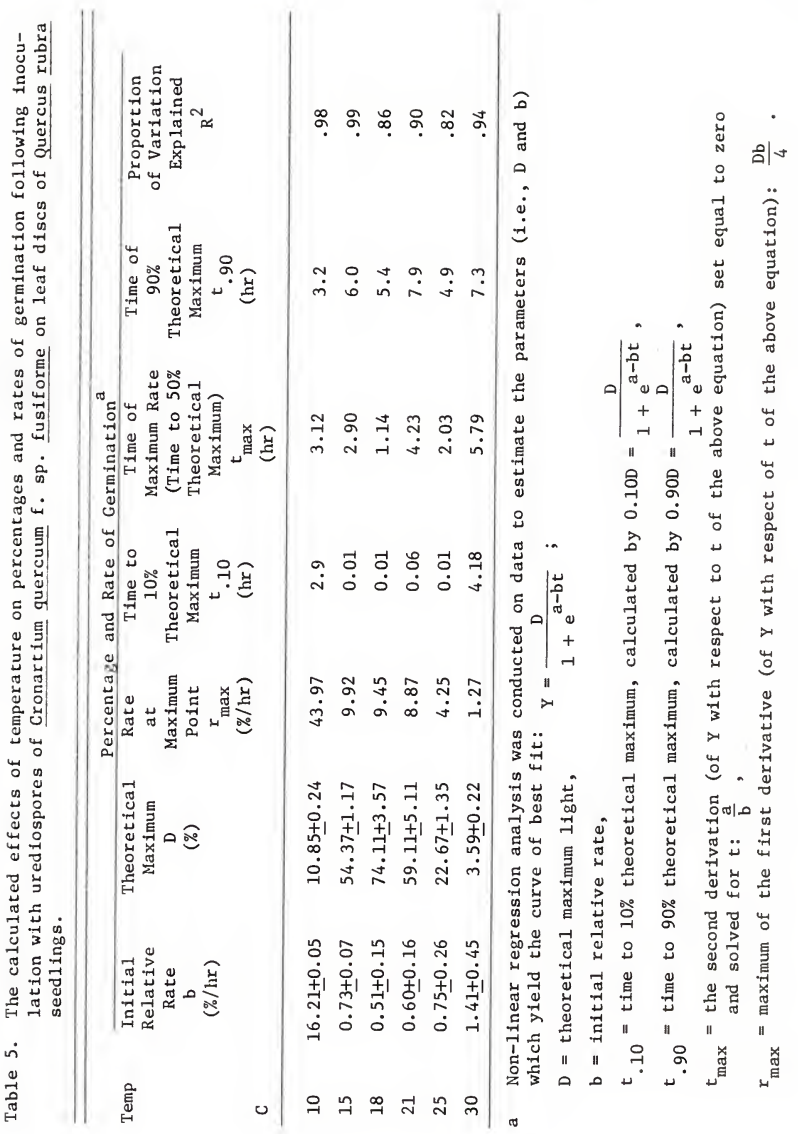


The optimum temperature for appressorial formation form urediospores was also $18 \mathrm{C}$ (Fig. 10). Slightly higher percentages of appressorial formation were observed at 21 and $25 \mathrm{C}$ than at $15 \mathrm{C}$. No appressoria were observed after 24 hours at either 10 or $30 \mathrm{C}$. The theoretical maximum appressorial formation (28\%) occurred at $18 \mathrm{C}$ and the maximum formation rate occurred after 5.9 hours (Table 6). An additional 2.1 hours were required before $90 \%$ of the theoretical maximum appressorial formation occurred. These theoretical maxima increased until the optimum temperature was surpassed after which these values decreased. The maximum rate of appressorial formation decreased to a minimum at $18 \mathrm{C}$. At temperatures greater than $18 \mathrm{C}$ this rate increased linearly.

\section{Leaf Surface Moisture Experiments --Aeciospore Inoculations}

Percent germination of aeciospores steadily increased with increasing duration of continuous leaf disc moisture, although high germination levels $(>24 \%$ ) did not occur until at least 6 hours of moisture were provided (Fig. 11). A low level of aeciospore germination occurred (8\%) in the absence of continuous surface moisture. This was presumably due to the inherent moisture levels present around ungerminated spores or on the leaf surfaces. A minimum of 6 hours at $21 \mathrm{C}$ was required to attain the highest maximum average percent germination (Table 7). Although the average percent germination increased with increasing durations of continuous surface moisture, average germination after 5 hours of moisture was half that at 6 hours. No significant differences in maximum average germination were observed during 6 to 9 hours of continuous moisture. However, a significant relationship $(\alpha=.001)$ existed 
Figure 10 - The effect of temperature on appressorial formation following inoculation with urediospores of Cronartium quercuum f. sp. fusiforme on Quercus rubra leaf discs. 


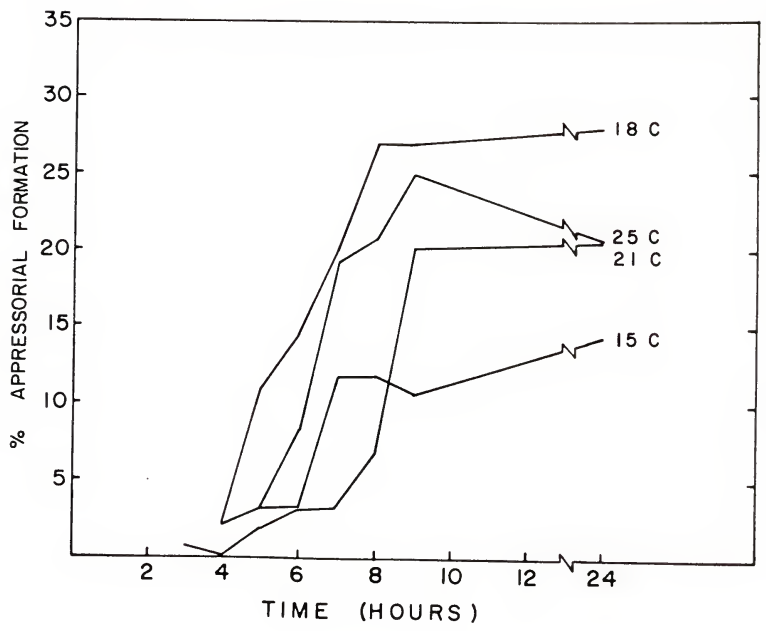




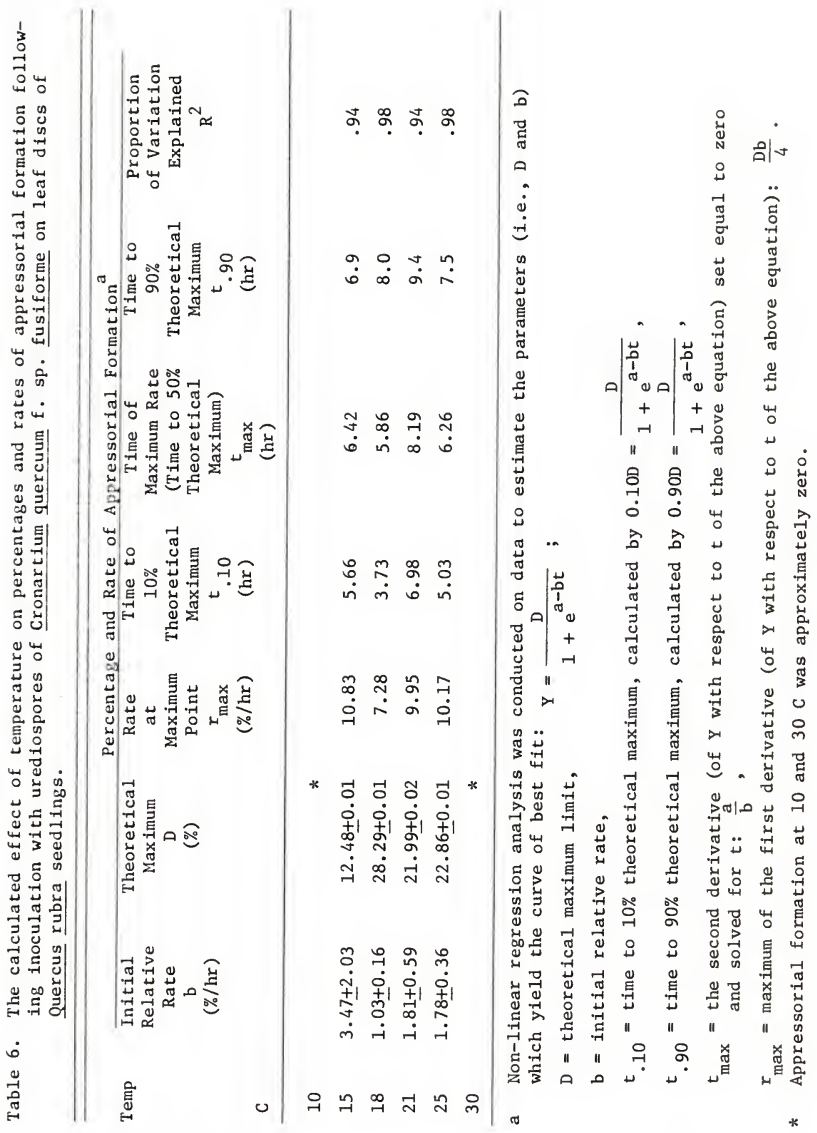


Figure 11 - The effect of continuous leaf surface moisture on germination following inoculation with aeciospores of Cronartium quercuum f. sp. fusiforme on Quercus rubra leaf discs. 


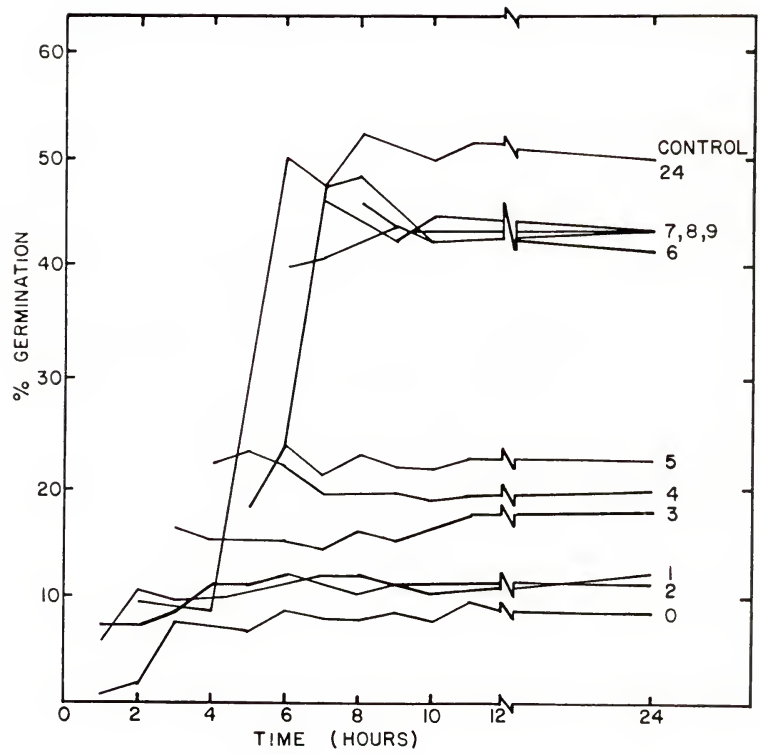




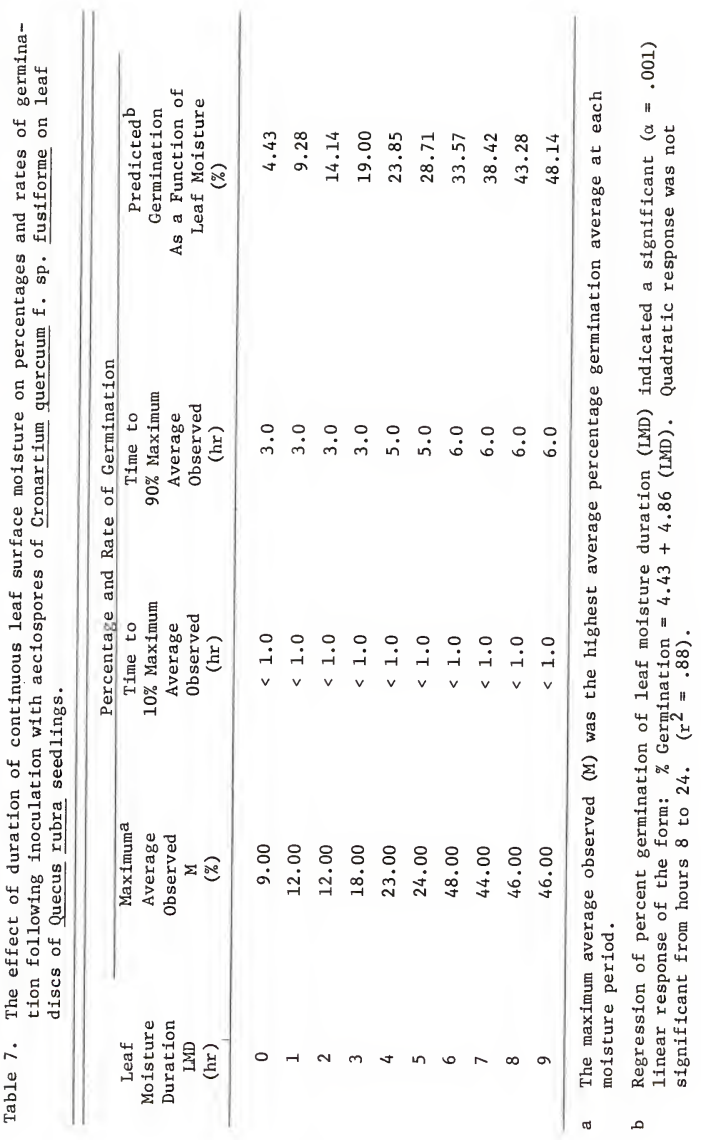


between the percentage of aeciospore germination and the regression of leaf surface moisture duration. The response progressed linearly as moisture duration increased.

The greatest aeciospore appressorial formation (38\%) occurred after 24 hours of leaf surface moisture (Fig. 12). No appressoria were formed when continuous leaf surface moisture was 0 to 2 hours in duration. The percent appressorial formation steadily increased after 2 hours of continuous leaf surface moisture. The maximum average appressorial formation (38\%) occurred after a minimum of 9 hours of continuous leaf surface moisture (Table 8). A significant relationship $(\alpha=.001)$ existed between the percentage of aeciospore appressorial formation and the regression of leaf surface moisture duration. The response progressed quadratica11y as moisture duration increased. Despite little difference in maximum average appressorial formation at 9 and 24 hours, the actual maximum appressorial formation occurred after the longest exposure to continuous moisture, i.e., 24 hours (Fig. 12).

In the first experiment with interrupted leaf surface moisture, $26 \%$ of the aeciospores germinated and 30\% of these formed appressoria at 2 hours of wetness plus 6 hours of drying plus 16 hours of wetness (Fig. 13). In the second experiment, $22 \%$ of the spores germinated and $3.7 \%$ of these formed appressoria at 6 hours of wetness plus 2 hours of dryness plus 16 hours of wetness. Only $25 \%$ of the spores germinated on water agar which was used as a spore viability check. Little difference was observed between the two experiments in either germination (Table 9) or appressorial formation (Table 10). 
Figure 12 - The effect of continuous leaf surface moisture on appressorial formation following inoculation with aeciospores of Cronartium quercuum f. sp. fusiforme on Quercus rubra leaf discs. 


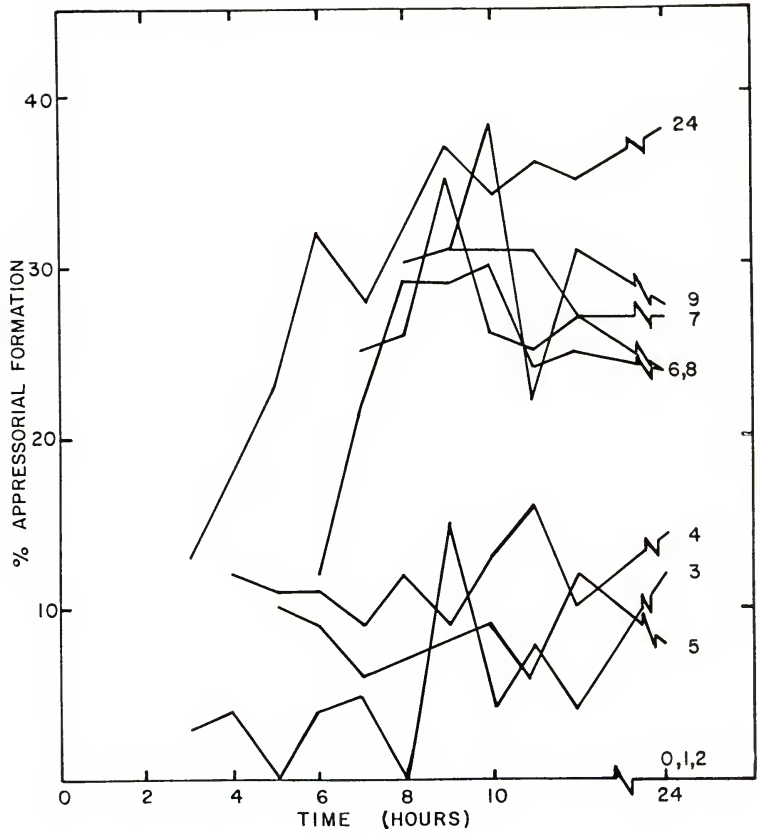




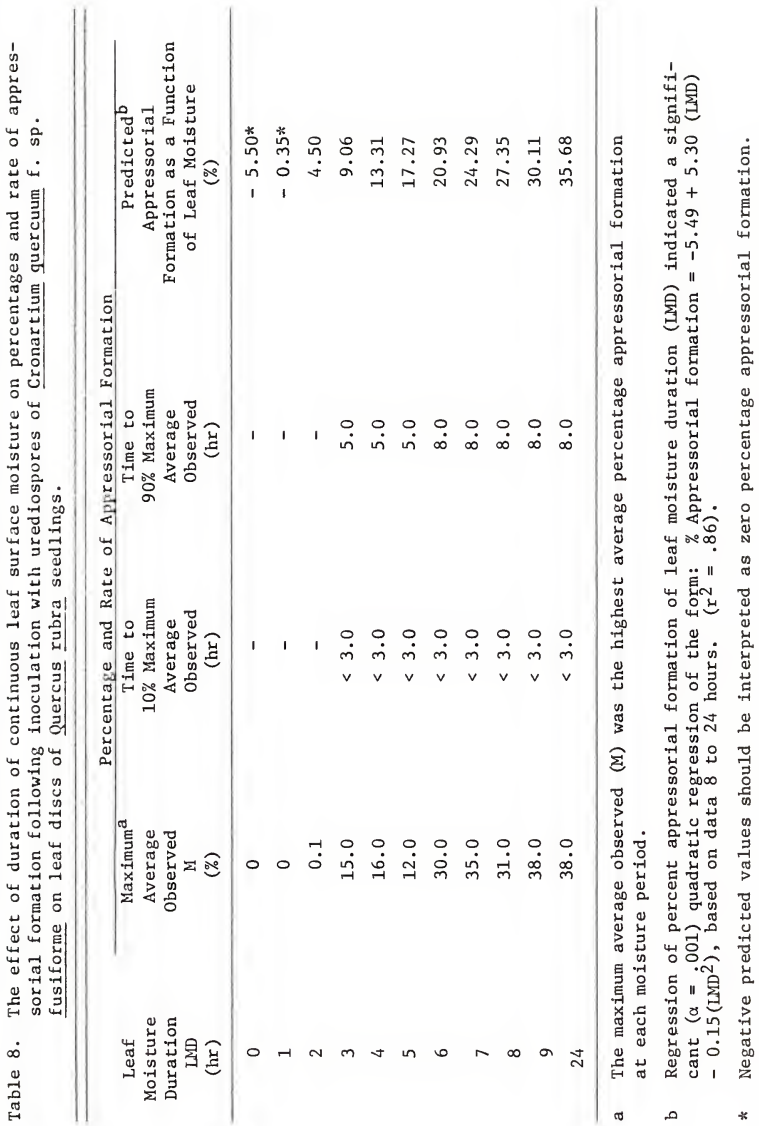


Figure 13 - The effect of an interruption in the period of leaf surface moisture on germination and appressorial formation following inoculation with aeciospores of Cronartium quercuum f. sp. fusiforme on Quercus rubra leaf discs. 


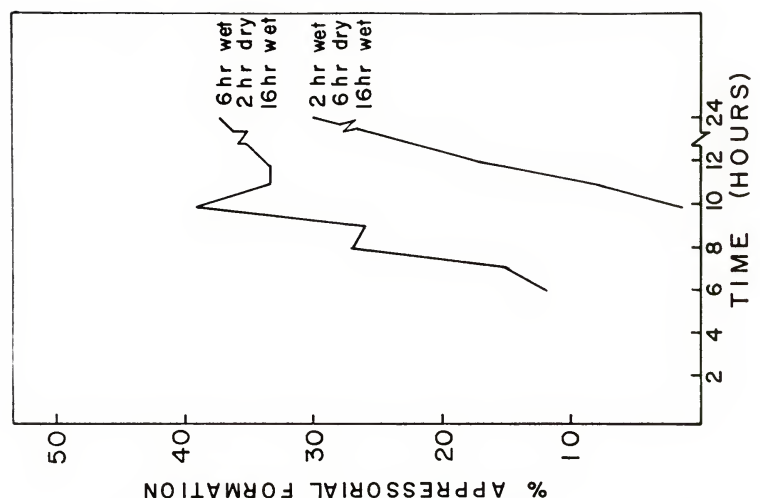

NOII

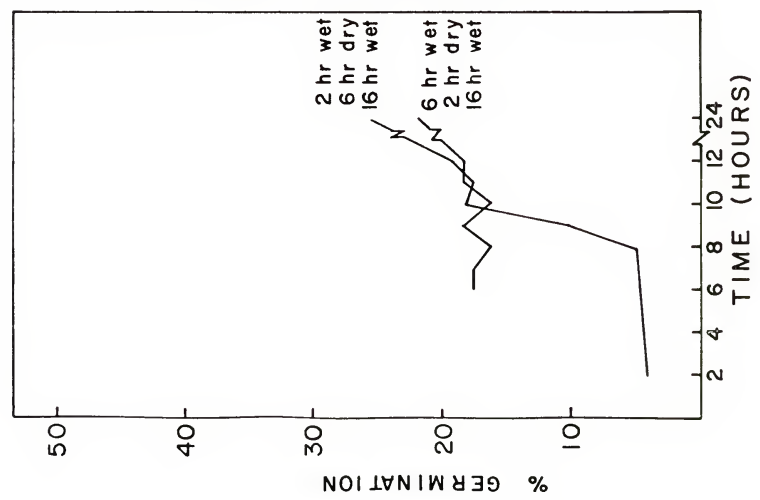




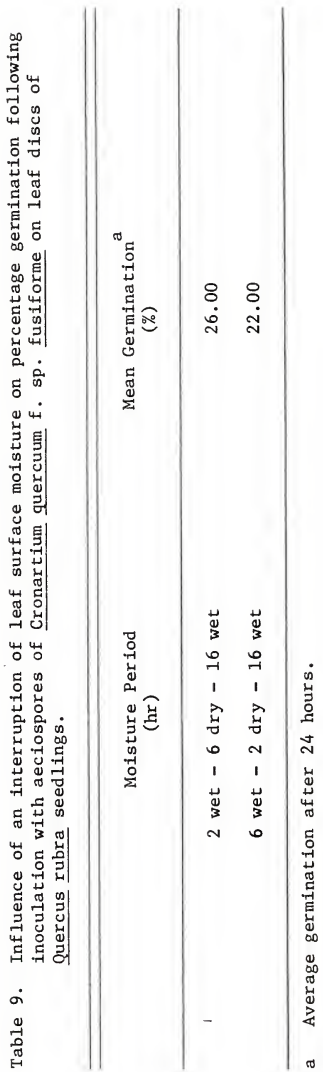




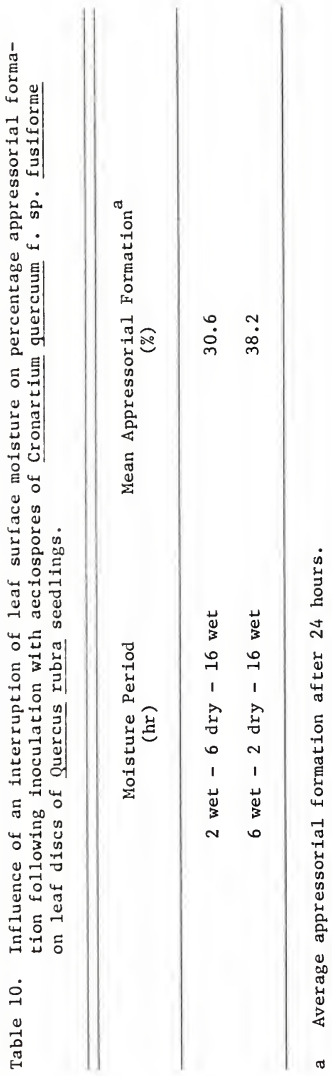


Leaf Surface Moisture Experiments--Urediospore Inoculations

Minimal urediospore germination (3\%) occurred in the absence of leaf surface moisture (Fig. 14). Percent germination steadily increased with increasing duration of surface moisture with maximum germination (70\%) occurring after 24 hours of surface moisture. The maximum average germination (68\%) was reached after only 8 hours of continuous leaf surface moisture (Table 11). Less than $1 \%$ of the urediospores formed appressoria at less than 1 hour of surface moisture (Fig. 15). Appressorial formation progressively increased from $1 \%$ at 2 hours moisture to $28 \%$ at 24 hours moisture. The maximum average percent appressorial formation also occurred after 24 hours of surface moisture (Table 12). A significant relationship $(\alpha=.001)$ existed between the percentage of urediospore germination and appressorial formation and the regression of leaf surface moisture duration. The response progressed quadratically as moisture duration increased.

In the first experiment with interrupted leaf surface moisture, $55 \%$ of the urediospores germinated and $4 \%$ of these formed appressoria at 1 hour of wetness plus 1 hour of drying plus 16 hours of wetness (Fig. 16). In the second experiment, $57 \%$ of the spores germinated and $2 \%$ of these formed appressoria at 1 hour of wetness plus 3 hours drying plus 20 hours wetness (Fig. 16). However, $71 \%$ of the urediospores germinated on the water agar check plate. Little difference in either germination (Table 13) or appressorial formation (Table 14) was observed between the two experiments. 
Figure 14 - The effect of continuous leaf surface moisture on germination following inoculation with urediospores of Cronartium quercuum $\mathrm{f}$. sp. fusiforme on Quercus rubra leaf discs. 


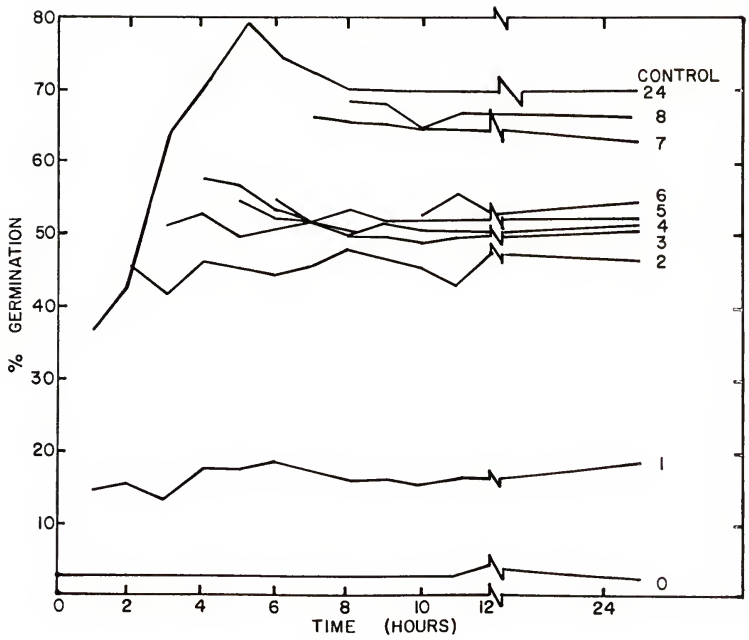




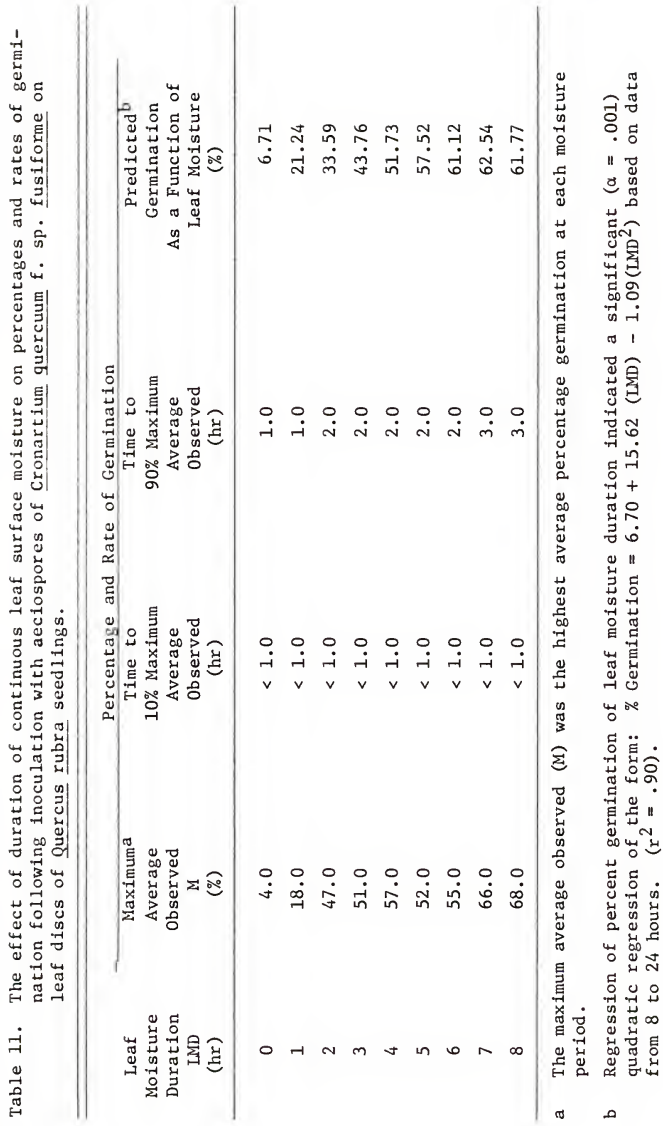


Figure 15 - The effect of continuous leaf surface moisture on appressorial formation following inoculation with urediospores of Cronartium quercuum f. sp. fusiforme on Quercus rubra leaf discs. 


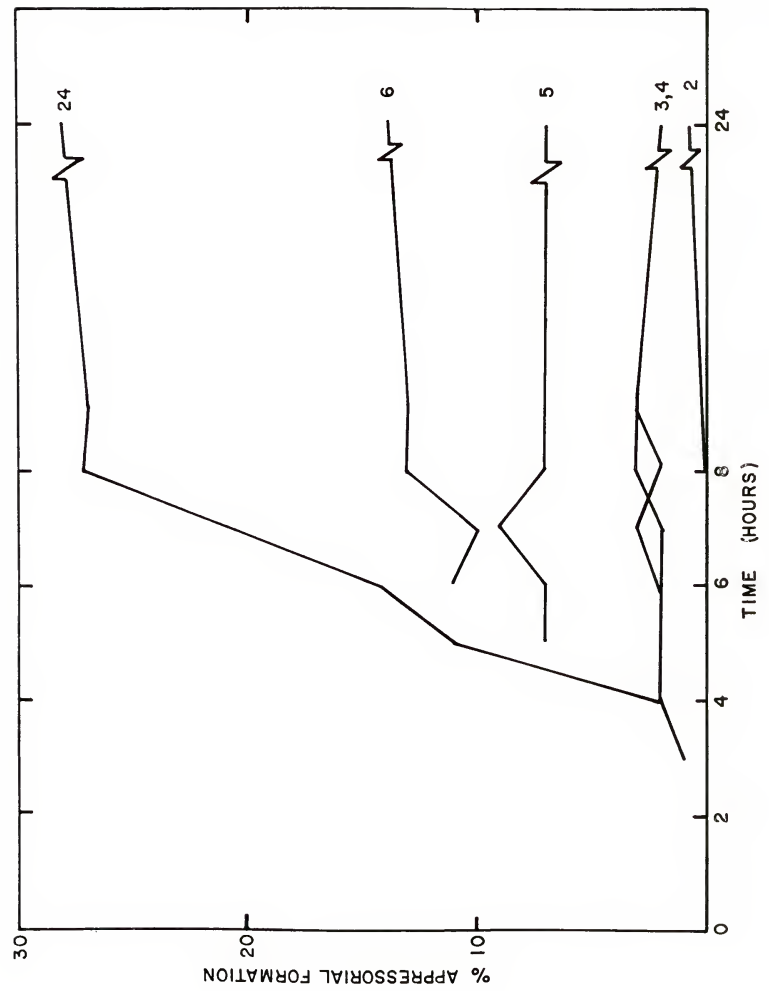




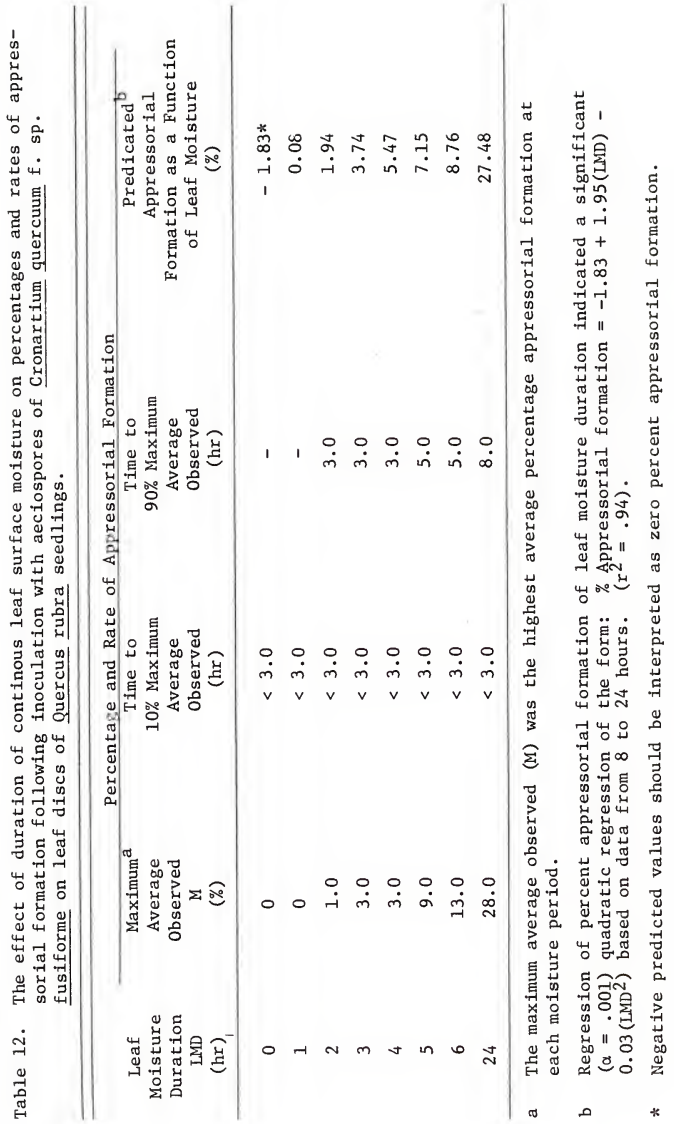


Figure 16 - The effect of an interruption in the period of leaf surface moisture on germination and appressorial formation following inoculation with urediospores of Cronartium quercuum f. sp. fusiforme on Quercus rubra leaf discs. 

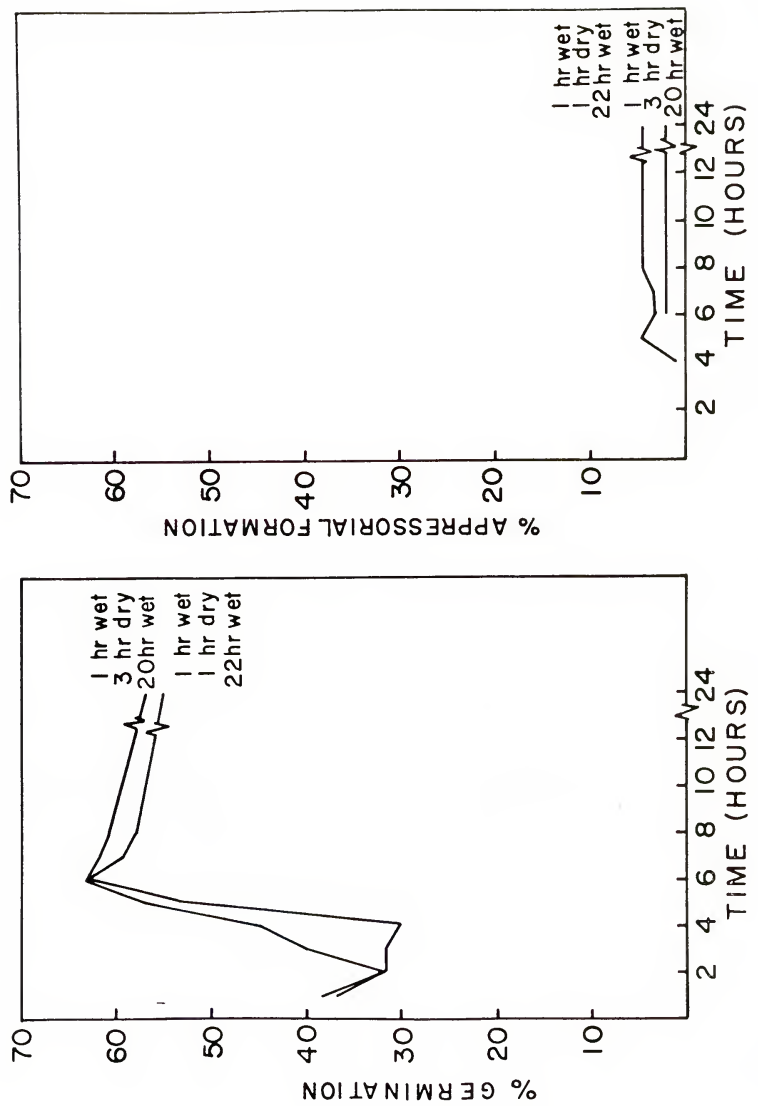


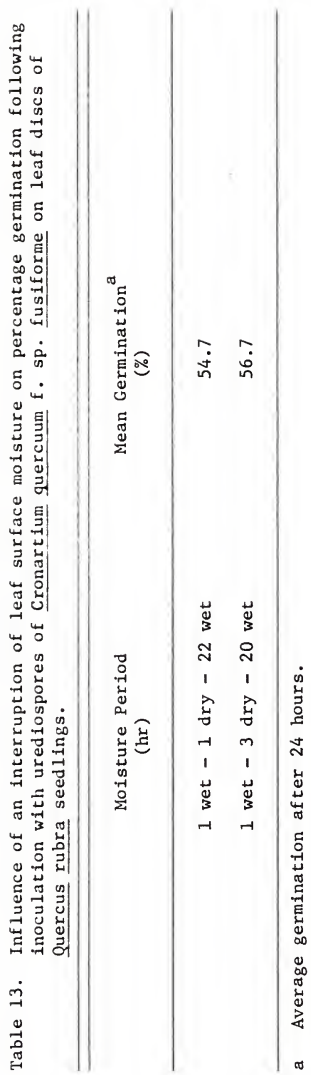




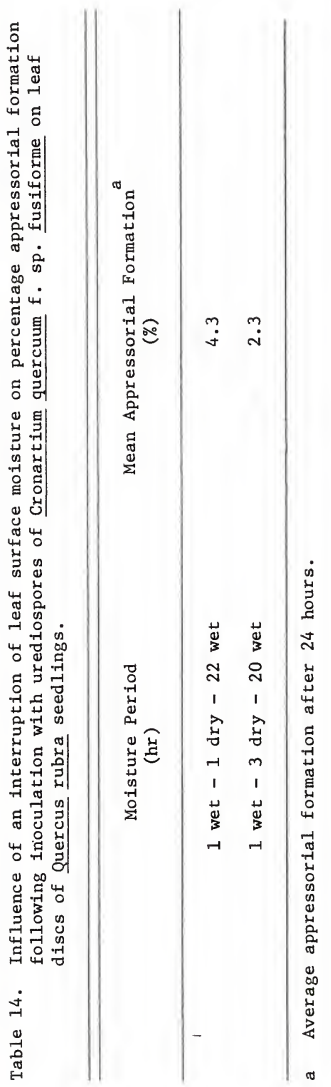




\section{Leaf Age Experiments-- Aeciospore Inoculations}

Aeciospore germination was approximately $20 \%$ at all leaf ages of 2, 4, 5, 6, 11, and 16 days (Fig. 17). Percent appressorial formation was slightly more variable and increased with leaf age; for example, $36 \%$ of the aeciospores formed appressoria at 2 days compared to $42 \%$ at 16 days. The theoretical maximum aeciospore germination (25\%) occurred at 5 days (Table 15). The theoretical maximum appressorial formation (37\%) occurred when leaves were 11 days old (Table 16).

\section{Leaf Age Experiments -- Urediospore Inoculations}

Percent urediospore germination was approximately $53 \%$ at all leaf ages of $2,4,9,13$, and 20 days (Fig. 18). No significant difference in theoretical maximum germination was observed among all leaf ages (Table 17). Percent appressorial formation was also consistent (12 to $14 \%$ ) across the leaf age classes. Maximum percent germination (54\%) occurred after 20 days and maximum percent appressorial formation (14\%) occurred at 4 and 13 days (Fig. 18). The theoretical maximum percent germination (51\%) also occurred at 20 days (Table 17). The theoretical maximum appressorial formation occurred when leaves were 4 days old (Table 18).

\section{Quantification of Inoculum}

Uredial sori developed 6 days after aeciospore inoculation of 2-, 5-, and 6-day-old leaves (Fig. 19). No sori developed on the 8- or 11day-old leaves. The latent period for uredial sori was approximately 7 days. The maximum average number of uredial sori per $\mathrm{cm}^{2}(0.5)$ of leaf surface occurred on 5-day-old leaves with only 0.2 and 0.1 sori appearing on 2- and 6-day-old leaves respectively (Tables 19 and 20). 
Figure 17 - The effect of leaf age on germination and appressorial formation following inoculation with aeciospores of Cronartium quercuum f. sp. fusiforme on Quercus rubra leaf discs. 

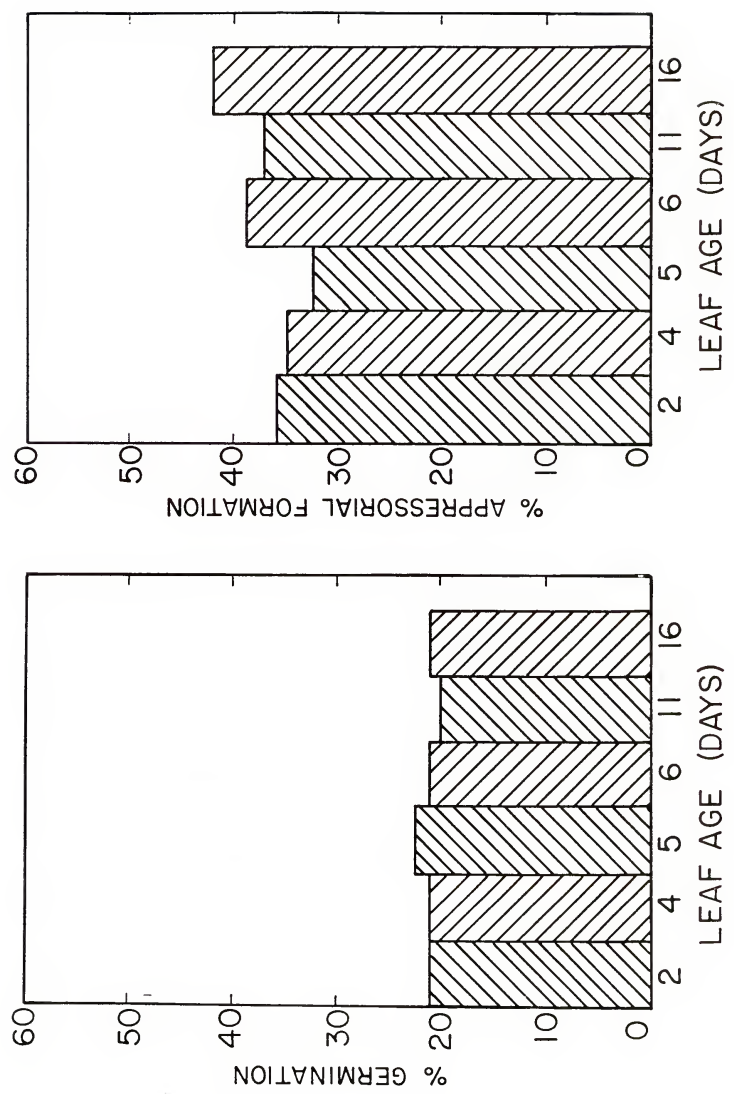


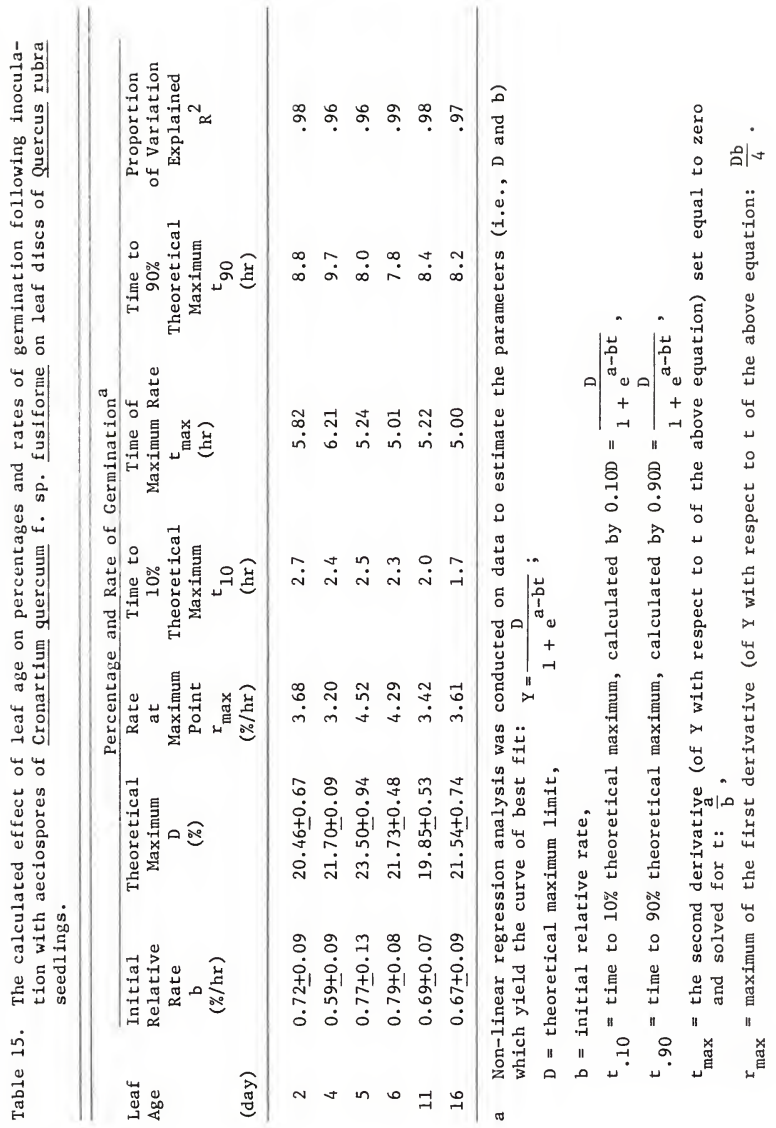




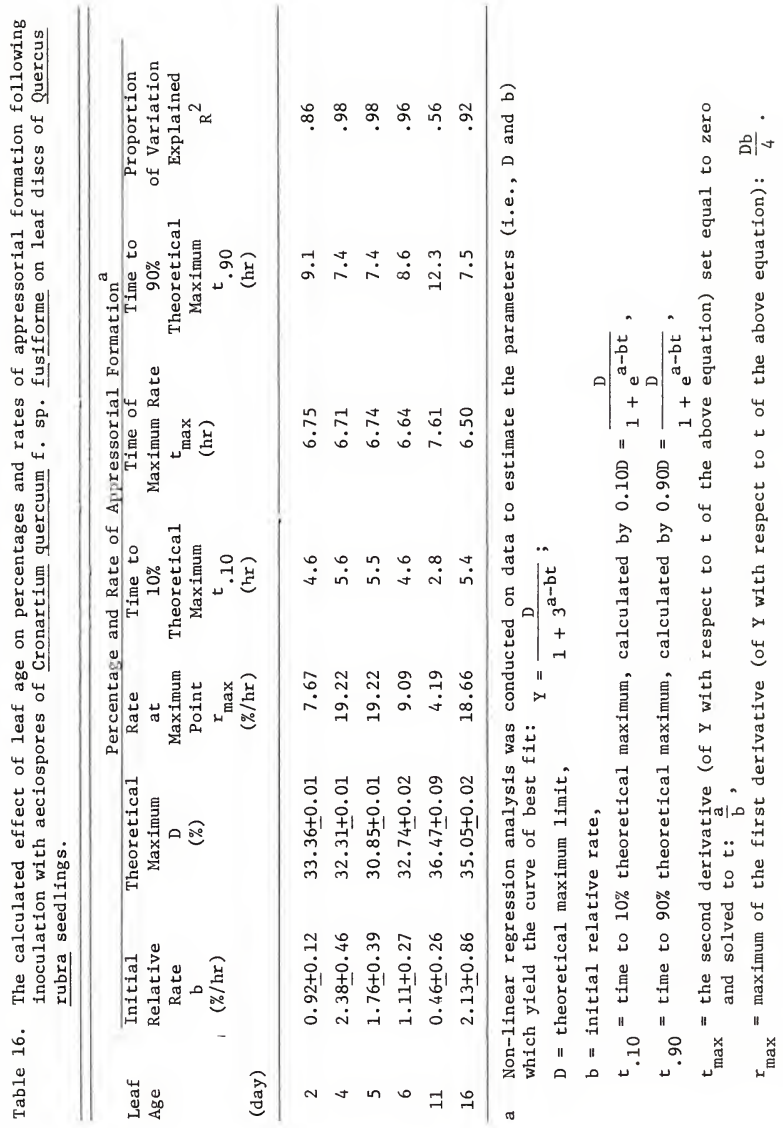


Figure 18 - The effect of leaf age on germination and appressorial formation following inoculation with urediospores of Cronartium quercuum $\mathrm{f}$. $\mathrm{sp}$. fusiforme on Quercus rubra leaf discs. 

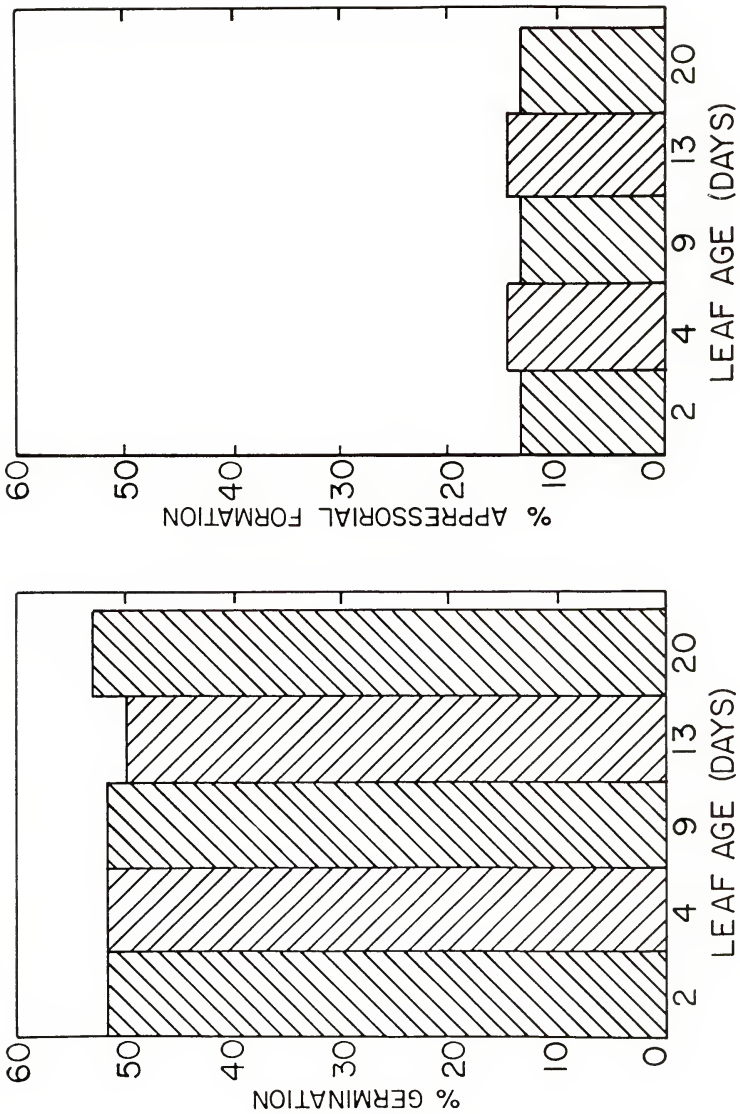


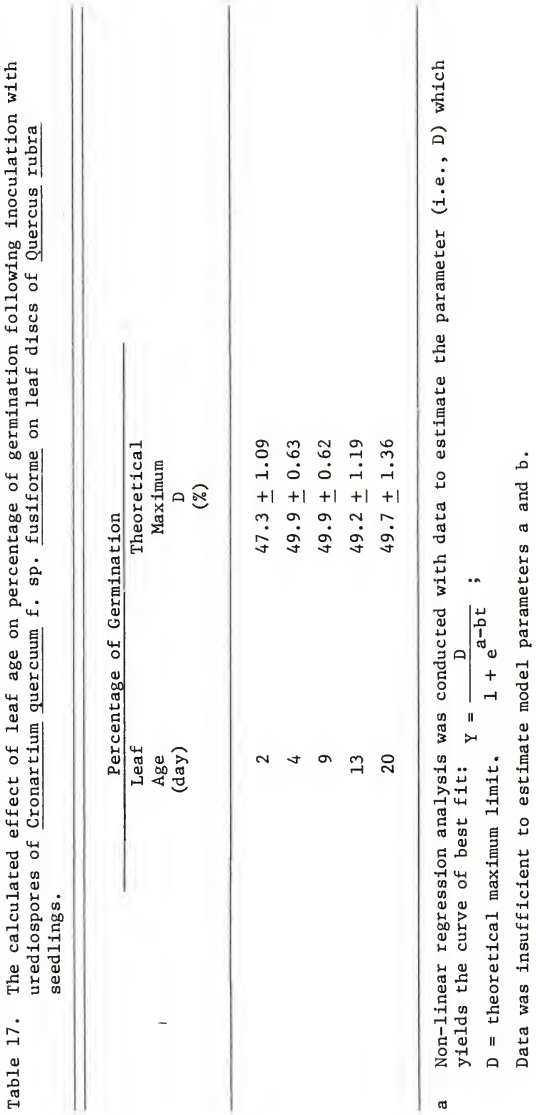




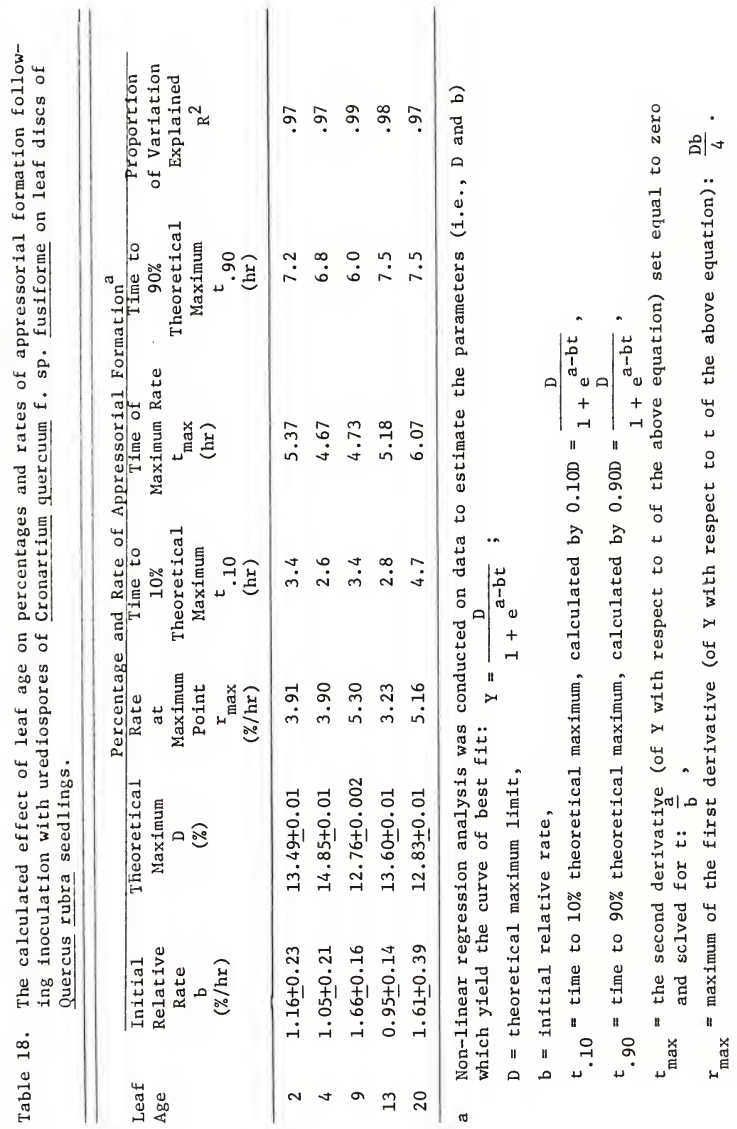


Figure 19 - The effect of leaf age on the number of sori per $\mathrm{cm}^{2}$ produced following inoculation with aeciospores of Cronartium quercuum $\mathrm{f}$. sp. fusiforme on 2- to 11-dayold Quercus rubra seedlings. 


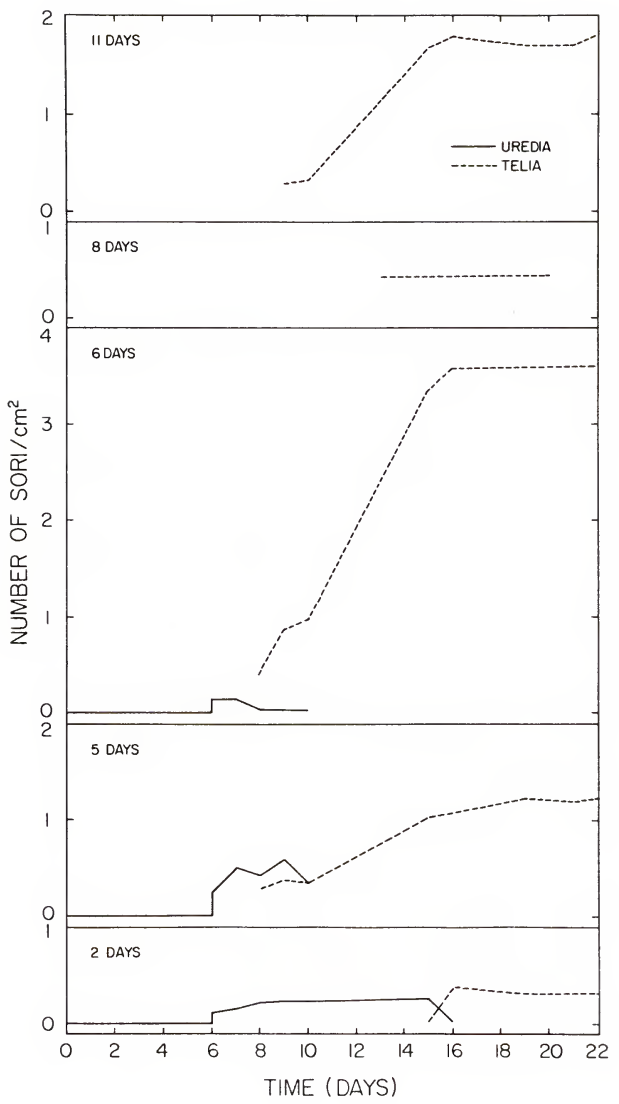




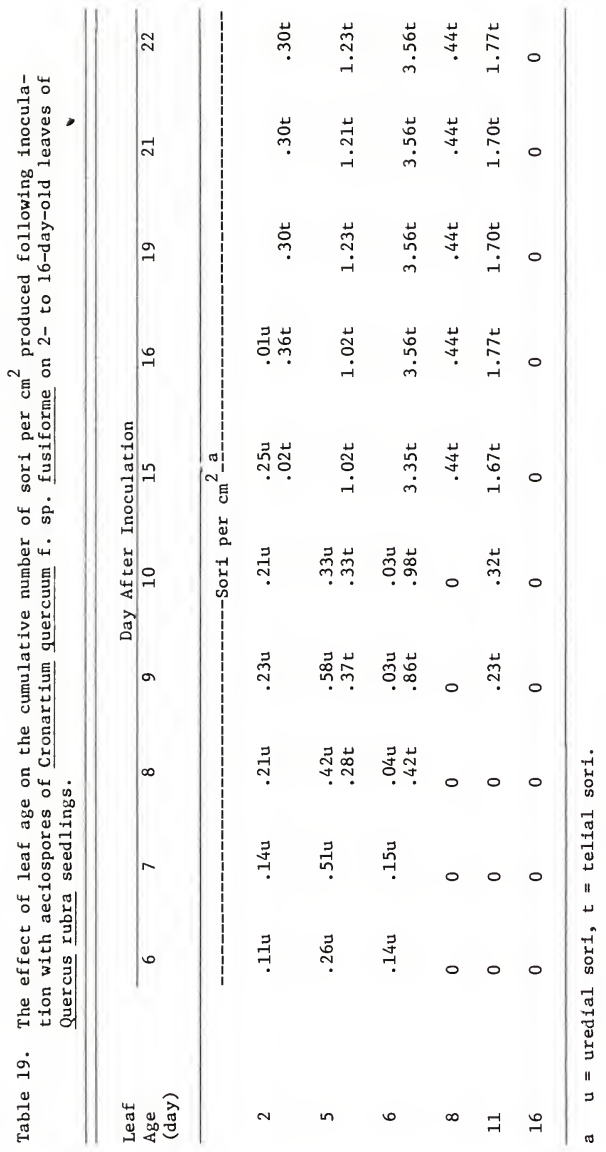


Table 20. The effect of leaf age on number of uredia and telia produced following inoculation with aeciospores of Cronartium quercuum f. sp. fusiforme on 2- to 11-day-old leaves of Quercus rubra seedlings.

\begin{tabular}{|c|c|c|c|}
\hline & $\begin{array}{l}\text { Age of } \\
\text { Seedlings } \\
\text { (days) }\end{array}$ & $\begin{array}{l}\text { Average } \\
\text { Number } \\
\text { of Sori } \\
\left(\text { Sori/cm }{ }^{2}\right)\end{array}$ & \\
\hline \multirow[t]{3}{*}{ Uredia } & 2 & $0.17 \pm 0.03$ & $A^{a}$ \\
\hline & 5 & $0.42 \pm 0.06$ & B \\
\hline & 6 & $0.08 \pm 0.03$ & A \\
\hline \multirow[t]{5}{*}{ Telia } & 2 & $0.26 \pm 0.06$ & A \\
\hline & 5 & $0.84 \pm 0.15$ & A, B \\
\hline & 6 & $2.48 \pm 0.51$ & $\mathrm{C}$ \\
\hline & 8 & $0.44 \pm 0$ & A \\
\hline & 11 & $1.32 \pm 0.26$ & B \\
\hline
\end{tabular}

a Means accompanied by different letters are statistically different at the $\alpha=.05$ level as determined by the Student T-Test. 
Telial columns appeared 8 to 9 days after inoculation of 5-, 6-, and 11-day-old leaves (Fig. 19). Telial columns appeared only after 15 days when 2- and 8-day-old oak leaves were inoculated. The maximum number of telial columns per $\mathrm{cm}^{2}$ occurred on leaves that were 6 days old when inoculated (Table 20).

An aeciospore inoculum efficiency schedule based upon uredial and telial formation was calculated from inoculation of $2-, 5-, 6-, 8-$, and 11-day-old oak leaves (Table 21). An average of 1.07 telial sori per $\mathrm{cm}^{2}$ of leaf surface developed 20 days after inoculation $(1000 \pm 100$ aeciospores $\left(\mathrm{cm}^{2}\right.$ ).

A temporal sequence for infection and disease development following aeciospore inoculations of northern red oak seedlings is described in Fig. 20. The first incubation period is defined as the period from inoculation to the production of immature uredia which occurred in 6 days. The first latent period (inoculation through mature uredia) required an additional 24 hours. The second incubation period (inoculation through immature telia) required 8 days while the second latent period (inoculation through mature telia) also required an additional day.

Uredial pustules developed in 5 days after urediospore inoculation $\left(1000 \pm 100\right.$ spores $\left./ \mathrm{cm}^{2}\right)$ of $2-, 5-, 7-$, and 9-day-old leaves (Fig. 21). No uredial pustules developed on 11-day-old leaves. The latent period for uredial pustules was approximately 6 days. The average number of uredial sori per $\mathrm{cm}^{2}$ was greatest on 2-day-old leaves and was progressively less on 5-, 7-, and 9-day-old leaves, respectively (Tables 22 and 23). 
Table 21. Inoculum efficiency following inoculation with aeciospores of Cronartium quercuum f. sp. fusiforme on 2- to 11-day-old of Quercus rubra seedlings maintained in a growth chamber at $21^{\circ} \mathrm{C}$.

\begin{tabular}{clc}
\hline $\begin{array}{c}\text { Time } \\
\text { (day) }\end{array}$ & \multicolumn{1}{c}{ Process } & $\begin{array}{c}\text { Infection Units } \\
\text { (per } \mathrm{cm}^{2} \text { ) }\end{array}$ \\
\hline 0 & Inoculation & 1000 spores \pm 100 \\
1 & Germination & 340 spores \pm 20 \\
.1 & Appressoria formation & 210 spores \pm 10 \\
$6-16$ & Uredial Production & 0.22 sorus \pm .06 \\
$8-20$ & Telial Production & 1.07 sori \pm .25 \\
\hline
\end{tabular}


Figure 20 - Time of occurrence for infection and disease development following inoculation with aeciospores of Cronartium quercuum f. sp. fusiforme on Quercus rubra seedlings maintained at optimal temperature and moisture conditions for the pathogen. 


\section{AECIOSPORES}

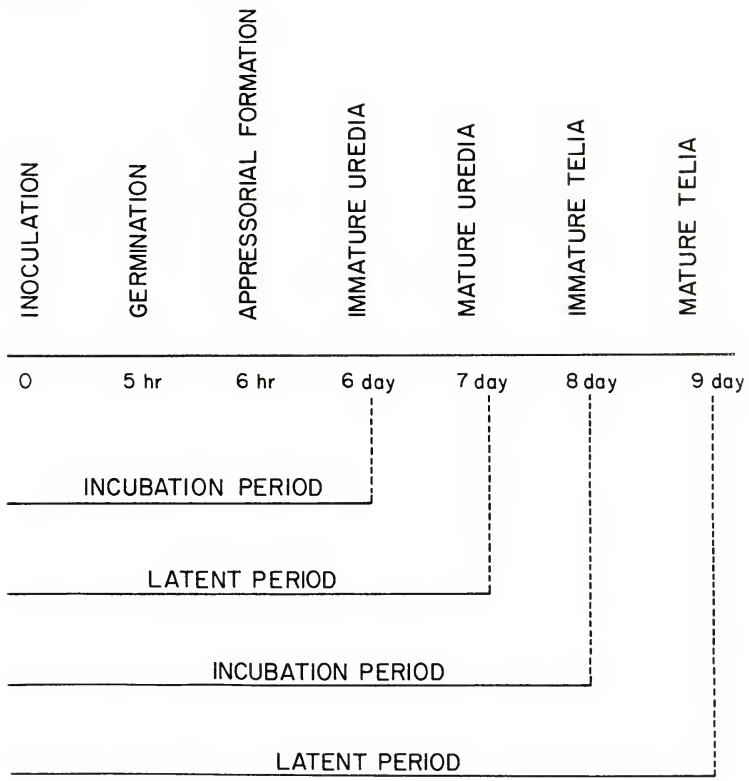


Figure 21 - The effect of leaf age on the number of sori per $\mathrm{cm}^{2}$ produced following inoculation with urediospores of Cronartium quercuum f. sp. fusiforme on 2- to 11-dayold Quercus rubra seedlings. 


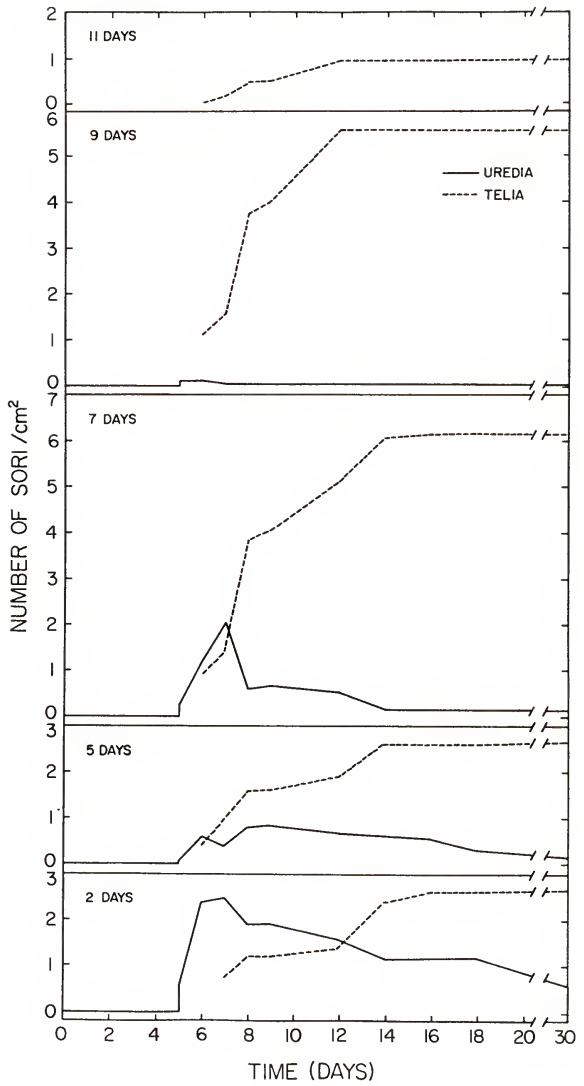




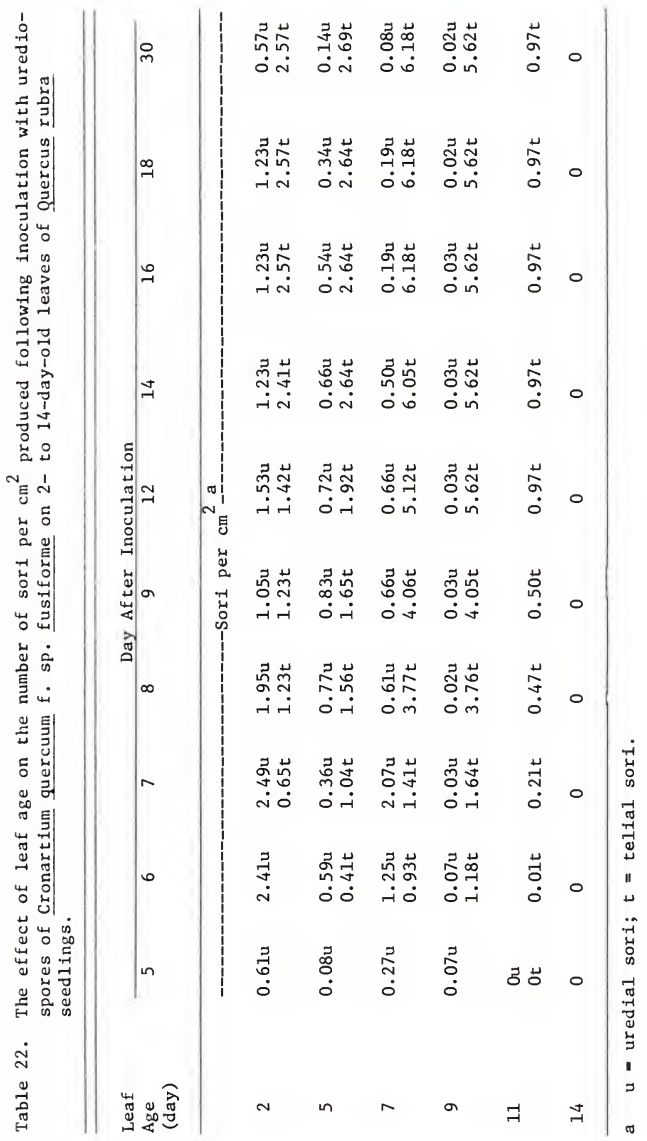


Table 23. The effect of leaf age on number of uredia and telia produced following inoculation with urediospores of Cronartium quercuum f. sp. fusiforme on 2- to 11-day-old leaves of Quercus rubra seedlings.

\begin{tabular}{|c|c|c|}
\hline & $\begin{array}{l}\text { Age of } \\
\text { Seedling } \\
\text { (days) }\end{array}$ & $\begin{array}{c}\text { Average } \\
\text { Number } \\
\left.\text { of Sor } \frac{i}{2}\right) \\
\left.\text { (Sori } / \mathrm{cm}^{2}\right)\end{array}$ \\
\hline \multirow[t]{4}{*}{ Uredia } & 2 & $1.52 \pm 0.21 \mathrm{~A}^{\mathrm{a}}$ \\
\hline & 5 & $0.50 \pm 0.08 \mathrm{~B}$ \\
\hline & 7 & $0.60 \pm 0.20 \mathrm{~B}$ \\
\hline & 9 & $0.04 \pm 0.01 \mathrm{C}$ \\
\hline \multirow[t]{5}{*}{ Telia } & 2 & $1.83 \pm 0.28 \mathrm{~A}$ \\
\hline & 5 & $1.91 \pm 0.27 \mathrm{~A}$ \\
\hline & 7 & $4.43 \pm 0.69 \mathrm{~B}$ \\
\hline & 9 & $4.30 \pm 0.60 \mathrm{~B}$ \\
\hline & 11 & $0.67 \pm 0.13 \mathrm{~A}$ \\
\hline
\end{tabular}

a Means accompanied by different letters are statistically different at the $\alpha=.05$ level as determined by the Student T-Test. 
Telial columns appeared 6 days after urediospore inoculation of 5-, 7-, 9-, and 11-day-old leaves (Fig. 21 and Table 22). Telia appeared on 2-day-old leaves after 7 days. The average number of telial sori per $\mathrm{cm}^{2}$ increased to a maximum (4.4) on 7-day-old leaves and was progressively less on 9- and 11-day-old leaves.

A urediospore inoculum efficiency schedule was calculated from inoculations of 2-, 5-, 7-, 9-, and 11-day-o1d oak leaves (Table 24). An average of 2.63 telial sori $/ \mathrm{cm}^{2}$ of leaf surface developed 30 days after inoculation $\left(1000 \pm 100\right.$ spores $\left./ \mathrm{cm}^{2}\right)$.

A temporal sequence of urediospore infection and disease development in inoculated oak leaves is presented in Fig. 22. The first incubation period (inoculation through production of immature uredia) required 5 days with an additional day required for production of mature uredia (first latent period). The second incubation period (inoculation through production of immature telia) lasted 6 days with an additional day required for production of mature telia (latent period). 
Table 24. Inoculum efficiency following inoculation with urediospores of Cronartium quercuum f. sp. fusiforme on 2- to 11-day-old leaves of Quercus rubra seedlings maintained in a growth

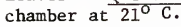

\begin{tabular}{clc}
\hline $\begin{array}{c}\text { Time } \\
\text { (day) }\end{array}$ & \multicolumn{1}{c}{ Process } & $\begin{array}{c}\text { Infection Units } \\
\left(\text { per } \mathrm{cm}^{2}\right)\end{array}$ \\
\hline 0 & Inoculation & 1000 spores \pm 100 \\
1 & Germination & 740 spores \pm 40 \\
1 & Appressorial formation & 207 spores \pm 10 \\
$6-30$ & Uredial production & 0.66 sorus \pm .15 \\
& Telial production & 2.63 sori \pm .35 \\
\hline
\end{tabular}


Figure 22 - Times of occurrence for infection and disease development following inoculation with urediospores of Cronartium quercuum $f$. sp. fusiforme on Quercus rubra seedlings maintained at optimal temperature and moisti:e conditions for the pathogen. 
UREDIOSPORES

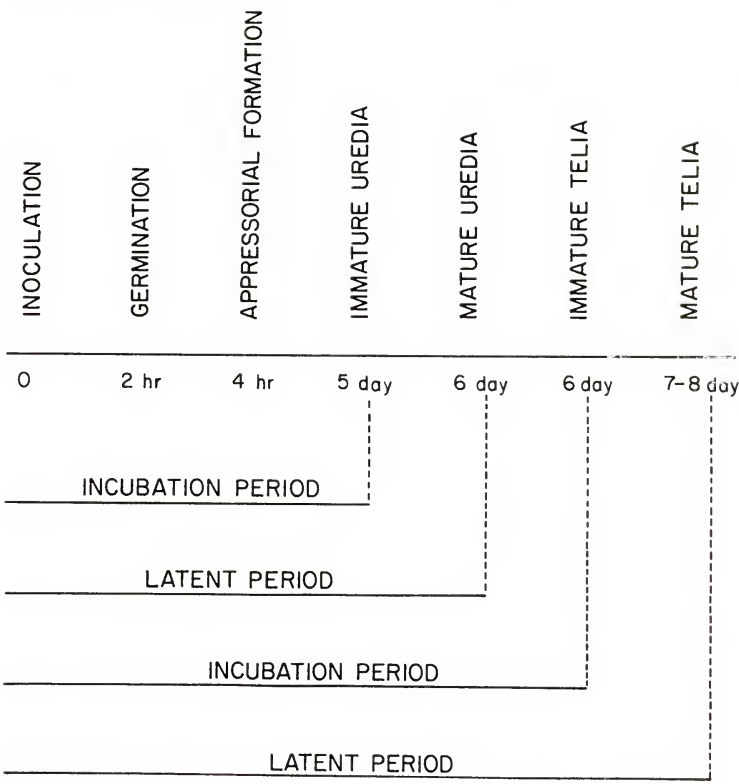




\section{DISCUSSION}

Pathogenic variability among regional and individual aecial gall isolates of $\underline{\mathrm{C}}$. quercuum f. sp. fusiforme is well known. Powers (1972) obtained four aeciospore collections from single galls in each of three geographic areas of the South. Infection percentages among slash pine seedlings inoculated with aeciospores ranged from $42 \%$ to $58 \%$. Snow and Kais (1970) inoculated pine progenies with $\underline{\mathrm{C}}$. quercuum $\mathrm{f}$. sp. fusiforme aeciospore isolates; one of the two slash pine progenies was regarded as resistant and the other was regarded as susceptible to the fusiform rust fungus. Seedlings were examined 12 months after inoculation for gall. formation. The resistant slash pine progeny was moderately resistant (40-57\% infection) to the North Carolina, Mississippi, and Texas isolates, but was highly susceptible to isolates from Alabama and Florida $(98-100 \%)$. The susceptible slash pine progeny was highly susceptible to all geographic isolates $(94-100 \%)$. Snow et al. (1976) reported that inoculum collected from a highly rust-resistant slash pine family infected more seedlings of this family than did inocula collected from the general rust population. This was interpreted as evidence of increasing pathogenic specialization in $\underline{C}$. quercuum f. sp. fusiforme. Snow et al. (1975) inoculated slash pine families with known degrees of fusiform rust resistance using aeciospore isolates from eastern and western axeas of the southeastern U.S. Variability in percent infection of two resistant and two susceptible families demonstrated pathogenic variation 
between and within the eastern and western isolates. The genetic diversity within populations of the host and pathogen was emphasized.

In this study, aeciospores were collected from numerous galls at each of three locations: Macon and Valdosta, GA, and Gainesville, FL. The collections were combined prior to mass inoculations of northern red oak leaves, leaf discs, and water agar. No attempt was made to determine geographical variation in pathogenicity although prior studies had demonstrated this variation.

Dwinell (1974) surveyed 21 species of southern oak for susceptibility to aeciospore inoculations of $\underline{C}$. quercuum $f$. sp. fusiforme. He reported that water and willow oaks were highly susceptible: blackjack, cherrybark, bluejack, running, southern red, northern red, and turkey oaks were moderately to highly susceptible; and, scarlet and black oaks were hypersensitiv? to infection. In this study northern red oaks were selected for aeciospore and urediospore inoculations due to the quali-tative susceptibility to the fusiform rust fungus, the rapid germination rate of the acorns, and the ample, uniform leaf surface area which facilitated the observation of abundant development of signs and symptoms. Utilization of the incident light microscope to assist in the observation of fungal development on unprepared leaf discs was unique to C. quercuum f. sp. fusiforme. No staining or stripping of the leaf surface was required for in situ examination of aeciospore and urediospore germination and appressorial formation.

In studying the infection biology of $\underline{C}$. quercuum $f$. sp. fusiforme for the production of germ tubes and appressoria, several important differences with the existing literature was observed. Walkinshaw et al. (1967) reported primarily single germ tubes emerging from germinating 
aeciospores. However, in this study the majority of germ tubes from both aeciospores and urediospores produced secondary and tertiary branching. Littlefield and Heath (1979) suggested a thigmotropic response in directional growth of the germ tubes toward stomata among urediospores of several rust fungi. In this study a similar response could not be substantiated in scanning electron photomicrographs of germinating aeciospores and urediospores of $\underline{\mathrm{C}}$. quercuum $\mathrm{f}$. sp. fusiforme. Aeciospore and urediospore germ tubes were not observed to form appressoria consistently at the nearest stomata; some germ tubes traversed the nearest stomata and formed appressoria upon contact with more distant stomata. Perhaps a chemical or gaseous stimulus released from stomata was responsible for the growth of the germ tubes to stomata. Failure of the spores to form appressoria over some stomata may be due to an insufficient amount of the stimulus.

Appressoria are associated with the establishment of infection by C. quercuum f. sp. fusiforme on oak and pine hosts (Eleuterius, 1968). In this study, appressoria formed only over stomata following germination of both aeciospores and urediospores and no direct penetration of leaf tissue was observed. Eleuterius (1968) reported similar results. Miller et al. (1980) reported direct penetration of slash pine needles by the germ tubes of $\underline{\mathrm{C}}$. quercuum f. sp. fusiforme basidiospores. In some instances, however, definite appressoria were not observed, a1though there were usually slight swellings of the germ tubes near the points of penetration.

The use of oak leaf discs as host substrates for aeciospore and urediospore infection had not been attempted previously. Germination 
and appressorial formation were observed on leaf discs following inoculations with aeciospores and urediospores, but uredia or telia were not produced. The production of uredia and telia by $\underline{\mathrm{C}}$. quercuum f. sp. fusiforme on the leaf discs was not successful and was due probably to the prolonged contact of senescing leaf tissue with wet filter paper and high relative humidity (approximately 100\%) inside the petri plates. Growth by saprophytic fungi obscured the disc surface after 2 to 4 days.

In other experiments, germination and appressorial formation following aeciospore and urediospore inoculations of intact northern red oak leaves were observed and uredia and telia were produced. Intact oak leaves were required for uredial and telial production and the inoculation technique using oak leaf discs was not an acceptable substi.. tute. Cronartium quercuum f. sp. fusiforme is an obligate parasite and may be particularly sensitive to moribund host substrate. Shain and Cornelius (1979) inoculated cottonwood (Populus deltoides Bartr.) leaf discs with urediospores of Melampsora medusae Thuem., the causal agent of poplar leaf rust. Optimum uredial formation was obtained when leaf discs were washed with $52 \%$ ethanol prior to inoculation with urediospores in dilute agar $(0.1 \%)$ and incubated for 9 to 11 days on $1 \%$ water agar. Less than optimal urediospore infection was attributed to an inhibitor believed to be present on unwashed leaf surfaces. Perhaps a similar inhibitory mechanism for infection was responsible for the failure of uredia and telia to form on northern red oak leaf discs in this study.

Siggers (1947) reported that the cardinal temperature points for aeciospore germination on water agar were 11 and $29 \mathrm{C}$ with the optimum 
temperature for germination at $21 \mathrm{C}$. The temperature limits from water agar experiments in this study were similar to those found by Siggers. The maximum percentage of aeciospores germinated between 15 and $21 \mathrm{C}$; germination at other temperatures was reduced. This suggests an important ecological and temporal relationship may exist between germination and appressorial formation. Optimum aeciospore dispersal occurs in the spring in the early afternoon when temperature and wind velocity are high (Webb and Schmidt, 1981). If germination began shortly after deposition, ambient temperatures would still be as high as approximately 21 C. Optimum formation of appressoria several hours later would coincide with cooler temperatures (as low as $15 \mathrm{C}$ ) of the later afternoon and early evening. The theoretical maxima for percentage aeciospore germination on water agar at 15,20 , and $21 \mathrm{C}$ were 60,70 , and $75 \%$, respectively. At semperatures above and below this range, i.e., 10, 2.5, 27 , and $30 \mathrm{C}$, the theoretical maxima were approximately 10, 25, 3, and $1 \%$, respectively. Germination at the lowest temperature required 2.3 and 4.3 hours to reach 10 and $90 \%$, respectively, of the theoretical maximum. Germination at the optimum required 1.3 and 4.9 hours to reach 10 and $90 \%$, respectively, of the theoretical maximum. At $30 \mathrm{C}$, the probable influence of heat upon increased spore drying and respiration resulted in a low theoretical germination which occurred quickly, i.e. 1 hour to $90 \%$ of the theoretical maximum germination.

Compared to water agar inoculation, the theoretical maximum per. centage germination of aeciospores on leaf discs was greatly reduced; for example, approximately $78 \%$ germinated on water agar but only $34 \%$ germinated on leaf discs at the optimum temperature of $21 \mathrm{C}$. Also, the 
range of germination percentages was broader around the optimum (15-21 C) on water agar than on leaf discs at $21 \mathrm{C}$. Addition of the oak host component differed from Siggers' (1947) method; the optimum temperature for germination was substantiated, but the percentage of the aeciospores germinating at each of the seven temperature levels was lower. The times required to reach $90 \%$ theoretical maximum germination were approximately twice as long as those for spores on water agar.

Siggers (1947) reported that the lower and upper temperature limits for urediospore germination on water agar were 8 and $29 \mathrm{C}$, respectively, with $18 \mathrm{C}$ as the optimum temperature. A slightly different range of thermal limits, 10 and $30 \mathrm{C}$, respectively, was observed in this experiment on water agar. The theoretical maximum percentage germination of urediospores on water agar was uniformly high (50-75\%) except at $30 \mathrm{C}$ when only $4 \%$ of the urediospores germinated. The times to 10 and $90 \%$ of the theoretical maximum were approximately equivalent except at $30 \mathrm{C}$ where the former required the least four times as long and the latter twice as long compared to lower temperatures. As with the aeciospore germination experiments using leaf discs, urediospore germination was higher (55 to $74 \%$ ) across a more narrow temperature range (15 to $21 \mathrm{C}$ ) than that in water agar trials. The times to 10 and $90 \%$ theoretical maximum germination of urediospores on leaf discs were approximately the same as in the aeciospore-leaf disc experiments in that much longer time periods were required.

Walkinshaw et al. (1967) reported that the germination of C. quercuum f. sp. fusiforme aeciospores was dependent upon imbibition of water. In this study, maximum aeciospore germination and appressorial 
formation were dependent upon a total of at least 6 hours of leaf surface moisture. Six hours were required for $90 \%$ of the maximum average observed aeciospore germination (48\%) while 8 hours were required for $90 \%$ of the maximum average appressorial formation (38.0\%). The 2-hour difference between germination and appressorial production was presumed due to the formation of the appressorial structure. Interruptions in the moisture period had no significant effect on the eventual numbers of aeciospores that germinated and formed appressoria, but did increase the total time necessary for both processes. According to Walkinshaw et al. (1967), energy for aeciospore germination is provided by lipid utilization. Interruption of the moisture period, and therefore the lipid utilization process, may have delayed eventual germination and appressorial formation, but apparently did not permanently retard the processes.

Maximum urediospore germination required at least a total of 3 hours of leaf surface moisture as compared to 6 hours necessary for aeciospore germination. Maximum urediospore appressorial formation required at least a total of 4 hours of leaf surface moisture as compared to 6 hours needed for aeciospore appressorial formation. A positive relationship existed between longer periods of moisture and higher percentage urediospore appressorial formation. One hour after the initiation of germination and appressorial formation, an interruption of leaf surface moisture for either 1 or 3 hours did not result in a significant reduction of either process. Studies encompassing longer moisture interruption periods are necessary before the effects upon germination and appressorial formation are fully delineated. 
Snow and Roncadori (1965) reported that with increasing age, water oak leaves become increasingly resistant to both aeciospore and urediospore infection. In this study with detached 2- to 20-day-old leaf discs, percentages of aeciospore and urediospore germination and appressorial formation were only slightly different among the different age classes. The failure of uredia and telia to develop on older leaves probably occurred during some phase of colonization of $\underline{C}$. quercuum $f$. sp. fusiforme.

Previous studies outlined temperature and moisture conditions for aeciospore and urediospore germination (Snow and Roncadori, 1965 and Roncadori and Matthews, 1966). In this study the non-1inear regression analyses of temperature and moisture optima for aeciospore and urediospore germination and appressorial formation were unique to $\underline{C}$. quercuum f. sp. fusiforme and provided predictive utility for the performance of the pathogen under laboratory conditions. This analysis significantly enhanced the predictability of percentages of germination and appressorial formation at various temperature and moisture conditions. Aeciospore and urediospore germination and appressorial formation in the temperature and leaf age experiments were modelled using logistic equations since normal curves could be representative of the data. Goodness of fit using the logistic equations was apparent from the high $\mathrm{R}^{2}$ values. However, other models may describe the curves more accurately. Waggoner and Parlange (1974) and Schröedter (1975) have analyzed spore development under varying temperatures and concluded that a normal curve or a polynomial curve, respectively, were acceptable representatives of spore development. 
The rates of and times to 10 and $90 \%$ of the theoretical maximum germination and appressorial formation further clarified the temporal behavior of the pathogen. Further analysis should be conducted to predict germination and appressorial formation under fluctuating temperature and moisture conditions in the field.

In studying the temporal sequence of uredial and telial formation, Hedgcock and Siggers (1949) reported the appearance of uredia 9 to 11 days after inoculation with aeciospores. Snow and Roncadori (1965) observed initial uredia formation 5 to 6 days after aeciospore inoculation, and telia appeared after 7 to 8 days. Siggers (1947) first observed telia 6 days after inoculation with aeciospores. In this study uredia were first observed 6 days after inoculation with aeciospores. A range of .08 to .42 uredial sori $/ \mathrm{cm}^{2}$ of leaf surface existed throughout the subsequent 10 day period. The maximum number of uredia formed on leaves 5-days-old at the time of inoculation. The maximum infectious period for the population of uredial sori (which was the total time that the sori were infectious) was 9 days following aeciospore inoculation of 2-day-old leaves.

Telia were observed after 8 days after aeciospore inoculations with a range of .26 to $2.48 / \mathrm{cm}^{2}$ of leaf surface existing throughout the remaining 14 days of the experiments. The maximum number of telia formed on leaves 6-days-old at the time of inoculation. The latent period for telia was approximately 9 days based on the time from inoculation with aeciospores to the development of probasidia on the telial column (which were observed during scanning electron microscopic observations on infection biology). The number of viable uredia decreased after 8 
to 10 days. However, the number of telial columns present remained constant to the end of the experiment or 22 days after inoculation. No uredia developed on leaves 8 days or older and telia did not develop on leaves 16 days or older. The average population ratios of telia to uredia for 2-, 5-, and 6-day-old leaves following aeciospore inoculation were $1.53,2.00$, and 31.00 , respectively. As leaf age increased the average numbers of uredia decreased while the average numbers of telia remained relatively constant.

Secondary infection of oak leaves by urediospores apparently did not occur since the number of telia remained relatively constant per leaf age class beginning 15 days and 14 days after aeciospore and urediospore inoculations, respectively. Secondary urediospore infection apparently did not occur prior to these periods since the number of telia increased linearly rather than geometrically. If secondary infection cycles had occurred the number of telia would have been expected to continue increasing rather than remain constant. This may have been due to host resistance which may have increased as the oak leaves matured. Also, since there was no rewetting of the leaf surface after the initial inoculation, moisture conditions which facilitated the initial urediospore infection would not have been present for secondary infections.

Czabator (1971) reported that aeciospore inoculations of oak leaves resulted more frequently in the formation of telia than uredia. Furthermore, the uredial stage, presumably necessary for local inoculum buildup, may be bypassed when unfavorable host conditions prevailed. Fewer uredia and telia formed on oak leaves as the ages of the leaves at the time of inoculation increased. Leaves 8 days or older when inoculated 
with aeciospores did not exhibit uredia; leaves 11 days or older when inoculated with urediospores did not exhibit uredia. The maximum number of uredia and telia occurred after approximately 8 days and 14 days, respectively, after inoculation with either aeciospores or urediospores. More telia were observed than uredia following aeciospore inoculation and the occurrence of a telium was not necessarily preceeded by formation of a uredium. Telia, but no uredia, were produced on leaves older than 6 days and 9 days at the time of aeciospore and urediospore inoculations, respectively. The occurrence of unfavorable host conditions, such as leaf age, which led to bypassing uredial formation was evident and warranted further investigation.

Jewell and Eleuterius (1963) reported amphiphyllous uredia and telia but these occurred simultaneously from the same mycelial mass. In this study hyperphyllous uredia and telia occurred without accompanying hypophyllous uredia and telia.

Snow and Roncadori (1965) inoculated susceptible oak leaves with urediospores and observed uredial formation but did not report the time period for initial occurrence. In this study uredia first appeared 5 days after inoculation with urediospores. A range of .04 to 1.5 uredial sori/ $\mathrm{cm}^{2}$ of leaf surface existed throughout the 25 days of the experimental period. The maximum number of uredia and telia formed when leaves were 2- and 7-days-old, respectively, at the time of inoculation with urediospores. The maximum infectious period for the population of uredial sori was at least 24 days (which was the termination of the experiment) following urediospore inoculation of 2-, 5-, 7-, and 9-dayold leaves. The average number of uredial sori decreased approximately 
9 days after inoculation. No uredia developed on leaves 11 days or older.

Czabator (1971) reported that telia first appeared about 8 days after inoculation with urediospores. In this study telia were first observed after 6 days with a range of .67 to $4.4 / \mathrm{cm}^{2}$ of leaf surface existing throughout the subsequent 24-day period. The number of viable telial columns remained constant after 14 days of the 30-day experimental period. No telia developed on leaves inoculated when 14 days old or older. The average population ratios of telia to uredia for 2-, 5-, 7-, and 9-day-old leaves following urediospore inoculation were 1.20, $3.82,73.83$, and 107.50 , respectively. As leaf age increased the average numbers of uredia decreased while the average numbers of telia remained relatively constant.

Vanderplank (1963) stated that no increase in disease can begin unless conditions of the host, pathogen, and environment interact such that:

$$
i R_{c} \geq 1
$$

where, $\quad i=$ infectious period (time, usually days) over which a lesion remains infectious, $\begin{aligned} \mathrm{R}_{\mathrm{c}}= & \text { correct basic infection rate (corrected for removals); } \\ & \text { it is expressed as a rate, i.e., per unit per day. }\end{aligned}$ The infectious period for an individual pustule was not determined but the maximum infectious period for the population of pustules was 9 days and at least 24 days with aeciospore and urediospore inoculations, respectively. The inoculation of oak leaves with $1000 \pm 100$ aeciospores $/ \mathrm{cm}^{2}$ of leaf surface resulted in the formation of 0.22 uredial sorus and 1.07 telial columns. Approximately 5000 and 1000 aeciospores were necessary to form 1 uredial sorus and 1 telial column, respectively. 
Inoculation with $1000 \pm 100$ urediospores per $\mathrm{cm}^{2}$ of leaf surface resulted in the production of 0.66 uredia and 2.63 telia. Approximately 1500 and 377 urediospores were necessary to form 1 uredial sorus and 1 telial column, respectively. To maintain at least a constant level of urediospore infection, each uredial pustule must produce at least 1500 urediospores during the infectious period of that sorus. Conversely, the prerequisite of 1500 urediospores to produce 1 effective uredial sorus, as determined in this study, may not be realistic. Perhaps fewer spores are needed in order to perpetuate the fungus.

Despite the relatively high concentrations of aeciospores and urediospores $\left(1000 \pm 100\right.$ spores $/ \mathrm{cm}^{2}$ of leaf surface), few telia and even fewer uredia were formed. Mehta and Zadoks (1970) investigated urediospore production of $\underline{\text { P. }}$ recondita f. sp. triticina Rob. ex Desm. on wheat. Three cuncentrations of urediospores $(14,633,3565$, and 1784 spores/leaf) yielded 1917, 920, and 305 uredial pustules per leaf, respectively, and the ratios of pustules/leaf to urediospores/leaf were $0.13,0.26$, and 0.17 , respectively. These ratios were considerably higher than the ratios for uredial and telial formation on oak leaves from aeciospore inoculations, 0.00022 and 0.00107 , respectively, and urediospore inoculations, 0.00066 and 0.00263 , respectively. The concentrations of aeciospores and urediospores were believed to be realistic.

Schmidt and Webb (unpublished data) calculated aecial aeciospore concentrations during the peak of several spring sporulation seasons of over 1600 sporēs $/ \mathrm{cm}^{2}$ of trapping surface from a spore trap located $10 \mathrm{~m}$ from a slash pine plantation infected with $\underline{\mathrm{C}}$. quercuum $\mathrm{f}$. sp. fusiforme. The concentration of 1000 spores $/ \mathrm{cm}^{2}$ of leaf surface in this study may 
have represented inoculum deposition on leaves near severely infected pines. Since only one point source on the infinite inoculum curve was studied, perhaps additional spore concentrations could have provided different inoculum efficiency schedules.

Dwine1l (1974) surveyed the relative susceptibility of 21 southern oak species to mass inoculations of $\underline{\mathrm{C}}$. quercuum $\mathrm{f} \cdot \mathrm{sp}$. fusiforme aeciospores and the potential for telial production on each host species. Six to seven days after cessation of uredial development, the numbers of telia/ $\mathrm{cm}^{2}$ of oak leaf surface were counted and were the basis for assigning relative host susceptibility and telium productivity. All the oaks tested were susceptible based upon the production of telia, but inoculum efficiency can not be calculated since the initial concentration of the aeciospore inoculum was not specified.

Effects of weather upon $\underline{\text { C. }}$ quercuum f. sp. fusiforme basidiospore infection have been thorough1y examined (Davis and Snow, 1968; Kais, 1963; Powers and Roncadori, 1966; Snow and Froelich, 1968; and Snow et al., 1968). Similar investigations of weather effects on aeciospore infection are lacking. Siggers (1949) reported that warm weather in late winter and early spring coupled with typical ample rainfall stimulated $\underline{\text { C. quercuum }}$ f. sp. fusiforme aeciospore production from infected pines. Oak infection developed rapidly when average temperature exceeded 15 C. Roncadori and Matthews (1966) observed significantly greater germination of stored aeciospores when temperatures ranged between 15 and $21 \mathrm{C}$. In this study, optimum aeciospore germination and appressorial formation also occurred at 21 and $15 \mathrm{C}$, respectively, and optimum urediospore germination and appressorial formation occurred at $18 \mathrm{C}$. 
The potential for aeciospore infection of oaks is increased when warm humid weather is initiated each spring.

Adaptation of the pathogen to these temperature and relative humidity optima is an evolutionary process whereby aeciospore release from colonized pines coincides with bud break and early leaf flush on oaks. Oak leaves 4 to 6 days old or older exhibited decreased uredial formation following inoculation with aeciospores (Snow and Roncadori, 1965). In this study with oak leaf discs, percentage of infection was similar among 2- to 11-day-old leaves which emphasized the role of oak leaf resistance. Despite the occurrence of optimum weather conditions for infection over a long period, i.e., March through early June, the maximum potential for infection of individual leaves is reduced since oak leaves are susceptible for only brief periods. Kranz (1974) reported a similar pattern for $\underline{E}$. graminis. Due to the consistent production of leaves during the growth period, leaf tissue susceptible for aeciospore infection is constantly available. Despite the magnitude of present levels of infection, higher incidence would probably result if emerging leaves were susceptible for even slightly longer periods. This may help to explain the large regional volume of aeciospores necessary to perpetuate yearly infection in the southeastern U.S.

Zadoks and Schein (1979) stated that those airborne spores effective in establishing infection were only a small fraction of the total output. Furthermore, the minimum effective rate which perpetuates infection and subsequent colonization is proportional to the total spore output. The inoculum efficiency schedules for aeciospore and urediospore infection of oak seedlings underscored the ability of the pathogen 
to produce abundant levels of sporidial inocula. Initial concentrations of $1000 \pm 100$ spores $/ \mathrm{cm}^{2}$ of oak leaf surface resulted in about 1 and 3 telia, respectively, from aeciospore and urediospore inoculations. Snow (unpublished data) hypothesized that under optimum temperature and humidity conditions, about 1000 basidiospores could be produced daily per linear mm of telial column. Since telial columns are usually at least several mm long and are of ten abundant on infected oak leaves, the potential for increased sporidial production is enhanced many times. Thus, large numbers of aeciospores and urediospores are necessary to produce a single telium but each telium may produce many thousands of basidiospores. Snow (personal communication) obtained infection of slash pine seedlings under optimum laboratory conditions by placing as few as 30 to 60 basidiospores on a single pine needle. Squillace and Wilhite (1977) and Hollis and Schmidt (1977) demonstrated the positive correlation of fusiform rust incidence with local susceptible oak abundance. Rapid increases in fusiform rust incidence since the early 1950 's is due partly to the productivity of inoculum on oaks (Dinus, 1974). However, further clarification of these inoculum efficiency schedules under field conditions is necessary to substantiate these hypotheses. 


\section{CONCLUSIONS}

Aeciospore and urediospore germination occurred about 15 minutes after inoculation onto oak leaf discs or water agar. Both spore types produced branched and unbranched germ tubes. Growth of these germ tubes towards stomata appeared random. Appressoria developed only over stomata; penetration was observed to occur only through stomata.

The optimum temperatures of aeciospore and urediospore germination on water agar and oak leaf discs were 21 and $18 \mathrm{C}$, respectively. Maximum percentage germination of aeciospores on leaf discs was much less and occurred over a more narrow range of optimum temperatures than in the water agar trials.

The optimum temperatures for aeciospore and urediospore appressorial formation were 15 and $18 \mathrm{C}$, respectively. Aeciospores required longer periods to reach 10 and $90 \%$ of the theoretical maximum appressorfal formation than did urediospores. At higher temperatures percentage aeciospore appressorial formation was progressively reduced whereas percentage urediospore appressorial formation was approximately constant.

At least 6 hours of leaf surface moisture were required for abundant germination by aeciospores. No significant differences in percentage germination occurred between 6 and 9 hours of moisture. Percentage appressorial formation increased linearly as the moisture duration increased. Urediospore germination required more than 2 hours of 
surface moisture. Percentage appressorial formation steadily increased and was maximized after 24 hours.

Aeciospore and urediospore germination and appressorial formation were slightly greater when the moisture period was not interrupted. The availability of leaf surface moisture was important in perpetuating germination and appressorial formation.

Percentages of aeciospore and urediospore germination and appressorial formation were approximately constant over all leaf disc age classes although urediospore values were slightly higher.

In vitro sporulation by $\underline{\mathrm{C}}$. quercuum $\mathrm{f}$. $\mathrm{sp}$. fusiforme did not occur on oak leaf discs following aeciospore or urediospore inoculations.

Uredial sori developed 6 days after aeciospore inoculation of 2to 6-day-old leaves. The maximum number of uredia formed on leaves 5days-old at the time of inoculation. No uredial sori developed on 8-, 11-, or 16-day-old leaves. The latent period for uredial sori was approximately 7 days; the infectious period for the population of uredial sori was approximately 9 days on leaves 2-days-old at time of inoculation.

The latent period for telia was 8 to 9 days after aeciospore inoculation of 5-, 6-, and 11-day-old leaves. Telial columns appeared after 15 days when 2- and 8-day-old leaves were inoculated. The maximum number of telia formed on leaves 6-days-old at the time of inoculation. Telia, but not uredia, were produced on leaves older than 6 days and 9 days at the time of aeciospore and urediospore inoculations, respectively.

The average population ratios of telia to uredia for 2-, 5-, and 6-day-old leaves following aeciospore inoculation were $1.53,2.00$, and 
31.00 , respectively. The average population ratios of telia to uredia for 2-, 5-, 7-, and 9-day-old leaves following urediospore inoculation were $1.20,3.82,73.83$, and 107.50 , respectively.

Inoculation with $1000 \pm 100$ aeciospores $/ \mathrm{cm}^{2}$ of oak leaf surface resulted in approximately .22 uredial pustule $/ \mathrm{cm}^{2}$ after 6 to 16 days and 1.07 telial columns $/ \mathrm{cm}^{2}$ after 8 to 20 days on 2- to 6-day-old leaves and 2- to 11-day-old leaves, respectively.

Uredial sori developed 5 days after urediospore inoculation of 2to 9-day-old leaves. The maximum number of uredia and telia formed when leaves were 2- and 7-days-old, respectively, at the time of inoculation with urediospores. The latent period for uredial development was approximately 6 days; the infectious period for the population of uredial sori was at least 24 days (which was the termination of the experiment) when leaves were 2-, 5-, 7-, and 9-days-old at the time of inoculation with urediospores.

Telial columns appeared 6 days after urediospore inoculation of 5- to 11-day-old leaves and the latent period was approximately 7 to 8 days.

Inoculation of $1000 \pm 100$ urediospores $/ \mathrm{cm}^{2}$ of oak leaf surface resulted in approximately .66 uredial pustule $/ \mathrm{cm}^{2}$ after 5 to 30 days and 2.63 telial columns $/ \mathrm{cm}^{2}$ after 6 to 30 days on 2- to 9-day-old leaves and 2- to 11-day-old leaves, respectively. 


\section{FUTURE RESEARCH}

The effect of oak genotypic resistance upon aeciospore and urediospore germination and appressorial formation should be investigated further. The identification of susceptible, resistant, and immune oak species to aeciospore and urediospore inoculation should be more thoroughly investigated. Temperature and moisture effects on aeciospore and urediospore germination and appressorial formation and uredial and telial formation may then be conducted in the field to clarify optimum conditions across a range of interspecific and intraspecific oak genotypes. Inoculation with a range of fungal genotypes of $\underline{C}$. quercuuim f. sp. fusiforme would be performed to more thoroughly examine pathogenic variability relative to various temperature and moisture conditions.

Additional research should be conducted on the effects of interruption of moisture periods on aeciospore and urediospore germination and appressorial formation. A sufficiently large range of interruption periods was not incorporated into this study.

The importance of secondary infection of oak leaves by urediospores warrants further research. Continued laboratory and field investigations of the effects of temperature, leaf surface moisture, and light quality and quantity upon the quantity of urediospores produced are needed. In addition, the phenomenon of the bypassing of the uredial stage needs to be examined. The ratio of the production of uredial to 
telial sori needs to be studied in order to ascertain the importance of possible host resistance to the production of the structures.

Inoculum efficiency schedules for aeciospore, and urediospore germination and appressorial formation need to be refined. More quantitative and comprehensive experiments utilizing a broad range of environmental conditions and spore concentrations are necessary. Also, a range of fungal isolates with varying pathogenicity should be incorporated into inoculation using a range of oak genotypes. 


\section{LITERATURE CITED}

Allen, R. F. 1928. A cytological study of Puccinia glumarum on Bromus marginatus and Triticum vulgare. J. Agric. Res. 36:487-513.

Anon. 1977. Influence of climate on fusiform rust incidence and distribution. Page 80 in Management of fusiform rust in southern pines. R. J. Dinus and R. A. Schmidt, eds. Symp. Proc. Univ. Fla., Gainesville. 162 p.

Benny, G. L. and H. C. Aldrich. 1975. Ultrastructure observations on septal and merosporangial ontogeny in Linderina pennispora. Can. J. Bot. 53:2325-2326.

Berger, R. D. 1976. Computer simulation of Cercospora apii and Helminthosporium turcicum. Proc. Amer. Phytopathol. Soc. (Abstr.) 3:217.

Boyce, J. S. 1961. Forest pathology. McGraw-Hill, New York. 572 p.

Burdsa11, H. H. and G. A. Snow. 1977. Taxonomy of Cronartium quercuum and Cronartium fusiforme. Mycologia 69:503-508.

Colley, R. H. 1918. Parasitism, morphology, and cytology of Cronartium ribicola. J. Agric. Res. 15:619-660.

Czabator, F. J. 1971. Fusiform rust of southern pines - a critica1 review. USDA For. Serv. Res. Pap. SO-65. 39 p.

Davis, R. T. and G. A. Snow. 1968. Weather systems related to fusiform rust infection. Plant Dis. Reptr. 52:419-422.

Dinus, R. J. 1974. Knowledge about natural ecosystems as a guide to disease control in managed forests. Proc. Am. Phytopathol. Soc. 1:184-190.

Dinus, R. J. and R. A. Schmidt, eds. 1977. Management of fusiform rust in southern pines. Symp. Proc. Univ. Fla., Gainesville. 163 p.

Dwinel1, L. D. 1969. Volume-size distribution of aeciospores of Cronartium fusiforme and $\underline{\mathrm{C}}$. quercuum. Phytopathology 59:1024-1025.

Dwinel1, L. D. 1974. Susceptibility of southern oaks to Cronartium fusiforme and Cronartium quercuum. Phytopathology 64:400-403. 
Eleuterius, L. N. 1968. Morphology of Cronartium fusiforme in Quercus nigra. Phytopathology 58:1487-1492.

Goddard, R. E. and 0. 0. Wells. 1977. Susceptibility of southern pines to fusiform rust. Pages 52-58 in Management of fusiform rust in southern pines. R. J. Dinus and R. A. Schmidt, eds. Symp. Proc. Univ. Fla., Gainesville. 162 p.

Gooding, G. V., Jr. and H. R. Powers, Jr. 1965. Serological comparison

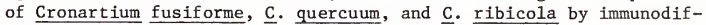
fusion tests. Phytopathology 55:670-674.

Griggs, M. M. and R. A. Schmidt. 1977. Increase and spread of fusiform rust. Pages 32-38 in Management of fusiform rust in southern pines. R. J. Dinus and R. A. Schmidt, eds. Symp. Proc. Univ. Fla., Gainesville. 162 p.

Harder, D. E. 1976. Electron microscopy of urediospore formation in Puccinia coronata avenae and $\underline{\mathrm{P}}$. graminis avenae. Can. J. Bot. 54: 1010-1019.

Hedgcock, G. G. and P. V. Siggers. 1949. A comparison of the pine-oak rusts. USDA Tech. Bull. No. 978, $30 \mathrm{p}$.

Hiratsuka, Y. 1973. The nuclear cycle and the terminology of spore states in Uredinales. Mycologia 65:432-443.

Hobbs, E. L. 1962. Some factors affecting germinability of urediospores of Puccinia coronata. Phytopathology 52:1223-1225.

Hollis, C. A. and R. A. Schmidt. 1977. Site factors related to fusiform rust incidence in north Florida slash pine plantations. For. Sci. $23: 69-77$.

Hughes, S. J. 1970. Ontogeny of spore forms in Uredinales. Can. J. Bot. $48: 2147-2157$.

Jewell, F. F. and L. N. Eleuterius. 1963. Amphiphyllous uredia and telia of southern fusiform rust. Plant Dis. Rep. 47:65.

Jewell, F. F., R. P. True, and S. L. Mallett. 1962. Histology of Cronartium fusiforme in slash pine seedlings. Phytopathology 52: 850-858.

Johnson, T. 1934. A tropic response in germ tubes of urediospores of Puccinia graninis tritici. Phytopathology 24:80-82.

Kais, A. G. 1963. In vitro sporidial germination of Cronartium fusiforme.- Phytopathology 53:987-988.

Kais, A. G. and G. A. Snow. 1972. Host response to various isolates of Cronartium quercuum and Cronartium fusiforme. Pages 495-503 in Biology of rust resistance in forest trees. USDA Misc. Publ. 1221. $681 \mathrm{p}$. 
Kato, H. 1974. Epidemiology of rice blast disease. Rev. Plant Protec. Res. $7: 1-20$.

Kranz, J. 1974. The role and scope of mathematical analysis and modeling in epidemiology. Pages 1-54 in Epidemics of plant diseases. Springer-Verlag, Berlin. $170 \mathrm{p}$.

Lewis, B. G. and J. R. Day. 1972. Behavior of urediospore germ tubes of Puccinia graminis tritici in relation to the fine structure of wheat of leaf surfaces. Trans. Br. Mycol. Soc. 58:139-145.

Littlefield, L. J. and M. C. Heath. 1979. Ultrastructure of rust fungi. Academic Press, New York. 277 p.

Maheshwari, R. and A. C. Hildebrandt. 1967. Directional growth of the urediospore germ tubes and stomatal penetration. Nature 214: 1145-1146.

Mehta, Y. R. and J. C. Zadoks. 1970. Urediospore production and sporulation period of Puccinia recondita f. sp. triticina on primary leaves of wheat. Neth. J. P1. Path. 76:267-276.

Miller, T. 1970. Inoculation of slash pine seedlings with stored basidiospores of Cronartium fusiforme. Phytopathology 60:1773-1774.

Miller, T., E. B. Cowling, H. R. Powers, Jr., and T. W. Blalock. 1976. Types of resistance and compatibility in slash pine seedings infected by Cronartium fusiforme. Phytopathology 66:1229-1235.

Miller, T., R. F. Patton, and H. R. Powers, Jr. 1980. Mode of infection and early colonization of slash pine seedlings by Cronartium quercuum f. sp. fusiforme. Phytopathology 70:1206-1208.

Patton, R. F. and D. W. Johnson. 1966. Penetration of pine needles by Cronartium basidiospores labeled with a fluorescent brightener. (Abstr.) Phytopathology 56:894.

Phelps, W. R. 1977. Incidence and distribution of fusiform rust. Pages 25-31 in Management of fusiform rust in southern pines. R. J. Dinus and R. A. Schmidt, eds. Symp. Proc. Univ. Fla., Gainesville. 163 p.

Phelps, W. R. and C. W. Chellman. 1975. Impact of fusiform rust in north Florida slash pine plantations. Plant Dis. Rep. 59:781-785.

Politowski, K. and J. A. Browning. 1974. The effect of temperature, light and dew duration on the development of infection structures of Puccinia coronata avenae. (Abstr.). Annu. Proc. Am. Phytopathol. Soc. 1:107.

Politowski, K. and J. A. Browning, 1975. Effect of temperature, light and dew duration on relative numbers of infection structures of Puccinia coronata avaea. Phytopathology 65:1400-1404. 
Powers, H. R., Jr. 1972. Testing for pathogenic variability with Cronartium fusiforme and $\mathrm{C}$. quercuum. Pages 505-511 in Biology of rust resistance in forest trees. USDA Misc. Pub1. 1221. 681 p.

Powers, H. R., Jr. 1975. Relative susceptibility of five southern pines to Cronartium fusiforme. Plant Dis. Rep. 59:312-314.

Powers, H. R., Jr., J. P. McClure, H. A. Knight, and G. F. Dutrow. 1974. Incidence and financial impact of fusiform rust in the south. J. For. 72:398-401.

Powers, H. R., Jr. and R. W. Roncadori. 1966. Teliospore germination and sporidial production by Cronartium fusiforme. Plant Dis. Reptr. 50:432-434.

Roncadori, R. W. and F. R. Matthews. 1966. Storage and germination of aeciospores of Cronartium fusiforme. Phytopathology 56:1328-1329.

Schmidt, R. A., R. E. Goddard, and C. A. Hollis. 1974. Incidence and distribution of fusiform rust in slash pine plantations in Florida and Georgia. Fla. Agric. Exp. Stn. Tech. Bull. 763, 21 p.

Schröedter, H. 1965. Methodisches zur Bearbeitung phytometeoropathologischer Untersuchungen, dargeste1lt am Beispiel der Temperaturrelation. Phytopatho1. Z. 53:154-166.

Shain, L. and P. L. Cornelius. 1979. Quantitative inoculation of eastern cottonwood leaf tissue with Melampsora medusae under controlled conditions. Phytopathology $\overline{69: 301-304}$.

Siggers, P. V. 1947. Temperature requirements for generation of spores of Cronartium fusiforme. Phytopathology 37:855-864.

Siggers, P. V. 1949. Weather and outbreaks of the fusiform rust of southern pines. J. For. 47:802-806.

Snow, G. A., R. J. Dinus, and A. G. Kais. 1975. Variation of pathogenicity of diverse sources of Cronartium fusiforme on selected slash pine families. Phytopathology 65:170-175.

Snow, G. A., R. J. Dinus, and C. H. Walkinshaw. 1976. Increase in virulence of Cronartium fusiforme on resistant slash pine. Phytopathology 66:511-513.

Snow, G. A. and R. C. Froelich. 1968. Daily and seasonal dispersal of basidiospores of Cronartium fusiforme. Phytopathology 58: 1532-1536.

Snow, G. A., R. C. Froelich, and T. W. Popham. 1968. Weather conditions determining infection of slash pine by Cronartium fusiforme. Phytopathology 58:1537-1540. 
Snow, G. A. and A. G. Kais. 1970. Pathogenic variability in isolates of Cronartium fusiforme from five southern states. Phytopathology $60: \overline{1730-1731 .}$

Snow, G. A. and R. W. Roncadori. 1965. Oak leaf age and susceptibility to Cronartium fusiforme. Plant Dis. Rep. 49:972-973.

Squillace, A. E. and L. P. Wilhite. 1977. Influence of oak abundance and distribution on fusiform rust. Pages 59-70 in R. J. Dinus and R. A. Schmidt eds. Management of fusiform rust in southern pines. Symp. Proc. Univ. Fla., Gainesville. 163 p.

Teng, P. S. and J. C. Zadoks. 1980. Computer simulation of plant disease epidemics. Pages 22-31 in McGraw-Hill Yearbook of Science and Tech., New York. 447 p.

Van Arsdel, E. P., A. J. Riker, and R. F. Patton. 1956. The effects of temperature and moisture on the spread of white pine blister rust. Phytopathology 46:307-318.

Vanderplank, J. E. 1963. Plant diseases: epidemics and control. Academic Press, New York. 349 p.

Vanderplank, J. E. 1975. Principles of plant infection. Academic Press, New York. 216 p.

Vargas, J. M., Jr., H. C. Young, Jr., and E. E. Saari. 1967. Effect of light and temperature on urediospore germination, infection, and disease development of Puccinia cynodontis, and isolation of pathogenic races. Phytopathology 57:405-409.

Waggoner, P. E. and J. G. Horsfa11. 1969. EPIDEM- a simulation of plant disease written for a computer. Conn. Agr. Exp. Sta. Bull. No. 698. $80 \mathrm{p}$.

Waggoner, P. E. and J. Y. Parlange. 1974. Mathematical model for spore germination at changing temperature. Phytopathology 64: 605-610.

Waggoner, P. E. and J. Y. Parlange. 1974. Verification of a model of spore germination at variable, moderate temperatures. Phytopathology 64:1192-1196.

Walker, J. C. 1957. Plant pathology. McGraw-Hill Book Co., Inc., New York. 707 p.

Walkinshaw, C. H., J. M. Hyde, and J. VanZandt. 1967. Fine structure of quiescent and germinating aeciospores of Cronartium fusiforme. J. Bacteriol. 94:245-254. 
Webb, R. S. and R. A. Schmidt. 1981. The diurnal periodicity of Cronartium quercuum f. sp. fusiforme aeciospore dispersal in north Florida and associated meteorological variables. (Abstr.) Southwide Forest Disease Workshop. University of Florida, Gainesville. F1.

Wynn, W. K. 1976. Appressorium formation over stomates by the bean rust fungus: Response to a surface contact stimulus. Phytopathology $66: 136-146$.

Zadoks, J. C. 1965. Epidemiology of wheat rusts in Europe. FAO Plant Prot. Bull. 13:97-108.

Zadoks, J. C. 1978. Methodology of epidemiological research. Pages 63-94 in Plant disease an advanced treatise, Vol. II. J. G. Horsfall and E. B. Cowling, eds. Academic Press, New York. $435 \mathrm{p}$.

Zadoks, F. C. and R. D. Schein. 1979. Epidemiology and plant disease management. Oxford University Press, New York. 427 p. 


\section{BIOGRAPHICAL SKETCH}

Patricia Gardner Patterson was born in Ocala, Florida, on June 10, 1949. She attended Williston schools and graduated from Williston High School in June, 1967. She enrolled in the University of Florida, Gainesville, F1orida, in September, 1967, and graduated in June, 1971, with a B.S. in biology-chemistry education. During her undergraduate years she was a member of the President's List for academic achievement and Phi Theta Kappa, a national honor society.

She was employed as a chemist by Ordnance Research Institute in the summer of 1971 and was employed as a chemistry $\circ$ physiology instructirx at Niceville High School from August, 1971, until June, 1979. In June, 1973, she entered graduate school in the College of Education at the University of Florida and graduated in June, 1974, with a M.S. in biology education. In June, 1979, she entered the University of Florida as a graduate research assistant in the Department of Plant Pathology to pursue a curriculum culminating in the Doctor of Philosophy degree in plant pathology.

She has two children, LaBeth and Amber. 
I certify that I have read this study and that in my opinion it conforms to acceptable standards of scholarly presentation and is fully adequate, in scope and quality, as a dissertation for the degree of Doctor of Philosophy.

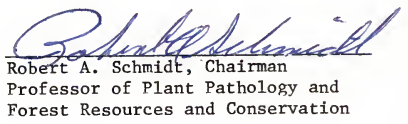

I certify that I have read this study and that in my opinion it conforms to acceptable standards of scholarly presentation and is fully adequate, in scope and quality, as a dissertation for the degree of. Doctor of Philosophy.

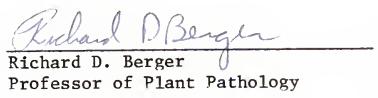

I certify that I have read this study and that in my opinion it conforms to acceptable standards of scholarly presentation and is fully adequate, in scope and quality, as a dissertation for the degree of Doctor of Philosophy.

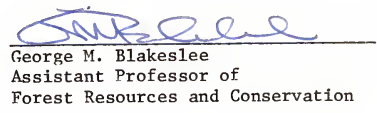

I certify that I have read this study and that in my opinion it conforms to acceptable standards of scholarly presentation and is fully adequate, in scope and quality, as a dissertation for the degree of Doctor of Philosophy.

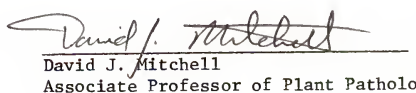

Associate Professor of Plant Pathology 
This dissertation was submitted to the Graduate Faculty of the College of Agriculture and to the Graduate Council, and was accepted as partial fulfillment of the requirements for the degree of Doctor of Philosophy.

June, 1981

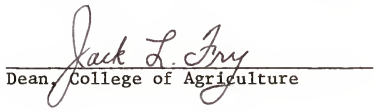

Dean for Graduate Studies and Research 